\title{
Female reproductive strategies and the ovarian cycle in hamadryas baboons
}

A thesis submitted in partial requirement of the Master's Degree of Science in Conservation Biology at Victoria University of Wellington by

\section{R. E. Tobler}


ABSTRACT: This thesis examines the relationship between sexual behaviour and the ovarian cycle in a group-living primate, Papio h. hamadryas. Of particular interest is whether females modify their ovarian cycle in a manner that is expected increase their reproductive success. The study was conducted on a captive colony where the resident males (RM) had been vasectomised prior to start of the study resulting in all mature females undergoing repeated ovarian cycling throughout the study period. This made the analysis of sexual behaviour relative to fine scale changes in the ovarian cycle possible. One year of ovarian cycle data and 280 hours of behavioural data was collected via observational sampling during the study. RM vasectomisation did not alter the archetypal one male unit social structure nor the typical socio-spatial organisation of wild hamadryas populations. Females were found to be more promiscuous than in wild populations, however, presumably because of the confounding effect that the high number of simultaneously cycling females had on RM herding (Chapter 1). RMs dominated copulations over the optimal conceptive period of the ovarian cycle, while the majority of extra-OMU copulations occurred outside this period and were rarely solicited by females. This pattern supports a dual paternity concentration/paternity confusion strategy, and not female choice or fertility insurance strategies (Chapter 2). Females were not found to synchronise or asynchronise their cycles over the 1 year study period, although a review of the literature on hamadryas breeding patterns suggests that they may be able to do so over shorter periods (Chapter 3). Females did, however, appear to regulate the length of the turgescent phase of their ovarian cycle in a manner that would facilitate a paternity confusion strategy and maximise their expected fitness payoff (Chapter 4). Consequently, this study provides empirical evidence that female hamadryas baboons manipulate their ovarian cycle in a manner that is expected to increase their reproductive success. 


\section{Table of contents}

List of figures $\quad$ v

List of tables

Acknowledgements vii

1 General Introduction 1

The mammalian ovarian cycle 2

Evolution of the ovarian cycle in mammals

Evolution of the ovarian cycle in primates $\quad 6$

$\begin{array}{lr}\text { Exaggerated perineal swellings } & 9\end{array}$

$\begin{array}{ll}\text { Female control of the ovarian cycle } & 10\end{array}$

$\begin{array}{ll}\text { Hamadryas baboons } & 13\end{array}$

$\begin{array}{ll}\text { Thesis structure and research questions } & 15\end{array}$

$\begin{array}{ll}\text { References } & 17\end{array}$

2 The structure and organisation of social and sexual interactions

in the Wellington Zoo hamadryas baboon colony 29

$\begin{array}{ll}\text { Abstract } & 29\end{array}$

$\begin{array}{ll}\text { Introduction } & 30\end{array}$

$\begin{array}{ll}\text { Methods } & 31\end{array}$

$\begin{array}{ll}\text { Results } & 45\end{array}$

$\begin{array}{ll}\text { Discussion } & 63\end{array}$

$\begin{array}{ll}\text { Conclusion } & 76\end{array}$

$\begin{array}{ll}\text { References } & 79\end{array}$

3 The pattern and function of sexual behaviour in relation to

$\begin{array}{ll}\text { the ovarian cycle in hamadryas baboons } & 84\end{array}$

$\begin{array}{ll}\text { Abstract } & 84\end{array}$ 
$\begin{array}{ll}\text { Introduction } & 85\end{array}$

$\begin{array}{ll}\text { Methods } & 87\end{array}$

$\begin{array}{ll}\text { Results } & 95\end{array}$

$\begin{array}{ll}\text { Discussion } & 116\end{array}$

$\begin{array}{ll}\text { Conclusion } & 124\end{array}$

$\begin{array}{ll}\text { References } & 125\end{array}$

$4 \quad$ No evidence for ovarian synchrony or asynchrony

in hamadryas baboons 131

$\begin{array}{ll}\text { Abstract } & 131\end{array}$

$\begin{array}{ll}\text { Introduction } & 132\end{array}$

$\begin{array}{ll}\text { Methods } & 134\end{array}$

Results 141

$\begin{array}{ll}\text { Discussion } & 145\end{array}$

$\begin{array}{ll}\text { Conclusion } & 152\end{array}$

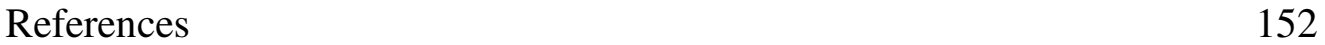

5 Manipulation of the ovarian cycle in response to behavioural and physiological factors in hamadryas baboons 160

$\begin{array}{ll}\text { Abstract } & 160\end{array}$

$\begin{array}{ll}\text { Introduction } & 161\end{array}$

$\begin{array}{ll}\text { Methods } & 165\end{array}$

$\begin{array}{ll}\text { Results } & 171\end{array}$

$\begin{array}{ll}\text { Discussion } & 177\end{array}$

$\begin{array}{ll}\text { Conclusion } & 182\end{array}$

$\begin{array}{ll}\text { References } & 182\end{array}$

$\begin{array}{lll}6 & \text { Summary } & 187\end{array}$ 
References

Appendix 1: Age classes for hamadryas baboons

used in this study

193

Appendix 2: Distribution of samples across ovarian

cycle for individual females

194 


\section{List of Figures}

Figure 1. Schematic overhead view of Wellington Zoo hamadryas enclosure 35

Figure 2. Temporal distribution of sampling 46

Figure 3. Nearest neighbour dendrogram (social organisation of the colony) 48

Figure 4. Spatial distribution of individuals by groups 49

Figure 5. Activity budget in relation to the time of year (by month) 52

Figure 6. Activity budget for individual colony members 53

Figure 7. Distribution of affiliative interactions for each individual by group $\quad 55$

Figure 8. Distribution of approaches for each individual by group 56

Figure 9. Distribution of agonistic interactions for each individual by group $\quad 58$

Figure 10. Distribution of conciliatory interactions for each individual by group $\quad 59$

Figure 11. Distribution of sexual interactions for each individual by group $\quad 60$

Figure 12. Average hourly mount rate relative to ovarian cycle day 100

Figure 13. Proportion of mounts aborted/rejected for each day of ovarian cycle 101

Figure 14. Average hourly ejaculatory mount rate relative to ovarian cycle day 105

Figure 15. Average hourly present/inspection rate relative to ovarian cycle day 108

Figure 16. Average hourly approach rate relative to ovarian cycle day 112

Figure 17. Changes in ovarian cycle status for each female over study period $\quad 147$

Figure 18. Turgescent phase fitness costs/benefits model 164

Figure 19.Box plots of turgescent phase bias for individual females 173

Figure 20. Turgescent phase bias against cycle length for females grouped by OMU 174 


\section{List of tables}

Table 1. Demographic profile of members of Wellington Zoo colony (Ch. 1) 32

Table 2. Ethogram (Ch. 1) 37

Table 3. Demographic profile of members of Wellington Zoo colony (Ch. 2) 88

Table 4. Ethogram (Ch. 2) 92

Table 5. Tallied sexual interactions between individual females and males by group 97

Table 6. Pemutation test results: attempted mounts 103

Table 7. Pemutation test results: successful mounts 104

Table 8. Pemutation test results: ejaculatory mounts 106

$\begin{array}{ll}\text { Table 9. Pemutation test results: presents } & 109\end{array}$

Table 10. Pemutation test results: perineal inspections 111

Table 11. Pemutation test results: approaches initiated by females 114

Table 12. Pemutation test results: approaches received by females 115

Table 13. Demographic profile of members of Wellington Zoo colony (Ch. 3) 135

Table 14. Menstrual cycle parameters (Ch. 3) 142

$\begin{array}{ll}\text { Table 15. Ovarian synchrony permuation test results } & 144\end{array}$

Table 16. Demographic profile of members of Wellington Zoo colony (Ch. 4) 166

Table 17. Menstrual cycle parameters (Ch. 4) 172

Table 18. Menses to turgescent phase interval 176 


\section{Acknowledgements}

This thesis is the product of approximately two years of earnest labour. Following a year of data collection at the Wellington Zoo, I spent another year inputting and analysing the $250+$ hours of data and writing the final document. Several people were integral to this process, providing me with the advice and encouragement necessary to complete this document. To these people I am forever indebted, and I would like to thank them here. I am particularly grateful to my primary supervisor, Wayne Linklater, whose idea it was to study the Wellington Zoo hamadryas baboon colony and without whose wisdom and guidance this thesis would have been much the poorer. I am similarly indebted to my secondary supervisor, Alan Dixson, who suggested that I focus on the ovarian cycles of females and whose seminal work on primate sexuality served as a template for my own endeavours, and to Shirley Pledger, who conceived and designed the permutation models in chapters 3 and 4 and enlightened me to the power and importance of statistical modelling. Furthermore, this project would have been impossible without permission from the Wellington Zoo community to conduct my research there. The support and companionship that I received from the Wellington Zoo staff made my time there a pleasure and something that I shall always remember fondly. In particular I wish to thank Paul Horton, who helped to familiarise me with the individual baboons and provided me with a detailed history of the colony. Thanks also goes to my closest friend and confidant, Rebecca Paxton, who spent many hours tirelessly inputting data for little more than the odd bit of liquorice and many vague promises. Last but not least, I must thank the baboons themselves, whose trials and tribulations were always educational, often amusing, occasionally perplexing, and which provide the basis for this thesis. 


\section{Chapter 1: General introduction}

Rhythmical changes in reproductive status are common features of biological organisms, both across and within generations. The lifecycle of each individual follows a passage from fertilisation and embryonic development, through to immaturity, maturity and finally senescence, which is repeated in successive generations of offspring. Similarly, upon reaching sexual maturity many organisms exhibit cyclical reproductive patterns throughout their adult lives. For instance, in many organisms fertility is restricted to a relatively limited time period within each year, a pattern which is replicated at approximately the same time over successive years. In doing so females may improve their reproductive success by coordinating future reproductive events with favourable environmental conditions (Baker, 1938; Bronson, 1985; Bronson and Heideman, 1994; Nelson et al., 1990), or by limiting their fecundity to certain times of the year where there are sufficient resources to support reproductive functions (Asa, 1996; Bronson and Heideman, 1994; Nelson et al., 1990).

Many females also experience even finer-scale cyclical patterns called ovarian cycles that are associated with periodic release of gametes (i.e., ova) in the female gonads (i.e., the ovaries). These vary greatly in their basic features and length across the animal kingdom, and are likely to have also been shaped to some degree by evolution. In the remainder of this section, I will outline the archetypal features of the mammalian ovarian cycle and discuss its possible evolution, firstly for mammals in general and then for the most researched order in this respect, the primates. Next I discuss the evolution of exaggerated perineal swellings in primates and the possibility of individual female control of the ovarian cycle in mammals. Finally, information on the focal species of the study, the hamadryas baboon (Papio h. hamadryas), is provided, before the research questions and general synopsis of the thesis are outlined. 


\section{The mammalian ovarian cycle}

The ova of all female mammals mature in follicles; specialised organelles which are located within the ovary (Schroeder and Talbot, 1985). By the end of their neonatal period all females have produced a cohort of 'primordial' follicles, each of which contains a nascent ovum arrested in prophase one of meiosis (i.e.: the primary oocyte). Except in the case of prosimians (Kumar, 1974), these represent the full set of gametes from which mature ova will later be derived. Ova remain in this state until puberty, after which successive subsets of primordial follicles are recruited to undergo further development. Puberty is triggered by increases in the production of various pituitary (e.g., luteinising hormone, $\mathrm{LH}$, follicle stimulating hormone, $\mathrm{FSH}$, and prolactin) and ovarian hormones (e.g., progesterone and estradiol). As the name suggests, FSH is the hormone primarily responsible for facilitating follicular development, whilst sharp increases in the concentration of LH cause the follicles to rupture and release their ova (i.e., ovulation). Additionally, estradiol facilitates the build up of the endometrium within the uterine cavity during follicular development, which provides a surface on which the fertilised ova will later become embedded. Typically only one or a few follicles (i.e., the dominant or Graafian follicle) go on to produce a fully mature tertiary ovary, with the majority regressing before reaching this stage. However, while the Graafian follicle is the only follicle from which a mature ovum can be released, ovulation is not guaranteed (Fortune, 1994).

Following ovulation, the presence of LH causes the Graafian follicle to transform into a structure known as the corpus luteum. The corpus luteum releases large amounts of estradiol and progesterone which inhibit LH and FSH production, preventing further follicle development and triggering the vascularisation of the endometrium. Should conception fail to occur, the corpus luteum increases its production of estradiol and 
progesterone, further inhibiting LH secretion and precipitating its eventual demise. This is followed by the vaginal discharge of the endometrium in some species (i.e., menstruation), or else it is reabsorbed (Asa, 1996). Following the degeneration of the corpus luteum, the concomitant decline in circulating estradiol and progesterone results in the upscaling of FSH secretion and with it the commencement of a new round of follicle development and endometrial growth.

This sequence of follicle development, transformation into a corpus luteum and its eventual degeneration constitutes one complete ovarian cycle, and is the archetypal pattern observed in female mammals (Bullough, 1951; Slater, 1978). Each ovarian cycle is separated into a distinct follicular and luteal phase which accord to the intervals where each name-sake structure plays the predominant role in coordinating ovarian events. Ovarian cycles are also commonly categorised by the fate of the endometrium; menstrual cycles occurring in the species which expel the endometrium, and oestrous cycles occurring in the species which reabsorb it. In the latter case, the name is taken from the observation that the receptive period of many female mammals (i.e., oestrous; Heape, 1900) tends to coincide with the timing of ovulation.

Within this generalised framework, however, there is considerable inter-species variation in both the features and length of the basic ovarian cycle patterns. Authors generally divide the mammals into three broad groups (Conaway, 1971; Martin, 2003, 2007; Perry, 1972; Slater, 1978; Weir and Rowlands, 1973). The first group consists of those species in which both ovulation and the development of corpora lutea occurs spontaneously, i.e., the transition between each phase of the ovarian cycle occurs independently of any external stimuli. Exemplar taxa include primates, ungulates, canids and hystricomorph rodents. The second group also experience spontaneous ovulation, however the formation of the corpus luteum occurs only following coitus (this phase is 
commonly referred to as 'pseudo-pregnancy'). When coitus is absent, the follicle breaks down rather than being transformed into a corpus luteum, expediting the production of the next set of follicles. This type of cycle is common amongst members of the Crecidae and Muridae rodent families, which include the common house mouse (Mus musculus) and the black and brown rats (Rattus rattus and $R$. norvegicus). The final group consist of species where ovulation is initiated by coitus, and the development of the corpus luteum is spontaneous following ovulation. As with the previous type of cycle, follicles regress without forming corpora lutea in the absence of coitus, hastening the subsequent phase of follicular development. Cycles of this type have been observed in felids, mustelids, lagomorphs and some insectivores. Additionally, Conaway (1971) divided the first and last groups into sub-groups of species that exhibit medium (between 2 to 5 weeks and less than 4 weeks respectively) and long (greater than 4 and 5 weeks respectively) cycle lengths. This division is underscored by consistent differences in the length and stability of the component cycle phases within each sub-grouping.

The length of a complete ovarian cycle, and the component phases, vary broadly within the mammalian order. At the lower end of the scale are various rodents such as brown rats, hamsters (Mesocritus auratus) and the corn mouse (Calyomys musculinus) which have an average follicular phase length of 2 days and an overall cycle length averaging between 4 to 6 days (Buzzio et al., 2001; Johnson and Everitt, 2000; Orsini and Schwartz, 1966). At the upper end of the scale are the African (Loxodonta africana) and Asian (Elephas maximus) elephant, with follicular phases of around 40 days long on average and an overall average cycle length nearing 100 days (Heistermann et al., 1997; Hildebrandt et al., 2006; Hodges, 1998). Ruminants such as sheep (Ovis aries), cows (Bos taurus) and goats (Capra hircus), tend to have short follicular phases (averaging between 1 to 4 days) and intermediate length cycles (averaging around 20 days; Johnson 
and Everitt, 2000; Menchaca and Rubianes, 2001). In contrast primates tend to have some of the most prolonged follicular phases (average \pm standard deviation $=12.1 \pm 5.0$ days for 27 species; calculated from data presented in Barnett and Abbott, 2003) and lengthy ovarian cycles (average \pm standard deviation $=30.0 \pm 9.9$ days for 44 species; Martin, 2007) observed in the mammalian order.

\section{Evolution of the ovarian cycle in mammals}

The ultimate cause behind the origins of the ovarian cycle remains to be elucidated. One recent suggestion is that it may have be an evolutionary byproduct of the process of species specific follicular competition (i.e., selection of the dominant follicle), which has been exapted (sensu Gould and Lewontin, 1979) for other functions (Schank, 2004). However, exactly how and why this might have occurred was not explicated, as the full hypothesis was still awaiting publication at the time of writing.

Likewise, information on the ovarian cycle for broad sections of the mammalian order is still lacking, which makes determining the roles of selective forces and phylogenetic relationships in shaping ovarian cycle patterns within this order difficult to determine. However, it has been observed that species that are characterised by relatively short life spans and high reproductive turnover tend to exhibit the shortest cycles and have induced ovulation or corpora lutea formation (e.g., insectivores, myomorph and scuriomorph rodents), while species that have longer or spontaneous cycles tend to be longer lived and have lower reproductive turnover rates (e.g., primates, histricomorph rodents, cetaceans) (Conaway, 1971; Martin, 2003, 2007). Hence, given that the emphasis on quickly reinstating follicle development and ovulation should fertilisation fail to occur is expected to be greatest amongst females whose lifespans are relatively 
short, it appears that shortened cycles and expedited resumption of follicle development may be an adaptation to minimise the time that females spend in ovarian cycling. Notably, this does not explain why females still experience a delay in the return to follicle development following a sterile copulation. To this end Conaway (1971) points out that sterile copulations are "virtually unknown in natural populations", which suggests that this may largely be an artefact of experimental conditions and is unlikely, therefore, to be a problem for females in wild populations.

\section{Evolution of the ovarian cycle in primates}

By far the largest pool of ovarian cycle data collected from a single mammalian order is from the primates. All primates exhibit menstrual cycles, i.e., cycles characterised by spontaneous ovulation and corpora lutea formation and the expulsion of the endometrium (i.e., menses) at the end of the luteal phase. Only a few chiropteran species (Rasweiler, 1991; Rasweiler and De Bonilla, 1992; Zhang et al., 2007) and the elephant shrew (Elephantus myurus) (van der Horst and Gillman, 1941) are also known to exhibit this cycle (Asa, 1996).

A recent survey by van Schaik et al. (2000) found that prosimians had slightly longer cycles than catarrhines (average \pm standard deviation $=33.77 \pm 7.91$ and $31.01 \pm$ 3.67 days for 19 and 38 species respectively), which were both much longer than those found in platyrrhines (average \pm standard deviation $=20.03 \pm 5.84$ days for 20 species) . However, catarrhines had twice the average follicular phase length of either platyrrhines or prosimians (average \pm standard deviation $=14.99 \pm 3.37$ vs. $6.90 \pm 2.15$ and $7.33 \pm$ 4.04 days taken from 22,8 and 3 species respectively), such that the follicular phase makes up a much larger portion of the catarrhine ovarian cycle than is found amongst 
other mammals. Notably, there is no specific allometric relationship between body size and ovarian cycle length in primates (Martin, 2003), and although there is a positive relationship between body size and follicular phase length, it appears to be an artefact caused by simultaneous upwards shifts in both variables (van Schaik et al., 2000). Hence, it appears that diversity in ovarian cycle lengths found amongst primates has been shaped in part by natural selection.

A recent hypothesis suggests that the lengthy follicular phase observed in primates may be an adaptation that supports the development of large-brained offspring that are characteristic of the order (Barnett and Abbott, 2003). Primates exhibit the most invasive forms of placentae and the most rapid implantation of the embryo amongst the mammals. These features are thought to better support the nutritional requirements needed for the development of a large-brained foetus (Martin, 1974). As a result, unlike most other mammals, primates require much more extensive development of the endometrium during the follicular phase to accommodate the rapidly implanting embryo and highly invasive placentae (Mossman, 1987). Consequently, the follicular phase of primates may have become lengthened to cater for increased endometrial development. Indeed, the longest follicular phases, the most developed endometrium, and the most invasive forms of placentae amongst the primates all occur in the catarrhine primates (Mossman, 1987), where brain size also reaches its maximum within the order (Aiello and Dean, 1990).

Alternatively, van Shaik and colleagues $(1999,2000)$ have proposed a hypothesis that explains the follicular phase length differences in primates in terms of a behavioural factor, namely the risk of male-induced infanticide within each species. Female primates exhibit lengthy periods of gestation and amenorrhea (which is necessary for the development of precocious, large-brained offspring) and tend to resume cycling more 
rapidly after the death of offspring, such that males can increase their reproductive success by killing unweaned offspring that are unlikely to be their own (Hrdy, 1979). van Shaik and colleagues suggest that the lengthy and highly variable (both within and between females; Hodges, 1987) follicular phase that are typical of female primates evolved as part of a female strategy to make the timing of ovulation less predictable, thereby giving them more control over the paternity probability that is assigned to each male. In this manner females can confer higher paternity probability to a dominant male (e.g., by concentrating mating with them during times when ovulation is most likely), thereby increasing the likelihood of future offspring protection from the male that is best placed to do so (i.e., a paternity concentration strategy). At the same time, the lengthy follicular phase increases the opportunities for females to mate with subordinate males who may later assume the role of dominant male and subsequently become an infanticide threat. The probabilistic nature of ovulation means that these males are afforded some chance of paternity, thereby decreasing the likelihood that they will commit infanticide in the future (i.e., a paternity confusion strategy). The ability to enact both strategies within a single ovarian cycle helps females to solve the 'female dilemma' (i.e., that enacting one strategy counteracts the other; Nunn, 1999; van Schaik et al., 1999, 2000), and greatly reduces the future risk of infanticide.

Indeed, female control over which males they mate with appears to be much lower amongst the catarrhines than amongst the platyrrhines and prosimians (where body size and canine dimorphism is lower and arborialism is more common, making females less prone to male coercion), which suggests that longer cycles may be needed for catarrhine females to be able to mate with subordinate males. However, while most other predictions made by van Shaik et al were generally supported, several lacked statistical support (e.g., the relationship between demographic factors such as number of males in a 
group or the number of mating partners per cycle and follicular phase length). The authors suggested that this may have been due in part to a lack of power because of insufficient observations (i.e., data from individual species) and emphasised the need for further testing to elucidate the validity of their hypothesis.

\section{Exaggerated perineal swellings}

Several species of catarrhine primates exhibit cyclical periods of turgescence of the sexual skin referred to as exaggerated perineal swellings (EPS) that coincide with the follicular period of the ovarian cycle. Perineal turgescence is caused by extra- and intracellular retention of water in the tissues in and around the anogenital and perineal regions which is mediated by ovarian hormones (Dixson, 1983). While most primates exhibit a moderate degree of swelling of the sexual skin during the follicular phase (Dixson, 1983; Sillen-Tullberg and Moller, 1993), EPS are highly conspicuous, comprising up to $14 \%$ of adult female body mass in chacma baboons (Papio hamadryas ursinus; Bielert and Busse, 1983). That EPS impose both physiological and behavioural costs for females (Nunn, 1999) has led to the development of several hypotheses that that stipulate the net fitness benefits that EPS purportedly provide for females. Two hypotheses emerged in the 1990's that synthesised many of the key elements of previous adaptive explanations. These have garnered most attention in recent times, and are briefly summarised below.

The reliable indicator hypothesis (Pagel, 1994) argues that the absolute size of EPS in individual females accurately signal female fitness and incites inter-male competition, leading to fertilisation from the fittest male. A study on olive baboons (Papio hamadryas anubis) found a positive relationship between female fitness and the size of perineal turgescence (Domb and Pagel, 2001). However, the emergence of 
negative results (Emery and Whitten, 2003; Nunn et al., 2001; Setchell and Wickings, 2004) and empirical and theoretical criticisms (Zinner et al., 2002; Zinner et al., 2004) mean that hypothesis currently remains contentious.

The graded signal hypothesis (Nunn, 1999) proposes that EPS evolved as a mechanism which facilitates a dual paternity concentration/paternity confusion strategy and thereby solves the 'female dilemma' proposed by van Shaik and colleagues. Indeed, EPS appears to act as probabilistic fertility signal (Nunn, 1999) and its occurrence tends to be concentrated amongst species that live in multi-male groups with aseasonal breeding patterns, where the potential for male coercion is high (van Schaik et al., 1999). These factors are expected to favour the development of EPS as a means to confound male control and facilitate mating with multiple males as part of a paternity confusion strategy. However, while comparative data support this hypothesis, much of this data was used to provide its empirical foundations and therefore cannot be used to substantiate it (Zinner et al., 2004). Hence, in lieu of any direct empirical testing, the graded signal hypothesis remains speculative.

\section{Female control of the ovarian cycle}

Female primates are one of a select group of mammals that have been found to coordinate the timing of ovarian cycle events amongst female group members. The synchronisation of some part of the ovarian cycle (i.e., ovarian synchrony - while the term oestrus synchrony is often used to describe this phenomenon, the previous term is preferred here since the period of the ovarian cycle that is used to measure synchrony is not always the oestrous period; e.g., typically menses discharge in humans) has been observed in brown rats (McClintock, 1978), hamsters (Handelmann et al., 1980), 
humans, homo sapiens (Graham and McGrew, 1980; McClintock, 1971; Quadagno et al., 1981; Weller and Weller, 1993, 1997), chimpanzees, Pan troglodytes (Wallis, 1985) and golden lion tamarins, Leontopithecus rosalia (French and Stribley, 1987). Asynchronisation of the ovarian cycles (i.e., ovarian asynchrony) has been observed in hamsters (Gattermann et al., 2002), chimpanzees (Matsumoto-Oda et al., 2007) and ringtailed lemurs, Lemur catta (Pereira, 1991). Notably, that both synchronous and asynchronous ovarian cycles have been found to occur within the same species suggests that the type of ovarian cycle coordination practiced amongst groups of females may be context-dependent.

Unlike the seasonal synchronisation of breeding which is induced by environmental factors, ovarian cycle manipulation appears to be facilitated by social cues such as pheromones. Studies reveal that pheromones produced by females actively increase or reduce the length of the ovarian cycle amongst conspecific brown rats (McClintock, 1978, 1984) and women (Stern and McClintock, 1998). Such a mechanism has been shown to be sufficient to lead to the synchronisation or asynchronisation of ovarian cycles amongst a group of females in computer simulations based on these findings (Schank and McClintock, 1992).

The fine-scale tuning facilitated by social cues is most likely to have a function during the actual ovarian cycle, rather than in coordinating future events amongst the group which can be adequately achieved via seasonal cues. It has been suggested that females may be able to limit the degree to which they can be monopolised by dominant males by synchronising the receptive period of their ovarian cycle (Colinshaw and Dunbar, 1991; Emlen and Oring, 1977; Kutsukake and Nunn, 2006; Paul, 1997; Ridley, 1986; Shuster and Wade, 2003; Soltis et al., 2001). This may enable females to mate with non-dominant males (which may be important where dominant males are close kin), 
facilitate male sperm competition or cryptic female choice, or increase paternal investment by decreasing the probability of males obtaining multiple mates (Eberhard, 1996; Hrdy, 2000; Knowlton, 1979). Alternatively, by staggering the time when they are likely to be fertile, females increase the number of sexually available males relative to themselves (i.e., increasing the operational sex ratio, OSR; Emlen and Oring, 1977). This may decrease inter-female competition for access to mates (Gattermann et al., 2002; Pereira, 1991), or reduce the potential for coercive matings from subordinate males (Matsumoto-Oda et al., 2007), thereby increasing female reproductive success. Hence, whether females synchronise or asynchronise ovarian cycles may ultimately depend on both the intended end result and the current demographic composition of the group.

The validity of oestrus synchrony studies, however, have been criticised on a number of grounds. The empirical evidence for the existence of pheromones remains in doubt (Strassmann, 1999; Whitten, 1999; Wilson, 1987, 1988; Winman, 2004), and there is evidence to suggest that the statistical techniques employed in previous studies actually increase the likelihood of finding ovarian synchrony (Schank, 2000, 2001a, 2001b; Wilson, 1992). Furthermore, an increasing number of papers are emerging which show no evidence of ovarian synchrony in women (Jarett, 1984; Strassmann, 1997; Trevathan et al., 1993; Wilson et al., 1991; Yang and Schank, 2006; Ziomkiewicz, 2006). Finally, the potential high costs of ovarian synchrony (e.g., increased inter-female competition and increase in the OSR) have led Schank (2001b; 2004) to suggest that the high degree of variation in follicular phase length may in fact be an adaptation to avoid ovarian synchrony in group-living females. Consequently, the debate on ovarian synchrony remains contested (McClintock, 1998; Weller and Weller, 2002a, 2002b). This emphasises the importance of data on ovarian cycles and behaviour for a broad range of species to better assess the relationship between these variables. 


\section{Hamadryas baboons}

Hamadryas baboons (Papio h. hamadryas) form part of a highly successful branch of the catarrhine primate family, commonly referred to as savannah baboons. Baboons are broadly distributed over the African continent, with the hamadryas inhabiting the semiarid, highland regions around the Horn of Africa and the Arabian Peninsula (Newman et al, 2004). Baboons form an array of parapatric allotaxa, or "morphologically distinctive, geographically replacing populations" (Henzi and Barrett, 2005, pg 218), whose evolutionary history has been marked by alternating periods of reproductive isolation and admixture (Jolly, 1993, 2001). In keeping with these findings, hamadryas baboons are referred to by their sub-species in this thesis.

Unlike other baboons which tend to live in temporally stable multi-male/multifemale groups throughout their lives, hamadryas baboons live in modular societies which undergo regular fission and fusion events (Kummer, 1968, 1990). The basic constituent of hamadryas societies is the one male unit (OMU), which typically consists of a single adult male (resident male, RM), 1 to 3 adult females (maximum reported $=11$ ) and their offspring (Biquand et al., 1992; Kummer, 1968; Mori et al., 2007; Swedell, 2002; Zinner et al., 2001). OMUs are nested within clans, which comprise two or more OMUs whose RMs are thought to be related (Abegglen, 1984; Kummer, 1990). Several clans link up into bands during daily foraging excursions (Kummer, 1990), and, finally, troops form when bands assemble at predator-resistant sleeping sites at night. Troop formation is thought to be a byproduct of a lack of suitable sleeping sites rather than from an affinity between bands (Kummer, 1968).

Males are thought to play a larger role in structuring hamadryas societies than is typical amongst group-living primates (Abegglen, 1984; Kummer, 1968, 1990). Hamadryas RMs aggressively herd females in their OMU, attacking those that become 
either spatially or socially detached from the OMU. Experimental data suggest that males 'respect' the pair bonds of other males (Kummer, 1968; Kummer et al., 1974), having evolved a strategy where extra-OMU copulations are eschewed in favour of maintaining a constant vigil over the female members of their own OMU. As a result, almost all observed social and sexual interactions in hamadryas societies have taken place between members of the same OMU (Abegglen, 1984; Colmenares et al., 1994; Kummer, 1968; Swedell and Saunders, 2006). Furthermore, females are typically separated from other female kin following their recruitment into an OMU, such that the opportunities for relationships between adult female kin are typically low (Abegglen, 1984; Kummer, 1995). Hence the matrilineal dominance hierarchies that are prevalent in other baboon subspecies are absent in hamadryas societies and females tend to form the strongest bonds with their RM rather than with other females (i.e., hamadryas societies are crossbonded; Byrne et al., 1989).

The present study was conducted on a captive colony of hamadryas baboons located at the Wellington Zoo, in the North Island of New Zealand. Prior to the commencement of the study, all RMs within the colony were vasectomised in an effort to control population growth. Consequently, no pregnancies were observed in the interim such that all mature females exhibited repeated ovarian cycling for the duration of the study. Because female baboons exhibit EPS, which are known act as reliable indicators of ovarian cycle status (Hendrickx and Kraemer, 1969; Shaikh et al., 1982; Wildt et al., 1977), accurate information on ovarian cycle status could be collected in lieu of hormonal information by monitoring changes in the perineal turgescence of each female. This meant that a large amount of ovarian cycle data could be collected in a relatively short time span, providing the opportunity for fine-scale analyses on the relationship between the ovarian cycle and behaviour in this species. Indeed, because female 
hamadryas baboons generally conceive within 2 to 3 cycles and typically spend more than 12 months gestating and undergoing amenorrhea following conception (Asanov, 1972; Kaumanns et al., 1989; Sigg et al., 1982) there is very little ovarian cycle data currently available for hamadryas females, particularly for females that are concurrently cycling in the same OMU.

\section{Thesis structure and research questions}

This study contains four empirical chapters, each addressing a particular question, and a summary. Chapter 2 provides a demographic and ethological overview of the Wellington Zoo hamadryas baboon colony. The socio-spatial structure and organisation of the colony are quantified and compared with data from other captive, commensal and wild colonies, with an emphasis on examining how RM contraception may have affected these characteristics. Chapter 3 examines the sexual behaviour of colony members in relation to the ovarian cycle of female OMU members. Changes in the frequency of sexual activities occurring across each day of the ovarian cycle, and the relative contributions made by RMs and non-OMU males on each day, are examined. This information is used to infer the patterning of female sexual receptivity (willingness to be engaged in sexual behaviour), attractiveness (value as a sexual stimulus to males) and proceptivity (willingness to seek out sexual behaviour; all definitions based on Beach, 1976) across the ovarian cycle, and to assess the function of extra-OMU mating for females in light of these patterns. The plausibility of three strategies is examined; female mate choice, fertility insurance and paternity confusion. Chapter 4 looks at whether the females in the colony were actively synchronising or asynchronising their ovarian cycles over the one year study interval, using a purpose built permutation test. The findings are considered with respect to reports on ovarian synchrony from other hamadryas populations and I 
assess the potential for ovarian synchrony to have evolved in hamadryas baboons given the demographic and mating contexts that are characteristic of wild populations. In chapter 5 I investigate whether the ovarian cycle is manipulated by individual females in a manner which increases their reproductive success. Specifically, I hypothesise that the length of the turgescent phase in female hamadryas baboons is determined by where the difference between the fitness costs and benefits associated with perineal turgescence is maximised. The fundamental fitness benefit is assumed to be extra-OMU mating as part of a paternity confusion strategy, as based on the hypotheses outlined in van Schaik et al (2000) and Nunn (1999) that were introduced in this section. Finally, in chapter 6 I summarise the findings of the previous four chapters and discuss the implications of these findings on the current understanding of hamadryas reproductive behaviour and the relationship between ovarian cycle plasticity and female reproductive strategies in general. As a final note, each chapter was written as a stand-alone document in order to expedite the concurrent journal submission process. Hence, each chapter has been structured and worded as a unitary study, which necessitates the repetition of certain concepts and methods.

The central aim of this study was to examine the relationship between the ovarian cycle and sexual behaviour for a group living primate, under conditions that were amenable to a fine-scale analysis. Overall, I sought to elucidate whether females were actively manipulating the length of their ovarian cycle, specifically the turgescent phase, in order to implement mating strategies that are expected to improve their reproductive success. In other words, I expected that variation in ovarian cycle parameters was partly under the control of females themselves, as a result of selection acting within the particular social and breeding contexts that typify wild hamadryas populations. 


\section{REFERENCES}

Abegglen JJ. 1984. On Socialization in Hamadryas Baboons. London: Associated University Presses.

Aiello LC, Dean C. 1990. An Introduction to Human Evolutionary Anatomy. London: Academic Press.

Asa CS. 1996. Reproductive physiology. In: Kleiman DG, Allen ME, Thompson KV, Lumpkin S, editors. Wild Mammals in Captivity: University of Chicago Press.

Asanov SS. 1972. Comparative features of the reproductive biology of hamadryas baboons (Papio hamadryas), grivet monkeys (Cercopithecus aethiops) and rhesus monkeys (Macaca mulatta). Acta Endocrinologica Supplementum 166:458-471.

Baker JR. 1938. The evolution of breeding seasons. In: de Beer J, editor. Evolution. Oxford: Clarendon Press. p 161-177.

Barnett DK, Abbott DH. 2003. Reproductive adaptations to a large-brained fetus open a vulnerability to anovulation similar to polycystic ovary syndrome. American Journal of Human Biology 15:296-319.

Beach FA. 1976. Sexual attractivity, proceptivity, and receptivity in female mammals. Hormones and Behavior 7:105-138.

Bielert C, Busse C. 1983. Influences of ovarian hormones on the food intake and feeding of captive and wild female chacma baboons (Papio ursinus). Physiology and Behavior 30:103-111.

Biquand S, Biquand-Guyot V, Boug A, Gautier JP. 1992. Group composition in wild and commensal hamadryas baboons: A comparative study in Saudi Arabia. International Journal of Primatology 13:533-543.

Bronson FH. 1985. Mammalian reproduction: An ecological perspective. Biology of Reproduction 32:1-26. 
Bronson FH, Heideman PD. 1994. Seasonal regulation of reproduction in mammals. In: Knobil E, Neill JD, editors. The Physiology of Reproduction. p 541-584.

Bullough WS. 1951. Vertebrate Sexual Cycles. London: Methuen.

Buzzio OL, Koninckx A, Carreno NB, Castro-Vazquez A. 2001. Embryo implantation during the short luteal phase of the corn mouse, Calomys musculinus, and the apparent lack of a lactational diapause in South American murid rodents. Reproduction 121:815-823.

Byrne RW, Whiten A, Henzi SP. 1989. Social relationships of mountain baboons: leadership and affiliation in a non-female bonded monkey. American Journal of Primatology 18:191-207.

Colinshaw G, Dunbar RIM. 1991. Dominance rank and mating success in male primates. Animal Behaviour 41:1045-1056.

Colmenares F, Lozano MG, Torres P. 1994. Harem social structure in a multiharem colony of baboons (Papio spp.): A test of the hypothesis of the "star-shaped" sociogram. Current Anthropology 2:93-101.

Conaway CH. 1971. Ecological adaptation and mammalian reproduction. Biology of Reproduction 4:239-247.

Dixson AF. 1983. Observations on the evolution and behavioral significance of "sexual skin” in female primates. In: Rosenblatt JS, Hinde RA, Beer C, Busnel M-C, editors. Advances in the Study of Behaviour. New York: Academic Press. p 63106.

Domb LG, Pagel M. 2001. Sexual swellings advertise female quality in wild baboons. Nature 410:204-206.

Eberhard WG. 1996. Female Control: Sexual Selection by Cryptic Female Choice. Princeton University Press. 
Emery MA, Whitten PL. 2003. Size of sexual swellings reflects ovarian function in chimpanzees (Pan troglodytes). Behavioral Ecology and Sociobiology 54:340351.

Emlen ST, Oring LW. 1977. Ecology, sexual selection, and the evolution of mating systems. Science 197:215-223.

Fortune JE. 1994. Ovarian follicular growth and development in mammals. Biology of Reproduction 50:225-232.

French JA, Stribley JA. 1987. Synchronization of ovarian cycles within and between social groups in golden lion tamarins (Leontopithecus rosalia). American Journal of Primatology 12:469-478.

Gattermann R, Ulbrich K, Weinandy R. 2002. Asynchrony in the estrous cycles of golden hamsters (Mesocricetus auratus). Hormones and Behavior 42:70-77.

Gould SJ, Lewontin RC. 1979. The spandrels of San Marco and the Panglossian paradigm: A critique of the adaptationist programme. Proceedings of the Royal Society of London Series B-Biological Sciences 205:581-598.

Graham CA, McGrew WC. 1980. Menstrual synchrony in female undergraduates living on a coeducational campus. Psychoneuroendocrinology 5:245-252.

Handelmann G, Ravizza R, Ray WJ. 1980. Social dominance determines estrous entrainment among female hamsters. Hormones and Behavior 14:107-115.

Heape W. 1900. The "Sexual Season" of mammals and the relation of the "pro-oestrum" to menstruation. Quarterly Journal of Microscopical Science 44:1-70.

Heistermann M, Trohorsch B, Hodges JK. 1997. Assessment of ovarian function in the African elephant (Loxodonta africana) by measurement of 5-reduced progesterone metabolites in serum and urine. Zoo Biology 16:273-284. 
Hendrickx AG, Kraemer DC. 1969. Observations on the menstrual cycle, optimal mating time and pre-implantation embryos of the baboon, Papio anubis and Papio cynocephalus Journal of Reproduction and Fertility (Supplement) 6:119-128.

Henzi SP, Barrett L. 2005. The historical socioecology of savanna baboons (Papio hamadryas). Journal of Zoology 265:215-226.

Hildebrandt TB, Goritz F, Hermes R, Reid C, Dehnhard M, Brown JL. 2006. Aspects of the reproductive biology and breeding management of Asian and African elephants Elephas maximus and Loxodonta africana. International Zoo Yearbook 40:20-40.

Hodges JK. 1987. The ovarian cycle and control of ovulation. Journal of Zoology 213:383-394.

Hodges JK. 1998. Endocrinology of the ovarian cycle and pregnancy in the Asian (Elephas maximus) and African (Loxodonta africana) elephant. Animal Reproduction Science 53:3-18.

Hrdy SB. 1979. Infanticide among animals: a review, classification, and examination of the implications for the reproductive strategies of females. Ethology and Sociobiology 1:13-40.

Hrdy SB. 2000. The optimal number of fathers: Evolution, demography, and history in the shaping of female mate preferences. Annals of the New York Academy of Science 907:75-96.

Jarett LR. 1984. Psychosocial and biological influences on menstruation: synchrony, cycle length, and regularity. Psychoneuroendocrinology 9:21-28.

Johnson MH, Everitt BJ. 2000. Essential Reproduction. 5th ed: Blackwell Scientific Ltd. 
Jolly CJ. 1993. Species, subspecies, and baboon systematics. In: Kimbel WH, Martin LB, editors. Species, Species Concepts, and Primate Evolution. New York: Plenum Press. p 67-107.

Jolly CJ. 2001. A proper study for mankind: Analogies from the papionin monkeys and their implications for human evolution. Yearbook of Physical Anthropology 44:177-204.

Kaumanns W, Rohrhuber B, Zinner D. 1989. Reproductive parameters in a newly established colony of hamadryas baboons (Papio hamadryas). Primate Report 24:25-33.

Knowlton N. 1979. Reproductive synchrony, parental investment, and the evolutionary dynamics of sexual selection. Animal Behavior 27:1022-1033.

Kumar TC. 1974. Oogenesis in adult prosimian primates. Contributions to Primatology 3:82-96.

Kummer H. 1968. Social Organization of Hamadryas Baboons: A Field Study. Chicago: University of Chicago Press.

Kummer H. The social system of hamadryas baboons and its presumed evolution. In: Mello MT, Whiten A, Byrne RW, editors. Baboons: Behaviour and Ecology. Use and Care. Selected Proceedings of the XIIth Congress of the International Primatological Society; 1990; Brasilia, Brazil.

Kummer H. 1995. In Quest of the Sacred Baboon: A Scientist's Journey. Princeton, NJ: Princeton University Press.

Kummer H, Götz W, Angst W. 1974. Triadic differentiation: An inhibitory process protecting pair bonds in baboons. Behaviour 49:62-87. 
Kutsukake N, Nunn CL. 2006. Comparative tests of reproductive skew in male primates: the roles of demographic factors and incomplete control. Behavioral Ecology and Sociobiology 60:695-706.

Martin RD. 1974. The bearing of reproductive behavior and ontogeny on strepsirhine phylogeny. Contributions to Primatology 3:265-297.

Martin RD. 2003. Human reproduction: A comparative background for medical hypotheses. Journal of Reproductive Immunology 59:111-135.

Martin RD. 2007. The evolution of human reproduction: A primatological perspective. American Journal of Physical Anthropology 45:59-84.

Matsumoto-Oda A, Hamai M, Hayaki H, Hosaka K, Hunt KD, Kasuya E, Kawanaka K, Mitani JC, Takasaki H, Takahata Y. 2007. Estrus cycle asynchrony in wild female chimpanzees, Pan troglodytes schweinfurthii. Behavioral Ecology and Sociobiology 61:661-668.

McClintock MK. 1971. Menstrual synchrony and suppression. Nature 229:244-245.

McClintock MK. 1978. Estrous synchrony and its mediation by airborne chemical communication (Rattus norvegicus). Hormones and Behavior 10:264-275.

McClintock MK. 1984. Estrous synchrony: Modulation of ovarian cycle length by female pheromones. Physiology and Behavior 32:701-705.

McClintock MK. 1998. Whither menstrual synchrony? Annual Review of Sex Research 9:77-95.

Menchaca A, Rubianes E. 2001. Effect of high progesterone concentrations during the early luteal phase on the length of the ovulatory cycle of goats. Animal Reproduction Science 68:69-76. 
Mori A, Yamane A, Sugiura H, Shotake T, Boug A, Iwamoto T. 2007. A study on the social structure and dispersal patterns of hamadryas baboons living in a commensal group at Taif, Saudi Arabia. Primates 48:179-189.

Mossman HW. 1987. Vertebrate Fetal Membranes. New Brunswick, NJ: Rutgers University Press.

Nelson RJ, Badura LL, Goldman BD. 1990. Mechanisms of seasonal cycles of behavior. Annual Reviews in Psychology 41:81-108.

Newman TK, Jolly CJ, Rogers J. 2004. Mitochondrial phylogeny and systematics of baboons (Papio). American Journal of Physical Anthropology 124:17-27.

Nunn CL. 1999. The evolution of exaggerated sexual swellings in primates and the graded-signal hypothesis. Animal Behaviour 58:229-246.

Nunn CL, van Schaik CP, Zinner D. 2001. Do exaggerated sexual swellings function in female mating competition in primates? A comparative test of the reliable indicator hypothesis. Behavioral Ecology 12:646-654.

Orsini MW, Schwartz NB. 1966. Pituitary LH content during the estrous cycle in female hamsters: comparisons with males and acyclic females. Endocrinology 78:34-40.

Pagel M. 1994. The evolution of conspicuous oestrous advertisement in Old World monkeys. Animal Behaviour 47:1333-1341.

Paul A. 1997. Breeding seasonality affects the association between dominance and reproductive success in non-human male primates. Folia Primatologica 68:344349.

Pereira ME. 1991. Asynchrony within estrous synchrony among ringtailed lemurs (Primates, Lemuridae). Physiology and Behavior 49:47-52.

Perry JS. 1972. The Ovarian Cycle of Mammals. Edinburgh: Oliver and Boyd. 
Quadagno DM, Shubeita HE, Deck J, Francoeur D. 1981. Influence of male social contacts, exercise and all-female living conditions on the menstrual cycle. Psychoneuroendocrinology 6:239-244.

Rasweiler JJ. 1991. Spontaneous decidual reactions and menstruation in the black mastiff bat, Molossus ater. American Journal of Anatomy 191:1-22.

Rasweiler JJ, De Bonilla H. 1992. Menstruation in short-tailed fruit bats (Carollia spp.). Journal of Reproduction and Fertility 95:231-248.

Ridley M. 1986. The number of males in a primate troop. Animal Behaviour 34:18481858.

Schank JC. 2000. Menstrual-cycle variability and measurement: Further cause for doubt. Psychoneuroendocrinology 25:837-847.

Schank JC. 2001a. Measurement and cycle variability: Reexamining the case for ovariancycle synchrony in primates. Behavioural Processes 56:131-146.

Schank JC. 2001b. Menstrual-cycle synchrony: problems and new directions for research. Journal of Comparative Psychology 115:3-15.

Schank JC. 2004. Avoiding synchrony as a strategy of female mate choice. Nonlinear Dynamics, Psychology, and Life Sciences 8:147-176.

Schank JC, McClintock MK. 1992. A coupled-oscillator model of ovarian-cycle synchrony among female rats. Journal of Theoretical Biology 157:317-362.

Schroeder PC, Talbot P. 1985. Ovulation in the animal kingdom. Gamete Research $11: 191-221$

Setchell JM, Wickings EJ. 2004. Sexual swelling in mandrills (Mandrillus sphinx): A test of the reliable indicator hypothesis. Behavioral Ecology 15:438-445. 
Shaikh AA, Shaikh SA, Celaya CL, Gomez I. 1982. Temporal relationship of hormonal peaks to ovulation and sex skin deturgescence in the baboon. Primates 23:444452.

Shuster SM, Wade MJ. 2003. Mating Systems and Strategies. Princeton University Press.

Sigg H, Stolba A, Abegglen JJ, Dasser V. 1982. Life history of hamadryas baboons: Physical development, infant mortality, reproductive parameters and family relationships. Primates 23:473-487.

Sillen-Tullberg B, Moller AP. 1993. The relationship between concealed ovulation and mating systems in anthropoid primates: A phylogenetic analysis. American Naturalist 141:1-25.

Slater PJB. 1978. Sex Hormones and Behaviour. London: Edward Arnold.

Soltis J, Thomsen R, Takenaka O. 2001. The interaction of male and female reproductive strategies and paternity in wild Japanese macaques, Macaca fuscata. Animal Behaviour 62:485-494.

Stern K, McClintock MK. 1998. Regulation of ovulation by human pheromones. Nature 392:177.

Strassmann BI. 1997. The biology of menstruation in homo sapiens: total lifetime menses, fecundity, and nonsynchrony in a natural-fertility population. Current Anthropology 38:123-129.

Strassmann BI. 1999. Menstrual synchrony pheromones: cause for doubt. Human Reproduction 14:579-580.

Swedell L. 2002. Ranging behavior, group size and behavioral flexibility in Ethiopian hamadryas baboons (Papio hamadryas hamadryas). Folia Primatologica 73:95103. 
Swedell L, Saunders J. 2006. Infant mortality, paternity certainty, and female reproductive strategies in hamadryas baboons. In: Swedell L, Leigh SR, editors. Reproduction and Fitness in Baboons: Behavioral, Ecological, and Life History Perspectives: Springer. p 19-51.

Trevathan WR, Burleson MH, Gregory WL. 1993. No evidence for menstrual synchrony in lesbian couples. Psychoneuroendocrinology 18:425-435.

van der Horst CJ, Gillman J. 1941. The menstrual cycle in Elephantulus. South African Journal of Medical Sciences 6:27-47.

van Schaik CP, Hodges JK, Nunn CL. 2000. Paternity confusion and the ovarian cycles of female primates. In: Janson $\mathrm{CH}$, Van Schaik CP, editors. Infanticide by Males and its Implications. Cambridge: Cambridge University Press. p 361-387.

van Schaik CP, van Noordwijk MA, Nunn CL. 1999. Sex and social evolution in primates. In: Lee PC, editor. Comparative Primate Socioecology: Cambridge University Press. p 204-231.

Wallis J. 1985. Synchrony of estrous swelling in captive group-living chimpanzees (Pan troglodytes). International Journal of Primatology 6:335-350.

Weir BJ, Rowlands IW. 1973. Reproductive strategies of mammals. Annual Reviews in Ecology and Systematics 4:139-163.

Weller A, Weller L. 1993. Menstrual synchrony between mothers and daughters and between roommates. Physiology \& Behavior 53:943-949.

Weller A, Weller L. 1997. Menstrual synchrony under optimal conditions: Bedouin families. Journal of Comparative Psychology 111:143-151.

Weller A, Weller L. 2002a. Menstrual synchrony can be assessed, inherent cycle variability notwithstanding: Commentary on Schank (2001). Journal of Comparative Psychology 116:319-322. 
Weller L, Weller A. 2002b. Menstrual synchrony and cycle variability: A reply to Schank (2000). Psychoneuroendocrinology 27:519-526.

Whitten W. 1999. Pheromones and regulation of ovulation. Nature 401:232-233.

Wildt DE, Doyle LL, Stone SC, Harrison RM. 1977. Correlation of perineal swelling with serum ovarian hormone levels, vaginal cytology, and ovarian follicular development during the baboon reproductive cycle. Primates 18:261-270.

Wilson HC. 1987. Female axillary secretions influence women's menstrual cycles: A critique. Hormones and Behavior 21:536-550.

Wilson HC. 1988. Male axillary secretions influence women's menstrual cycles: A critique. Hormones and Behavior 22:266-271.

Wilson HC. 1992. A critical review of menstrual synchrony research. Psychoneuroendocrinology 17:565-591.

Wilson HC, Kiefhaber SH, Gravel V. 1991. Two studies of menstrual synchrony: Negative results. Psychoneuroendocrinology 16:353-359.

Winman A. 2004. Do perfume additives termed human pheromones warrant being termed pheromones? Physiology and Behavior 82:697-701.

Yang Z, Schank JC. 2006. Women do not synchronize their menstrual cycles. Human Nature 17:434-447.

Zhang X, Zhu C, Lin H, Yang Q, Ou Q, Li Y, Chen Z, Racey P, Zhang S, Wang H. 2007. Wild fulvous fruit bats (Rousettus leschenaulti) exhibit human-like menstrual cycle. Biology of Reproduction 77:358-364.

Zinner D, Alberts SC, Nunn CL, Altmann J. 2002. Significance of primate sexual swellings. Nature 420:142-143.

Zinner D, Nunn CL, van Schaik CP, Kappeler PM. 2004. Sexual selection and exaggerated sexual swellings of female primates. In: Kappeler PM, van Schaik 
CP, editors. Sexual Selection in Primates: New and Comparative Perspectives: Cambridge University Press. p 71-89.

Zinner D, Pelaez F, Torkler F. 2001. Group composition and adult sex-ratio of hamadryas baboons (Papio hamadryas hamadryas) in central Eritrea. International Journal of Primatology 22:415-430.

Ziomkiewicz A. 2006. Menstrual synchrony: fact or artefact? Human Nature 17:419-432. 


\title{
Chapter 2: The structure and organisation of social and sexual
}

\section{interactions in the Wellington Zoo hamadryas baboon colony}

\begin{abstract}
The socio-spatial characteristics of the Wellington Zoo hamadryas baboon (Papio h. hamadryas) colony were investigated following the vasectomisation of resident males (RM). 280 hours of behavioural data were collected during the 182 day study period. The colony displayed the archetypal OMU infrastructure of wild populations, despite all adult females in the colony having undergone repeated ovarian cycling during the study as a result of RM
\end{abstract} vasectomisation. Grooming was the dominant social interaction amongst one male unit (OMU) members, with play fighting being preferred by the younger colony members that were yet to join an OMU. While the RM was the primary social partner for most female OMU members, interactions with other female OMU members and close kin were frequent enough to suggest that crossbonding in this species may be less pronounced than previously supposed. Female colony members also appeared to be more promiscuous than their wild counterparts. I suggest that relatively large OMU sizes and the high number of simultaneously cycling females in the colony may have made it difficult for RMs to maintain a constant vigil over multiple oestrous females resulting in abnormally high levels of promiscuity. Furthermore, these conditions appear to have led to the presence of a 'floater' female and a young adult female who was only loosely attached to her OMU, as well as causing the absence of initial OMUs. These scenarios have also been reported in wild populations, and may reflect a species-typical response in populations with a highly female-biased adult sex ratio. 


\section{INTRODUCTION}

Hamadryas baboons (Papio h. hamadryas) live in hierarchical, modular societies that undergo periodic fission and fusion events. The majority of social and sexual interactions in hamadryas societies take place in the smallest stable social grouping, the one male unit (OMU; i.e., a single adult male, resident male, RM, and typically 1 to 3 adult females and their offspring; Biquand et al., 1992; Kummer, 1968; Swedell, 2002b; Zinner et al., 2001). This is thought to be a product of RMs actively inhibiting female OMU members from interacting with individuals outside of the OMU in order to maintain their sexual monopoly (Abegglen, 1984; Kummer, 1968, 1990). This appears to be an effective tactic for RMs, with only a few copulations between females and males other than their RM (i.e. extra-OMU copulations) having been observed in hamadryas populations despite being the subject of several hundreds of hours of empirical study (Abbeglen, 1984; Kummer, 1968; Swedell, 2006)

Female recruitment into OMUs typically results in them being separated from their close female kin. Hence, the hierarchical female kinship networks that characterise other old world primate groups are absent in hamadryas societies (Kummer, 1968, 1990, 1995). Consequently, hamadryas societies are generally regarded as being cross-bonded (i.e., male-female relationships are stronger than female-female relationships; Byrne et al., 1989). However, recent findings that hamadryas females maintain substantial relationships with other females, including close kin where possible, has led to suggestions that the degree of cross-bonding in hamadryas societies may not be as strong as has previously been supposed (Colmenares et al, 2004; Swedell, 2002a, 2006).

The characteristic OMU infrastructure of wild hamadryas populations appears to be largely unaltered by captive conditions (Caljan et al., 1987; Colmenares, 1992; Gore, 1994; Kummer and Kurt, 1965). This may be due to OMU formation being a genetically 
inherited trait for both sexes in hamadryas baboons (Beehner and Bergman, 2006; Bergman, 2006; Nagel, 1973; Sugawara, 1988). Hence, captive hamadryas colonies offer the opportunity to examine aspects of hamadryas behaviour in greater detail than is generally possible in wild populations without the likelihood of significant departures from their archetypal behavioural patterns.

In this chapter I provide information on the activity budget, social structure, and the socio-spatial organisation of the Wellington Zoo hamadryas baboon colony. In 2006 all RMs in the colony were vasectomised in order to limit further population growth. This resulted in all mature females in the colony undergoing repeated ovarian cycling in the interim due to the absence of pregnancy or amenorrhea. I examine whether the sociospatial patterns within the colony conform to the hamadryas baboon archetype, and whether the presence of multiple female OMU members concurrently experiencing ovarian cycling has affected OMU cohesion and socio-spatial organisation. The implications of these findings for hamadryas baboon socio-ecology are discussed.

\section{METHODS}

\section{Subjects}

The Wellington Zoo hamadryas baboon colony was established in 1967. At the time of the study the colony contained 19 individuals, comprising 7 males and 12 females (Table 1), having previously peaked at 21 members in 2005 . Other than two sets of females that were born in other zoos, all individuals were conceived and born within the colony. While no genealogical records were available for the introduced females, husbandry 
Table 1. Demographic profile of members of Wellington Zoo hamadryas baboon colony present during the study. Resident males are indicated by bold text. The list is organised by nominal OMU affiliation, with OMU-affiliated females and nonOMU members arranged from oldest to youngest in descending order. See Appendix 1 for description of age and sex classes. '-' = not applicable, $0=$ no recorded births, $(\mathrm{d})=$ individual is now deceased, $\mathrm{Ph}=$ Pharaoh, $\mathrm{Ram}=$ Rameses, $\mathrm{Al}=$ Albert, Med $=$ medium, $\mathrm{Juv}=$ juvenile, $\mathrm{Ad}=$ adult. Multiple sires and dams are listed where uncertainty over birth records exist (see Methods).

\begin{tabular}{lcccccc}
\hline Name & Sex & D.O.B. & OMU & Age Class & Sire $\$$ & Dam $\neq$ \\
\hline Rameses & M & 11.Oct.95 & Rameses & Adult & Randy(d) & Jackie/Tina \\
Tina $\dagger$ & F & 18.Apr.79 & Rameses & Adult & Unknown & Unknown \\
Sinead & F & 29.Jan.93 & Rameses & Adult & Randy(d) & Suzy(d) \\
Beth & F & 4.Jun.94 & Rameses & Adult & Randy(d) & Jackie/Tina \\
Kito & F & 21.May.02 & Rameses & Adult & Ph(d)/Ram/Al & Greet \\
Albert & M & 24.Jun.95 & Albert & Adult & Randy(d) & Jackie/Tina \\
Jackie† $\dagger$ & F & 17.Oct.86 & Albert & Adult & Unknown & Unknown \\
Grit* & F & 1.Jan.88 & Albert & Adult & Unknown & Unknown \\
Helen* & F & 3.Oct.92 & Albert & Adult & Unknown & Unknown \\
Zara & F & 21.Sep.94 & Albert & Adult & Randy(d) & Suzy(d) \\
Greet* & F & 16.Sep.96 & Albert & Adult & Unknown & Unknown \\
Ayisha & F & 4.Sep.01 & Albert & Adult & Ph(d)/Ram/Al & Zara \\
Carter & M & 14.May.93 & None & Adult & Randy(d) & Jackie/Tina \\
Taila & M & 2.Oct.01 & None & Subadult & Albert & Jackie/Tina \\
Les & M & 19.Sep.02 & None & Large juv & Albert & Jackie/Tina \\
Rafiki & M & 24.Sep.03 & None & Med juv & Albert & Jackie/Tina \\
Macey & F & 13.Mar.04 & None & Med-large juv & Rameses & Beth \\
Habib & M & 7.Dec.04 & None & Med juv & Albert & Jackie/Tina \\
Abeba & F & 24.Dec.04 & None & Med-large juv & Albert & Grit \\
\hline & & & & & & \\
\hline
\end{tabular}

* Introduced from Melbourne Zoo, Australia, on $12^{\text {th }}$ January 1988, genealogy unknown.

$\dagger$ Introduced from Dierenpark Emmen, the Netherlands, on $7^{\text {th }}$ June 2001, genealogy unknown. 
records have been maintained by Wellington Zoo staff for all locally born individuals. Genetic testing had not been performed on any of the colony members previously, however, such that parentage had been assigned on the basis of anecdotal observations. Paternity was assigned to the RM of the unit that the female resided in at the likely time of conception (taken as 6 months before parturition; Kaumanns et al., 1989), while maternity was based on physical signs of pregnancy and maternal behaviour. In cases where the RM was receiving contraception at the probable time of conception all other non-treated adult males in the colony at that time are listed as sires. Furthermore, Jackie is recorded as being the oldest female in the colony despite Tina appearing to be the elder of the two (no longer exhibiting perineal swellings and exhibiting a prominent limp and faded, thinning pelt). Therefore it appears that the identities of Jackie and Tina were mistakenly interchanged at some point prior to the start of this study, though when this occurred is not known. Because of this ambiguity, Tina and Jackie are both listed as dams in cases where either female had been listed as a dam previously.

All individuals were initially categorised according to their notional affiliation with certain sub-groupings within the colony (Table 1). Females were considered to be part of an active OMU if they were observed receiving threats or attacks from a particular adult male (i.e.: archetypal RM herding behaviours) consistently over the study period, with the male assailant being categorised as the RM for that OMU. All other individuals were neither observed in agonistic herding encounters nor displayed close associations with either OMU and were, therefore, classified as non-OMU members. These definitions are included for descriptive purposes only, with a statistically rigorous test of the social structure within the colony being presented as one of the analyses in this paper. 


\section{Housing}

Since March 2000, the colony has resided in a purpose-built 0.25 hectare naturalistic outdoor enclosure (Figure 1). This enclosure contains a number of trees, rocks, logs and open grassed areas, and is surrounded on all sides by a 3 metre tall chain-link wire fence. A $6 \times 4$ metre sleeping den adjoins the north-western section of the enclosure. Access to the sleeping den was restricted between the daily feeding times, which occurred at approximately 10 a.m. and 3 p.m. unless it was wet or cold. The public viewing area is located on the western side of the enclosure, with a 7 metre long glass wall forming part of the perimeter fence at this point to assist in viewing. The eastern perimeter of the enclosure adjoins a public park, with the remainder being bordered by other zoo exhibits. In August 2007 an electric fence that ran parallel with the northern and eastern sections of the perimeter fence was installed in order to protect several newly planted saplings. This reduced the area of the enclosure that is accessible to the baboons to approximately 0.2 hectares.

\section{Contraceptive treatments}

In order to control population growth within the colony the two RMs (along with another RM who died in November 2006) were vasectomised in October 2004. A further adult male (Carter, Table 1) was castrated as a juvenile and had not developed the characteristic mantle of adult hamadryas males, nor acquired an OMU of his own. Additionally, a subadult male (Taila) received a hormonal castration treatment (Suprelorin ${ }^{\circledR}$, a gonadotrophin-releasing hormone agonist produced by the Peptech corporation) in October 2006 after he was observed mating with females. No pregnancies or births were observed in the colony from March 


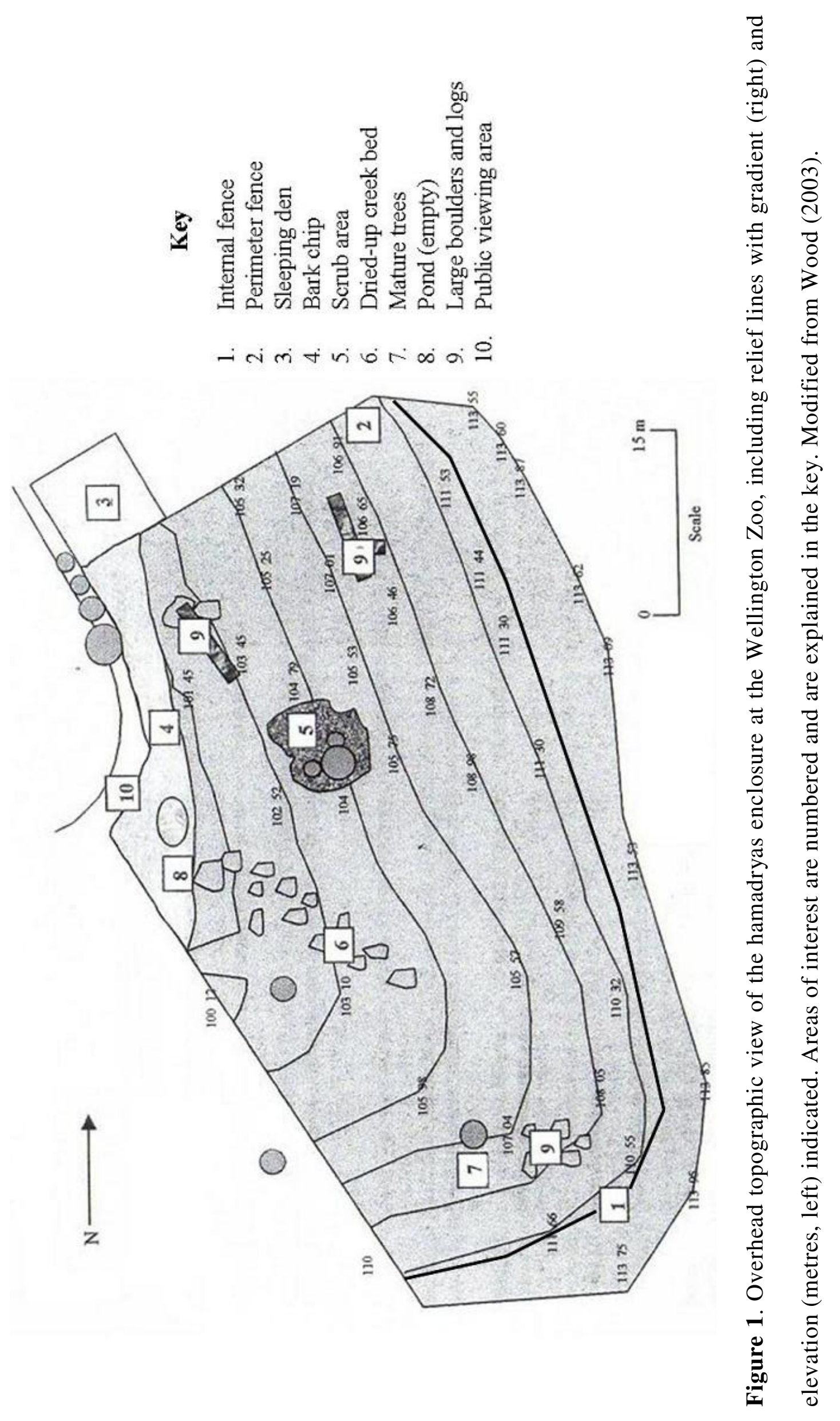


2005 until the end of the present study. Hence, 3 out of the 4 females in Rameses OMU (excluding Tina) and all 6 females in Albert's OMU underwent repeated ovarian cycling throughout the study period. This included Macey, who began exhibiting regular perineal swellings during the study, from late August 2008.

\section{Ethogram}

Prior to the commencement of behavioural sampling I conducted ad libitum observations over a 4 month period to compile a detailed list of behaviours observed within the group (i.e.: an ethogram, Table 2). All behaviours listed in the ethogram have been observed previously in other populations and are defined to maintain consistency with published descriptions of hamadryas behaviour (Abegglen, 1984; Kummer, 1968; Swedell, 2006). Each behaviour was allocated to one of six categories on the basis that they occur within a common qualitatively distinct context.

\section{Data Collection}

Data collection involved a combination of scan and focal sampling (Altmann, 1974). Up to five instantaneous scan samples were taken each day, with samples occurring at least 30 minutes apart in order to minimise autocorrelation between samples. The location and the behaviour of each individual were recorded on a scale map of the enclosure, such that each scan sample represented a spatial and behavioural snap-shot of the colony at a particular instant in time. In between each instantaneous scan sample a 30 minute focal sample was conducted which involved a mixture of focal animal and focal behaviour sampling. Each sample involved recording all proximity behaviours (Table 2) that 
Table 2. Ethogram listing the types of behaviour recorded during the study, and how each was defined. Behavioural categories are indicated in bold, and all the behaviours within that category are listed thereafter. ' $\mathrm{A}$ ' and ' $\mathrm{B}$ ' are instigator and recipient interactees respectively (continued over the next two pages).

\begin{tabular}{|c|c|}
\hline Behaviour & Description \\
\hline Agonistic & Behaviour involving hostile/violent interactions. \\
\hline Stare & A looks directly and intently at $\mathbf{B}$ for period beyond brief glance. \\
\hline Brow raise & $\begin{array}{l}\text { A looks directly at } \mathbf{B} \text { whilst raising his/her eye-brows, such that the } \\
\text { white portions of eyelids are visible. }\end{array}$ \\
\hline Ground slap & $\begin{array}{l}\text { A strikes the ground with the palm of hand while looking directly at } \\
\text { B. }\end{array}$ \\
\hline Head bob & $\begin{array}{l}\text { A moves head up and down several times in rapid succession while } \\
\text { looking directly at } \mathbf{B} \text {. }\end{array}$ \\
\hline Cheek pump & $\begin{array}{l}\text { A opens mouth so that canines are visible, and inflates cheeks at } \\
\text { regular intervals, while looking directly at } \mathbf{B} \text {. }\end{array}$ \\
\hline Lunge & $\begin{array}{l}\text { While looking at } \mathbf{B}, \mathbf{A} \text { thrusts upper body toward } \mathbf{B} \text { without moving } \\
\text { from present location. }\end{array}$ \\
\hline Charge & $\begin{array}{l}\text { A suddenly rushes towards } \mathbf{B} \text {, but stops at least a metre before } \mathbf{B} \\
\text { who does not move }\end{array}$ \\
\hline Chase & $\begin{array}{l}\text { A suddenly rushes towards } \mathbf{B} \text { who turns and moves quickly away } \\
\text { from } \mathbf{A} \text {, such that } \mathbf{A} \text { follows } \mathbf{B} \text { for some distance (A may or may not } \\
\text { make physical contact with } \mathbf{B} \text { ). }\end{array}$ \\
\hline Scream & $\begin{array}{l}\text { A emits a loud, shrill cry in response to some behaviour from } \mathbf{B} \text { (B's } \\
\text { behaviour may or may not be directed toward } \mathbf{A} \text { ) }\end{array}$ \\
\hline Attack & $\begin{array}{l}\text { A directs a series of forceful blows/bites toward } \mathbf{B} \text { with limbs/mouth } \\
\text { (which may or may not make physical contact). }\end{array}$ \\
\hline Neck bite & $\begin{array}{l}\text { A firmly grasps the fur/skin at the nape of the neck of } \mathbf{B} \text { (used } \\
\text { exclusively by RMs toward unit Females). }\end{array}$ \\
\hline
\end{tabular}


Table 2 continued

\begin{tabular}{|c|c|}
\hline & Description \\
\hline Affiliative & $\begin{array}{l}\text { Behaviour involving non-hostile interactions (excluding } \\
\text { sociosexual behaviours). }\end{array}$ \\
\hline Groom solicit & $\begin{array}{l}\text { A moves to stand side-on in front of } \mathbf{B} \text { such that he/she is within } \\
\text { reaching distance of } \mathbf{B} \text {. }\end{array}$ \\
\hline Groom & A systematically runs his/her hands through the pelage of $\mathbf{B}$. \\
\hline Huddle & A embraces $\mathbf{B}$ with his/her limbs and leans into B's torso. \\
\hline Play fight & $\begin{array}{l}\text { Tussling, challenging and chasing between individuals, generally } \\
\text { involving juvenile participants. }\end{array}$ \\
\hline Sit near & $\mathbf{A}$ and $\mathbf{B}$ sit within 0.25 metres of each other. \\
\hline Sexual & $\begin{array}{l}\text { Behaviours concerned with the acquisition and practice of } \\
\text { sexual activity. }\end{array}$ \\
\hline Presentation & $\begin{array}{l}\text { Female } \mathbf{A} \text { directs her hindquarters toward Male } \mathbf{B} \text { with tail upright } \\
\text { and both front and rear limbs unflexed. }\end{array}$ \\
\hline Perineal inspection & $\begin{array}{l}\text { Male A looks, smells, touches or licks (or combination thereof) the } \\
\text { genital area of Female } \mathbf{B} \text {. }\end{array}$ \\
\hline Sexual mount & $\begin{array}{l}\text { Male } \mathbf{A} \text { climbs onto hindquarters of Female } \mathbf{B} \text { by placing his feet } \\
\text { on her upper calves and grasping her hip area before intromitting. } \\
\text { Mount is not interrupted by a third party. }\end{array}$ \\
\hline Mount abort & $\begin{array}{l}\text { Prior to or shortly after intromitting Female B, Male A ceases } \\
\text { mount due to discovery by participating female's RM (only non- } \\
\text { OMU males) or incorrect body positioning (RM). }\end{array}$ \\
\hline Mount reject & $\begin{array}{l}\text { Male } \mathbf{A} \text { attempts to climb onto the hindquarters of female } \mathbf{B} \text {, but } \\
\text { Female } \mathbf{B} \text { before moves in such a way as to inhibit Male } \mathbf{A} \text { from } \\
\text { doing so. }\end{array}$ \\
\hline Ejaculatory pause & $\begin{array}{l}\text { After initiating several thrusts, Male A pauses for several seconds } \\
\text { before dismounting Female B. Indicative of ejaculation. }\end{array}$ \\
\hline
\end{tabular}


Table 2 continued.

\begin{tabular}{|c|c|}
\hline Behaviour & Description \\
\hline Conciliatory & $\begin{array}{l}\text { Sociosexual interactions observed in post-hostile or potentially } \\
\text { hostile situations. }\end{array}$ \\
\hline Presentation & $\begin{array}{l}\text { A directs hindquarters toward face of } \mathbf{B} \text {, lowering the front half of } \\
\text { torso by flexing front limbs and keeping hind limbs straight } \\
\text { (usually accompanied by a brief series of short bark like calls by } \\
\text { A). }\end{array}$ \\
\hline Conciliatory mount & $\begin{array}{l}\text { A grabs the hindquarters of } \mathbf{B} \text { by placing his/her hands either side } \\
\text { of } \mathbf{B} \text { 's hips, and makes several thrusting motions (simulating } \\
\text { copulation). Exclusive to same sex dyads. }\end{array}$ \\
\hline $\begin{array}{l}\text { Conciliatory mount } \\
\text { attempt }\end{array}$ & $\begin{array}{l}\mathbf{A} \text { attempts to grab hindquarters of } \mathbf{B} \text {, but } \mathbf{B} \text { moves away from } \mathbf{A} \\
\text { before } \mathbf{A} \text { begins thrusting motions. Exclusive to same-sexed dyads. }\end{array}$ \\
\hline Proximity & $\begin{array}{l}\text { Locomotive activity which is motivated by the } \\
\text { movement/presence of another individual. }\end{array}$ \\
\hline Approach & $\begin{array}{l}\text { A moves to within } 1 \text { body length of } \mathbf{B} \text { after being }>1 \text { body length } \\
\text { apart from } \mathbf{B} \text {. }\end{array}$ \\
\hline Leave & $\begin{array}{l}\text { Having been located } \leq 1 \text { body lengths from } \mathbf{B}, \mathbf{A} \text { moves }>1 \text { body } \\
\text { length away from } \mathbf{B} \text {. }\end{array}$ \\
\hline Follow: individual & A moves in the direction taken by $\mathbf{B}$. \\
\hline Follow: unit & $\begin{array}{l}\text { A moves in the direction taken by two or more of conspecifics, } \\
\text { involving a Resident Male at least one of the RM's female unit } \\
\text { members. }\end{array}$ \\
\hline Lead unit & $\begin{array}{l}\text { Resident Male } \mathbf{A} \text { is followed by } 2 \text { or more individuals, at least two } \\
\text { of which are female members of his unit. }\end{array}$ \\
\hline Non-Social & Behaviours involving only a solitary individual. \\
\hline Self grooming & Individual runs hands though his/her own pelage. \\
\hline Foraging & $\begin{array}{l}\text { Behaviour relating to the investigation, acquisition and } \\
\text { consumption of food. }\end{array}$ \\
\hline Locomotion & $\begin{array}{l}\text { Movement of individual from one point to another, not obviously } \\
\text { motivated by the location or prior movements of another } \\
\text { individual. }\end{array}$ \\
\hline Inactivity & $\begin{array}{l}\text { Periods of individual dormancy in which other behaviours are not } \\
\text { engaged. }\end{array}$ \\
\hline
\end{tabular}


involved the focal individual (i.e.: focal animal), as well as all occurrences of agonistic, sexual and conciliatory events for the entire colony (i.e.: focal behaviours). Because these behaviours occur infrequently and have a short duration relative to affiliative events, they are likely to be poorly represented in scan samples. Hence, focal sampling was utilised to generate a sufficiently large sample of these behaviours for later analyses. Up to five focal samples were collected each day.

A stratified random sampling procedure was employed when selecting individuals for focal animal sampling. Males (excluding Carter, Rafiki and Habib) and females (excluding Tina, Macey and Abeba) were separated into two different strata. At least one male and three females were sampled every day, unless sampling had to be terminated early because of inclement weather. RMs received double weighting over other males, such that each RM was sampled every 3 days and other males every 6 days on average. Females had equal weightings, whereby each female was sampled every 3 days on average. Instances where a fifth focal sample took place were assigned to a female with a maximum perineal swelling in order to increase the sample size for females in this state. If no female existed in this condition then the 5th sample was assigned to either Carter or Tina because data collection was prioritised for adult over pre-adult colony members. Furthermore, a prioritisation scheme was used to avoid time conflicts between the three sampling protocols. The low frequency and brief duration of sexual, agonistic and conciliatory behaviours meant that behavioural sampling received the highest priority overall, followed by focal and scan sampling respectively.

All observations were made from the public viewing area (Figure 1). This ensured that observer effects were minimised because the baboons were accustomed to people being in this area. Furthermore, because the enclosure slopes upward from west to east, most parts of the enclosure can be observed from this location. The majority of data was 
collected daily between the hours of 10 a.m. and 3 p.m. because it coincided with the period of time when sleeping den access was restricted and individuals were confined to the outdoor enclosure and, therefore, were readily observable. Sampling occasionally continued after 3 p.m. on days where the dens remained closed beyond that time. No sampling occurred on days when it was raining or unusually cold because the sleeping den was freely accessible on these days and the baboons spent the majority of their time inside the den where they could not be observed.

\section{Juvenile data reallocation}

Prior to $14^{\text {th }}$ of July 2006, all events involving either Rafiki or Habib were recorded under the title of 'Juvenile Male' because of difficulties in reliably distinguishing between the two before this date. Similarly, events involving Macey and Abeba were recorded under the title of 'Juvenile Female' prior to $26^{\text {th }}$ of August 2006, and under their own names thereafter. For the sake of convenience in subsequent analyses, data from these two juvenile dyads was reallocated in the following manner. If an individual was observed in $x$ interactions with Habib, $y$ interactions with Rafiki, and $z$ interactions with Juvenile Male, then $z[x /(x+y)]$ and $z[y /(x+y)]$ of the $z$ interactions were reallocated to Habib and Rafiki respectively. The same procedure was used to reallocate the Juvenile Female data to Macey and Abeba. Hence, the juvenile data is reallocated according to the ratio of interactions that the relevant pair of individuals was involved in with a third party (i.e.: a $3: 1$ ratio would result in a $3 / 4$ to $1 / 4$ split of the relevant juvenile data). The decision to use the observed ratio, rather than the more conservative approach of a 1:1 split, is based on the assumption that this ratio was consistent across the entire sampling period and therefore provides the best estimate overall for each individual. 


\section{Data analysis}

\section{Social structure}

The social structure of the colony was investigated using a hierarchical cluster analysis of nearest neighbour data. The nearest neighbour recorded the closest individual proximate to a given focal individual for each colony member in each instantaneous scan sample. Individuals that had no neighbour within 10 metres were not assigned a nearest neighbour. Where an individual had 2 or more equidistant nearest neighbours, then each of these individuals was assigned a value of $1 / n$, with $n$ being the number of equidistant individuals; i.e.: a single nearest neighbour would be assigned a value of 1 , while 3 equidistant nearest neighbours would each be assigned a value of $1 / 3$. As individuals were sometimes omitted from instantaneous scan samples as a result of being out of site at the time (less than $1 \%$ of all samples for each individual on average), the proportion of nearest neighbour events were used in place of the raw values. The hierarchical cluster analysis was conducted using SOCPROG 2.3., using the average linkage option (see Milligan, 1996 for details).

\section{Spatial organisation}

To ascertain how each individual and group of individuals used the space within the enclosure a home range analysis was carried out. This required partitioning the mapped enclosure into a grid of $1 \times 1$ metre squares and assigning each individual a single binary coordinate (i.e.: an $x, y$ value) based on their location. A stratified random sample of instantaneous scan samples was then selected, such that one sample was randomly selected from each day, and the location of every individual recorded for each sample. The home-range analysis was performed using a fixed kernel density estimator, which 
produces a series of polygons that bound the areas occupied for each individual or group (see Silverman, 1986 for details). Biotas 1.03.3 home range software (free trial version, created by Ecological Software Solutions LLC) was used to carry out the analysis.

\section{Activity budget}

\section{Longitudinal}

The typical routine of the colony as a whole was investigated by averaging the activity data from scan samples over each month of the study period. The same categories of behaviour are used as for the general activity budget, and are outlined below. The month of June was omitted from the analysis due to a lack of samples for that month.

\section{General}

The typical daily routine (i.e.: activity budget) of each individual was estimated as the ratio of scan samples that an individual was observed engaged in each behaviour against the total number of scan samples that that individual was visible. Because affiliative and non-social behaviours appeared more frequently in scan samples than behaviours in other categories (as a result of their longer duration), behaviours belonging to affiliative and non-social categories are listed individually, whereas other behaviours are grouped under their general behavioural category. Additionally, locomotion combines cases of socially motivated movement (i.e.: follow individual, follow unit and lead unit, which are proximity behaviours) and non-socially motivated movement (i.e.: locomotion), in order to provide information on the time spent moving in general. On occasions where an individual was involved in multiple behaviours in a single sample, i.e.: interactions involving 2 or more interactees, then behaviours are assigned partial values according to 
the number of interactees involved. For instance, when an individual was simultaneously grooming one conspecific whilst huddling with another, then that individual received a $1 \frac{1}{2}$ for each activity; i.e.: each behaviour is assigned a value of $1 / n$, where $n$ is the number of interactees.

\section{Social organisation}

Social organisation within the colony was investigated by examining how each individual distributed their social time between other colony members. The role of the OMU in determining social and sexual activity is of particular interest, such that interactees are classified by their sex and nominal OMU affiliation (Albert's OMU, Rameses' OMU and non-OMU). For OMU members, interactees are categorised by whether they were in the same OMU (intra-OMU), another OMU (inter-OMU) or were not affiliated to an OMU (extra-OMU). For non-OMU members, interactees are classified by the OMU type (Rameses, Albert or non-OMU). Each of the main categories of social and sexual interactions (affiliative, agonistic, conciliatory, proximity and sexual) are explored separately. Only approach data is included from the proximity behaviour. 'Follows' are excluded because they mostly occurred between females and RMs such that there inclusion would bias the overall results, whereas 'leaves' do not provide any additional information, essentially just doubling the number of approaches. For the sake of convenience, affiliative, agonistic, conciliatory and approach behaviours were grouped together as 'social behaviours'. However, affiliative behaviours are likely to be underrepresented relative to other social behaviours because of the different sampling methods used in the study (only being recorded during instantaneous scans and not during focal behavioural sampling). Consequently, averaging across the combined raw data will most likely result in an inaccurate estimate of the social behaviour mean. 
Therefore, the estimated social behaviour mean is derived by taking the average of the mean values for each behaviour. In this way each behaviour receives equal weighting in determining the mean, which is subsequently independent of the underlying sample size.

\section{Statistical analysis}

Chi-squared tests were used wherever comparisons were made between individuals and OMUs in their observed behavioural patterns. The relationships between behavioural data and continuous dependent variables were investigated using $t$-tests based on Pearson's correlation coefficient. All tests were considered significant at $\alpha<0.05$ and were conducted using $\mathbf{R}$ statistical software version 2.6.2.

\section{RESULTS}

Overall, 633 instantaneous scan samples and 560 focal samples, totaling 280 hours of observations, were gathered over 191 days between 6th of June 2007 and the 13th of December 2007 (Figure 2). However, because behaviour was only recorded in scan samples from the 29th of June onwards, only 567 of the 633 scan samples contained behavioural data (the other samples were retained on the basis that they still contained location information). Within the 191 day study period, 132 days contained at least one instantaneous scan sample, 131 days contained at least one focal sample, and 129 days contained at least one sample of both types. Overall, behavioural and locational information was obtained from approximately $69 \%$ of all possible days within the study period, with the longest continuous gap in that period being 6 days. 

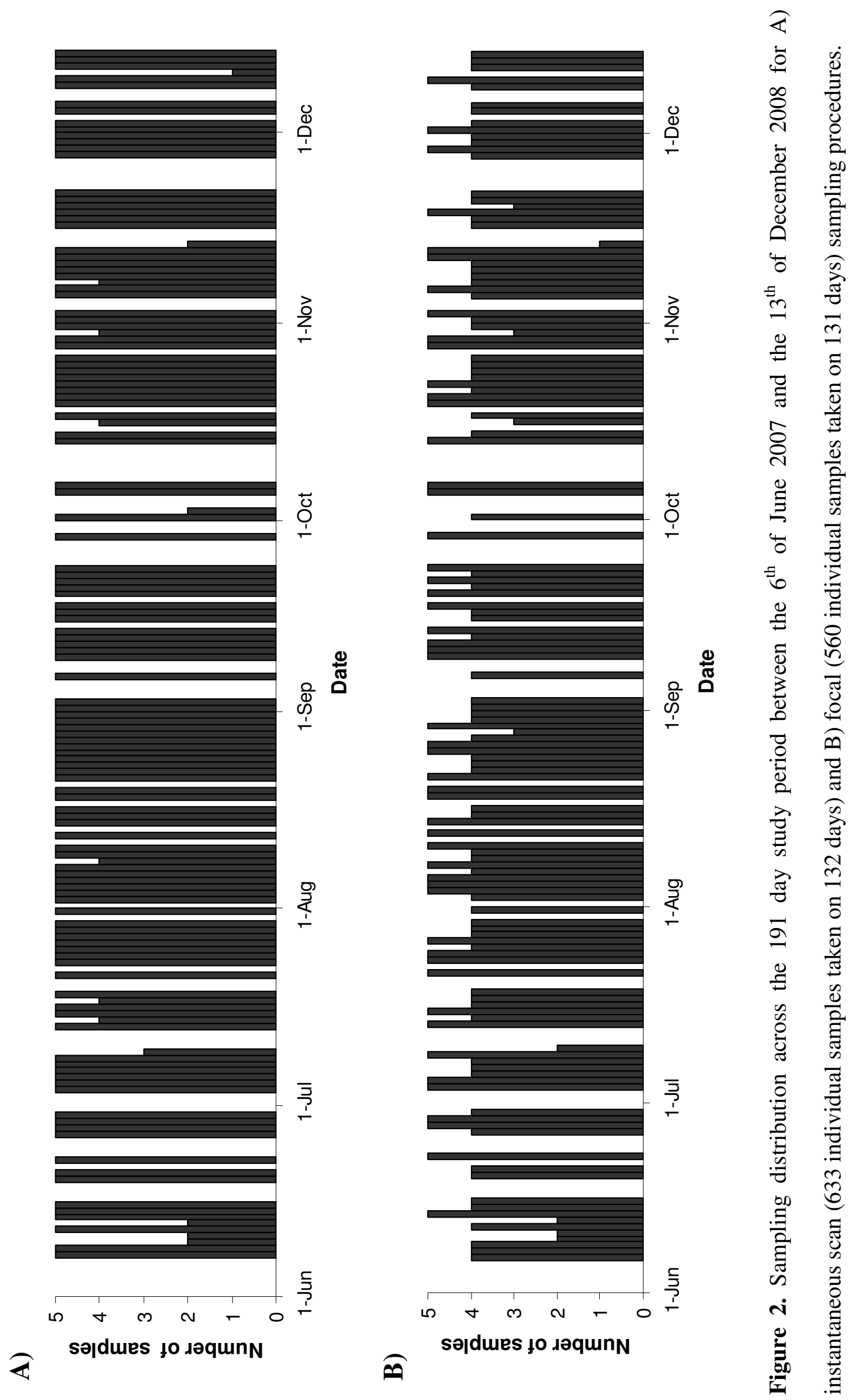


\section{Social structure}

According to the nearest neighbour data, the social structure of the colony largely supports the expectations from ad libitum observations. The dendrogram contains three distinct clusters (Figure 3), which approximately coincide with the two OMUs and the group of individuals that were not affiliated to any OMU (i.e.: the non-OMU members). The only anomaly involves the placement of Ayisha, the youngest female member of Albert's OMU, amongst the non-OMU members. All other individuals were placed within their nominal social groups.

\section{Spatial organisation}

The activity areas of all OMU and non OMU members were largely synonymous. The core range (represented by the dotted $50 \%$ polygons, Figure 4 ) of each individual occurred in the same area of the enclosure regardless of their OMU affiliation. However, members of Rameses' OMU tended to have slightly larger ranges than members of Albert's OMU while non-OMU members had the largest ranges overall (average core range size \pm standard error: Albert's OMU $=162.5 \pm 24.6 \mathrm{~m}^{2}$, Rameses OMU $=178.4 \pm$ $19.6 \mathrm{~m}^{2}$, Non-OMU $=298.4 \pm 28.9 \mathrm{~m}^{2}$ ). To test whether these differences were significant, a one-way ANOVA was run with core range size as the dependent variable and nominal OMU grouping as the independent variable. A significant difference was found between the three groups in core range size $\left(F_{2,16}=4.6, p=0.026\right)$. Furthermore, post hoc (Tukey-HSD) tests revealed that there were no differences between the two OMUs $(p=0.951)$, whereas non-OMU members had significantly larger ranges than members of Albert's OMU ( $p=0.031)$, and a nearly significant difference with members of Rameses’ OMU ( $p=0.087)$. 


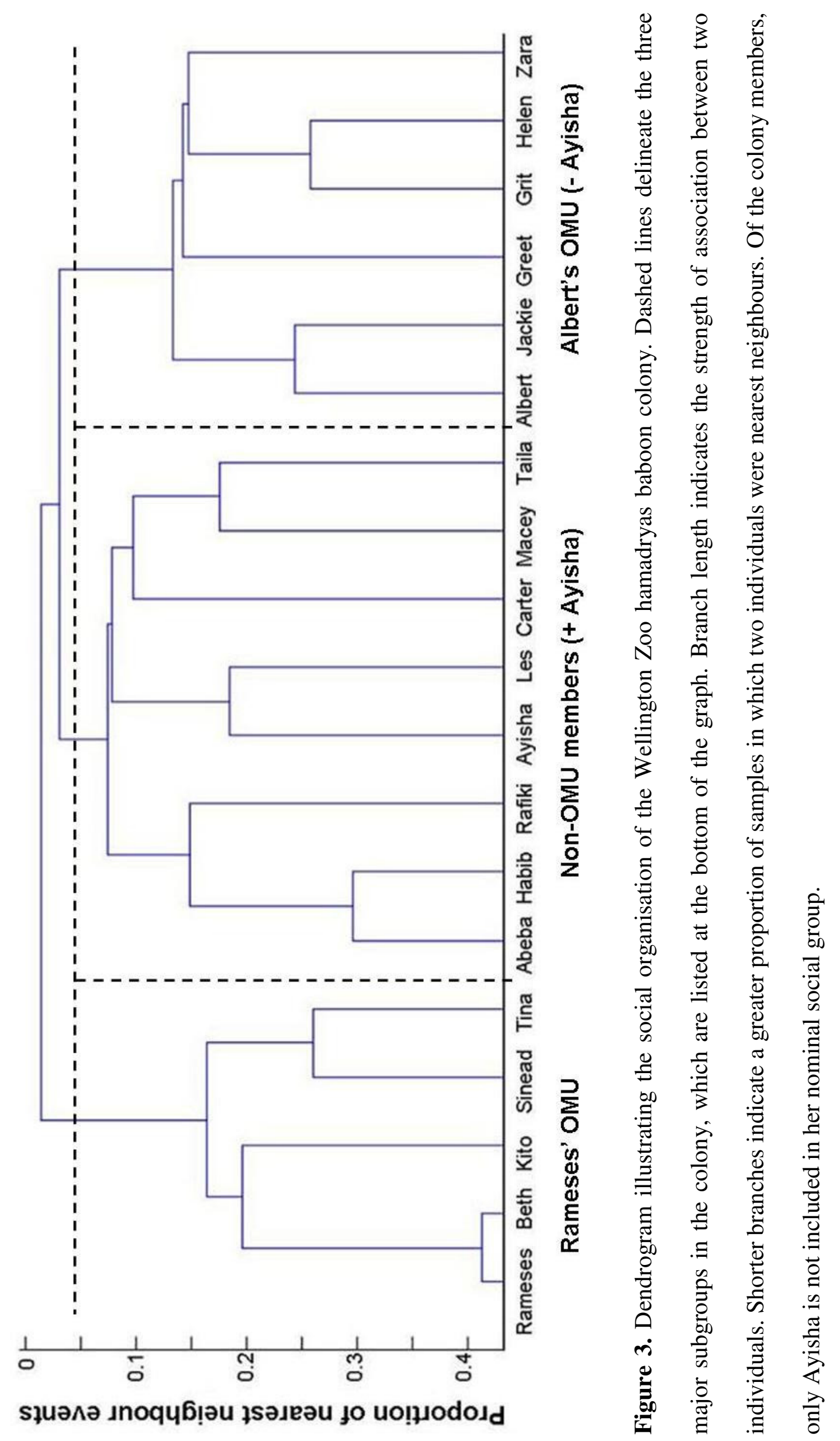




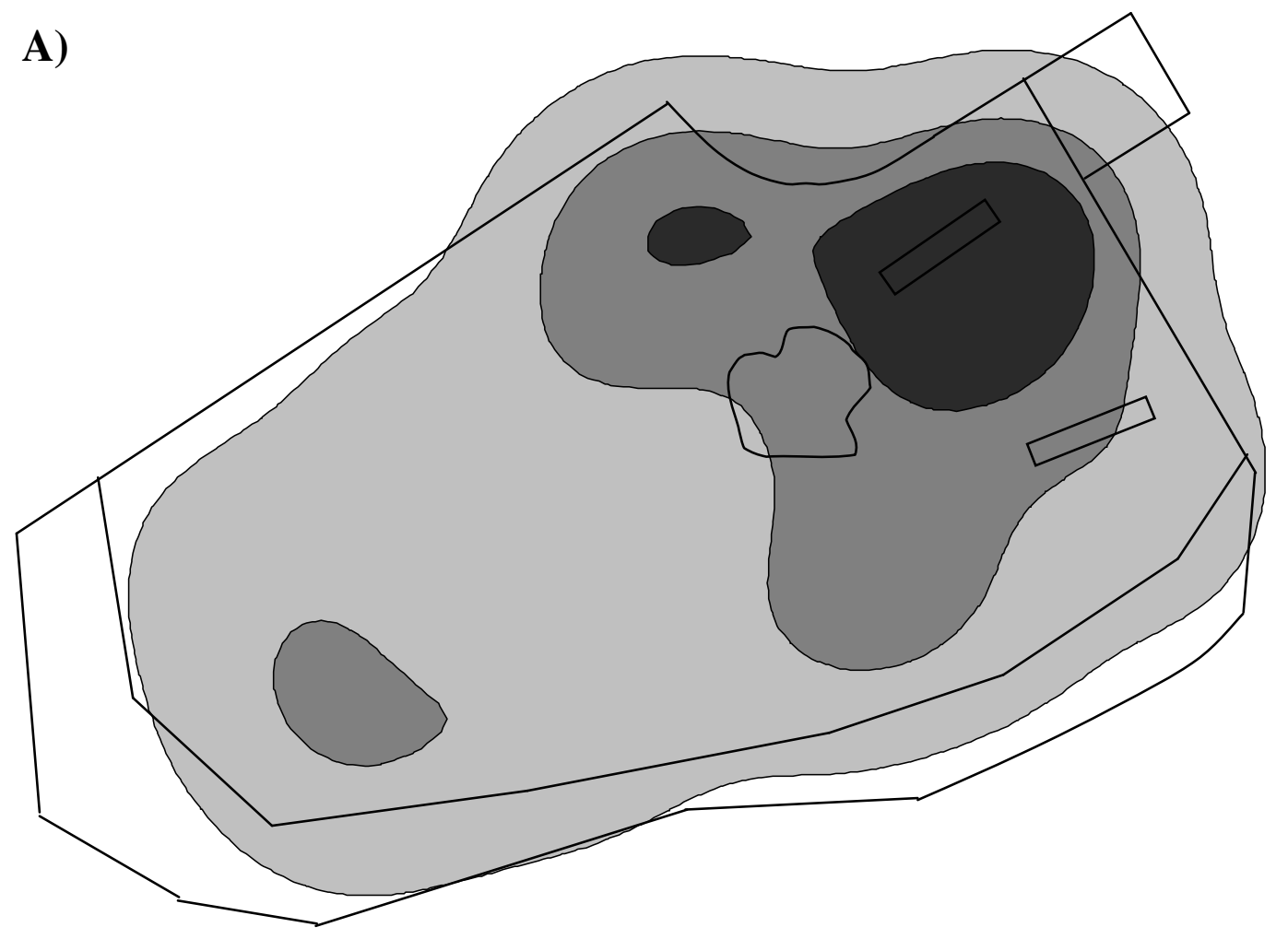

Figure 4. Spatial distribution of A) non-OMU members, B) Albert's OMU members, C) and Rameses' OMU members within the Wellington Zoo hamadryas enclosure (B and $\mathrm{C}$ are shown on the following page). Dark grey, medium grey and light grey polygons indicate areas in which group members spent $50 \%, 75 \%$ and $95 \%$ of their time respectively. Outlines of major vegetation, logs and the internal fence are included for reference. Note that the polygons exceed the area that was accessible to the baboons during the study. This is a result of the fixed kernel range estimation method and should not be interpreted literally. 

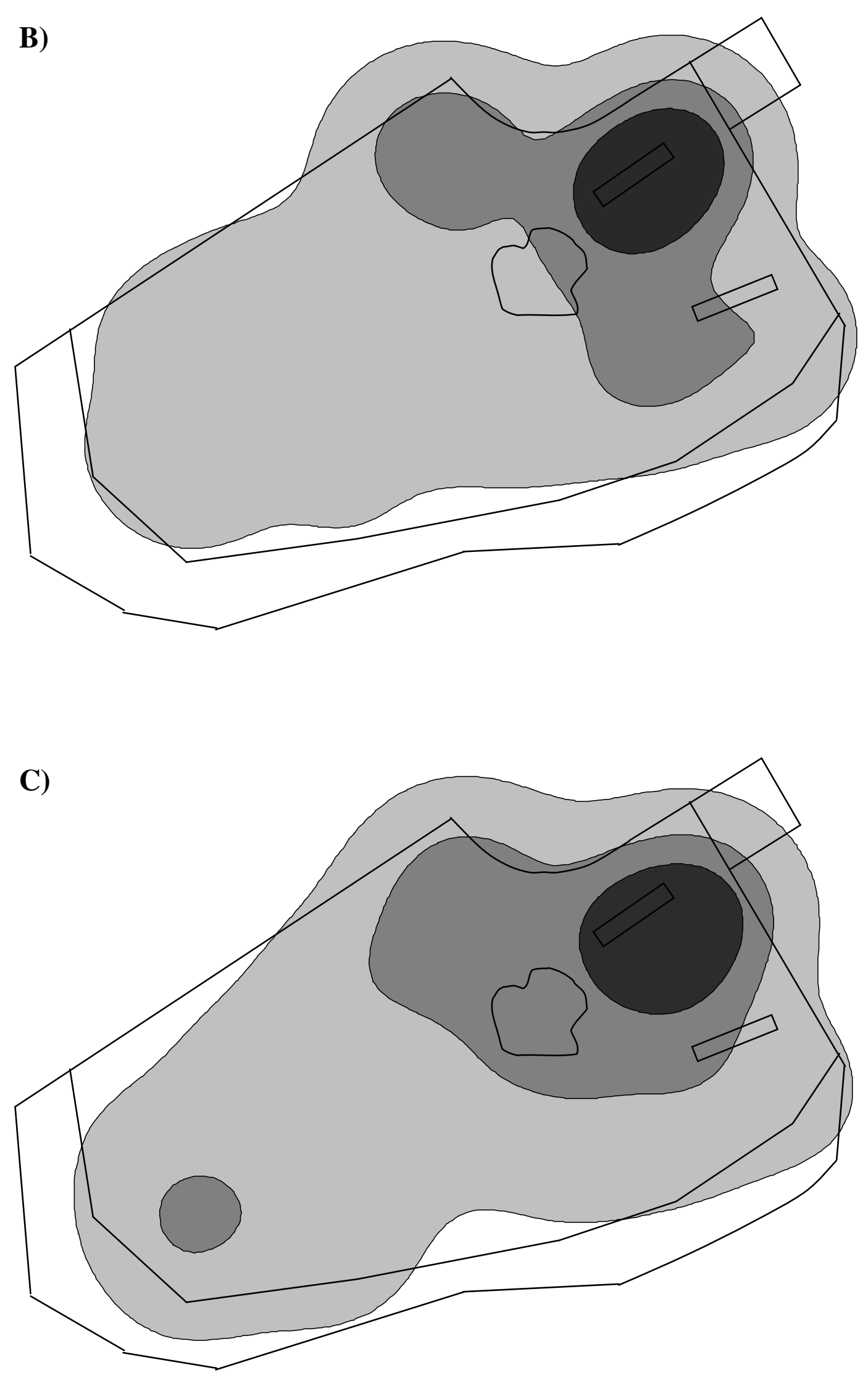


\section{Activity budget}

\section{Longitudinal}

Only grooming $(r=-0.81, p=0.050)$, inactivity $(r=0.83, p=0.042)$, conciliation $(r=-$ 0.93, $p=0.006)$ and sit-near $(r=0.89, p=0.018)$ displayed consistent changes across the study period (Figure 5). Grooming activity decreased from July to September and became stable thereafter, whereas inactivity and sit-near increased, and conciliation decreased, in a relatively systematic fashion throughout the study period.

\section{General}

Colony members spent most of their time foraging and grooming $(37 \%$ and $27 \%$ of the total activity time respectively, Figure 6). Other relatively common behaviours were inactivity, locomotion and sit-near which comprised $14.4 \%, 9.7 \%$ and $7.4 \%$ of daily activity respectively. Sexual $(0.2 \%)$, conciliatory $(0.2 \%)$ and agonistic behaviours $(0.1 \%)$ were rarely observed, and together comprised less than $1 \%$ of daily activity.

OMU members spent a greater proportion of their time engaged in social activities than non-OMU members $\left(42.0 \%\right.$ cf. $32.8 \%$ respectively; $\left.\chi_{1}^{2}=80.8, p<0.001\right)$. Most of this difference was accounted for by foraging and grooming differences, such that non-OMU members spent much more time foraging $\left(45.3 \% \mathrm{cf} .32 .9 \% ; \chi_{1}^{2}=245.7\right.$, $p<0.001)$ and less time grooming $\left(17.2 \%\right.$ vs. $\left.31.8 \% ; \chi_{1}^{2}=150.9, p<0.001\right)$ than $\mathrm{OMU}$ members. Nevertheless, grooming was the most common social activity amongst both OMU and non-OMU members, comprising $75.6 \%$ and $52.3 \%$ of their social time respectively. 

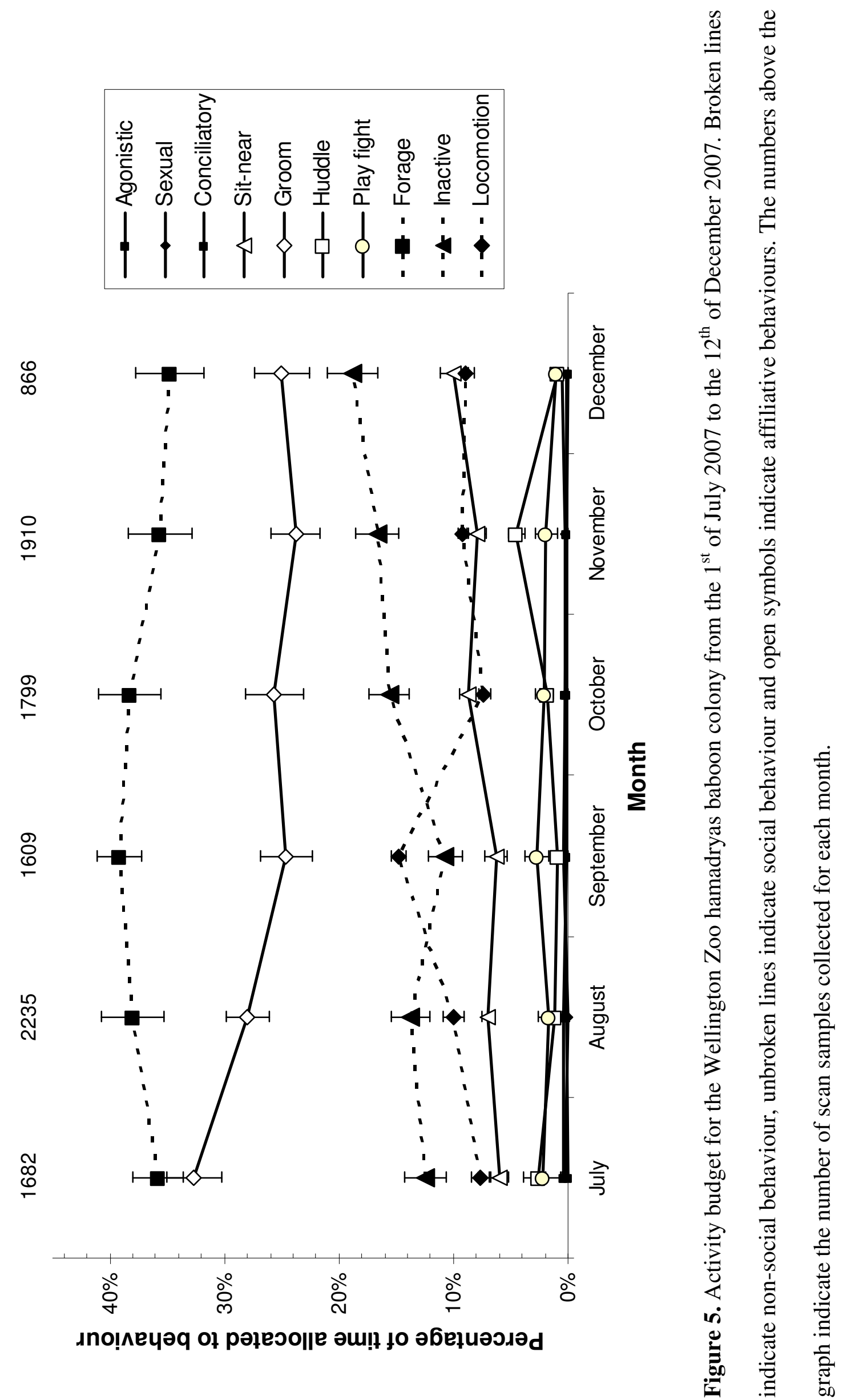

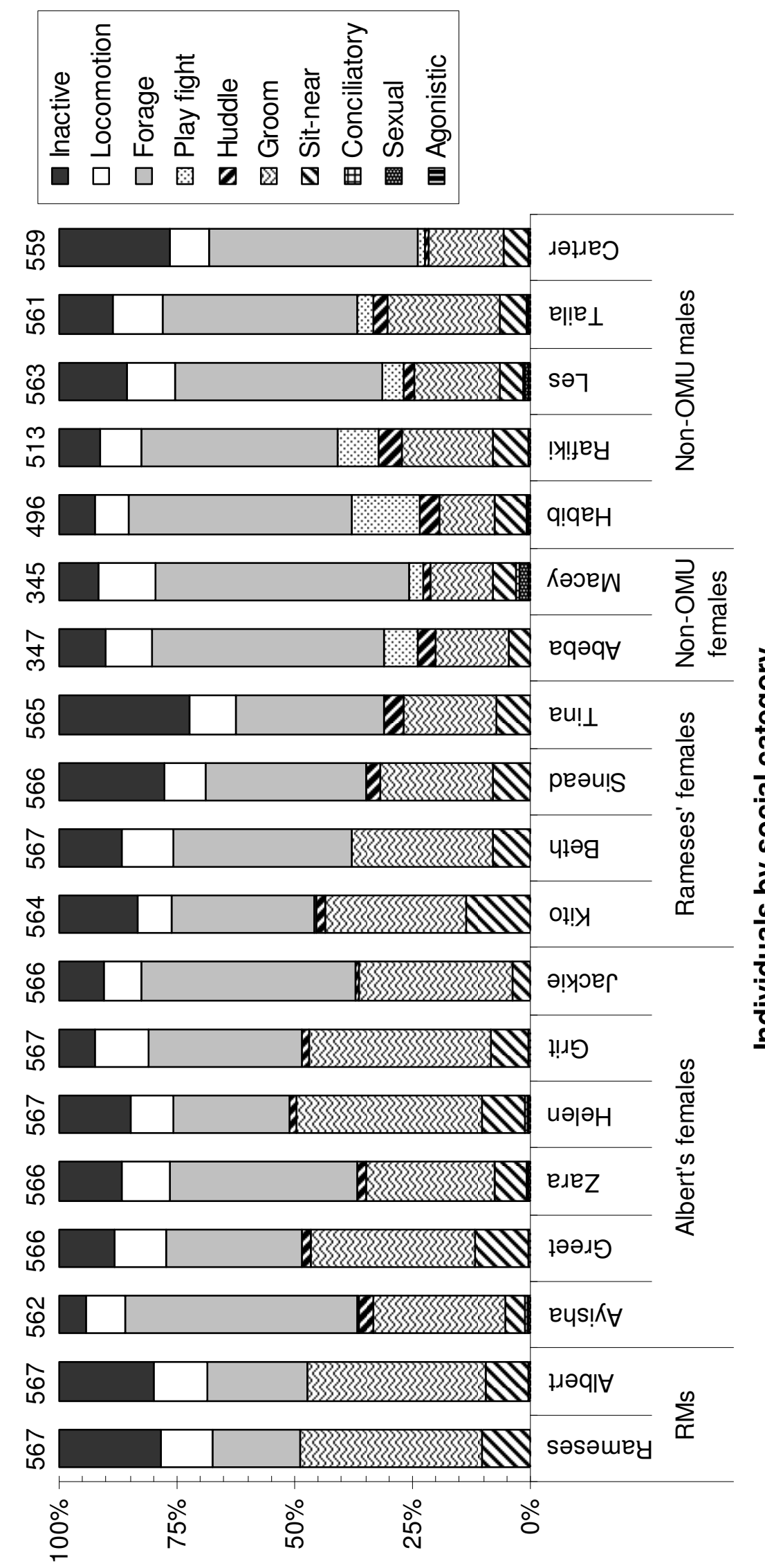

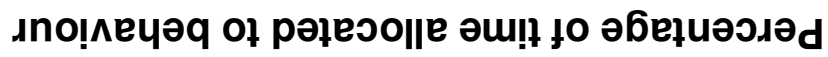


Play fighting was a common social activity amongst non-OMU members, particularly amongst the juveniles, where it occupied $25 \%$ of their social time on average, but was almost entirely absent in OMU members. Furthermore, the proportion of time spent play fighting tended to decrease (Pearson's correlation coefficient, $r=-0.61, p=0.072$ ) and grooming time tended to increase $(r=0.70, p=0.040)$ amongst non-OMU members as they got older, with grooming essentially replacing play fighting amongst OMU members. This pattern was stronger in females, such that males tended to engage in more play fighting and less grooming than females of the same age.

There was no difference between the two RMs in how they allocated their time $\left(\chi_{5}^{2}=3.6, p=0.602\right)$, whereas female OMU members were considerably more variable. Hence, while females from Albert's OMU tended to spend more time engaged in social activities than females in Rameses' OMU (43.1\% vs. $37.4 \%$ respectively, $\chi_{1}^{2}=17.9, p$ $<0.001$ ), there was considerable variation in the time allotted to social activities between females within each OMU (ranges; Albert's OMU $=36.8 \%$ to 51.0\%, Rameses' OMU = $31.2 \%$ to $45.7 \%)$.

\section{Social Organisation}

\section{OMU members - resident males}

RMs had over three quarters $(76.8 \%)$ of their social interactions with females from their own unit, including nearly all affiliative (Figure 7A) and approach (Figure 8A) behaviours (94.9\% and $95.4 \%$ respectively). In contrast, RMs had only $4.4 \%$ of their social interactions with individuals from the other OMU (i.e.: inter-OMU interactions), of which only $0.5 \%$ were with inter-OMU females. Approaches and affiliative interactions between RMs and females from the other OMU were entirely absent. Albert 

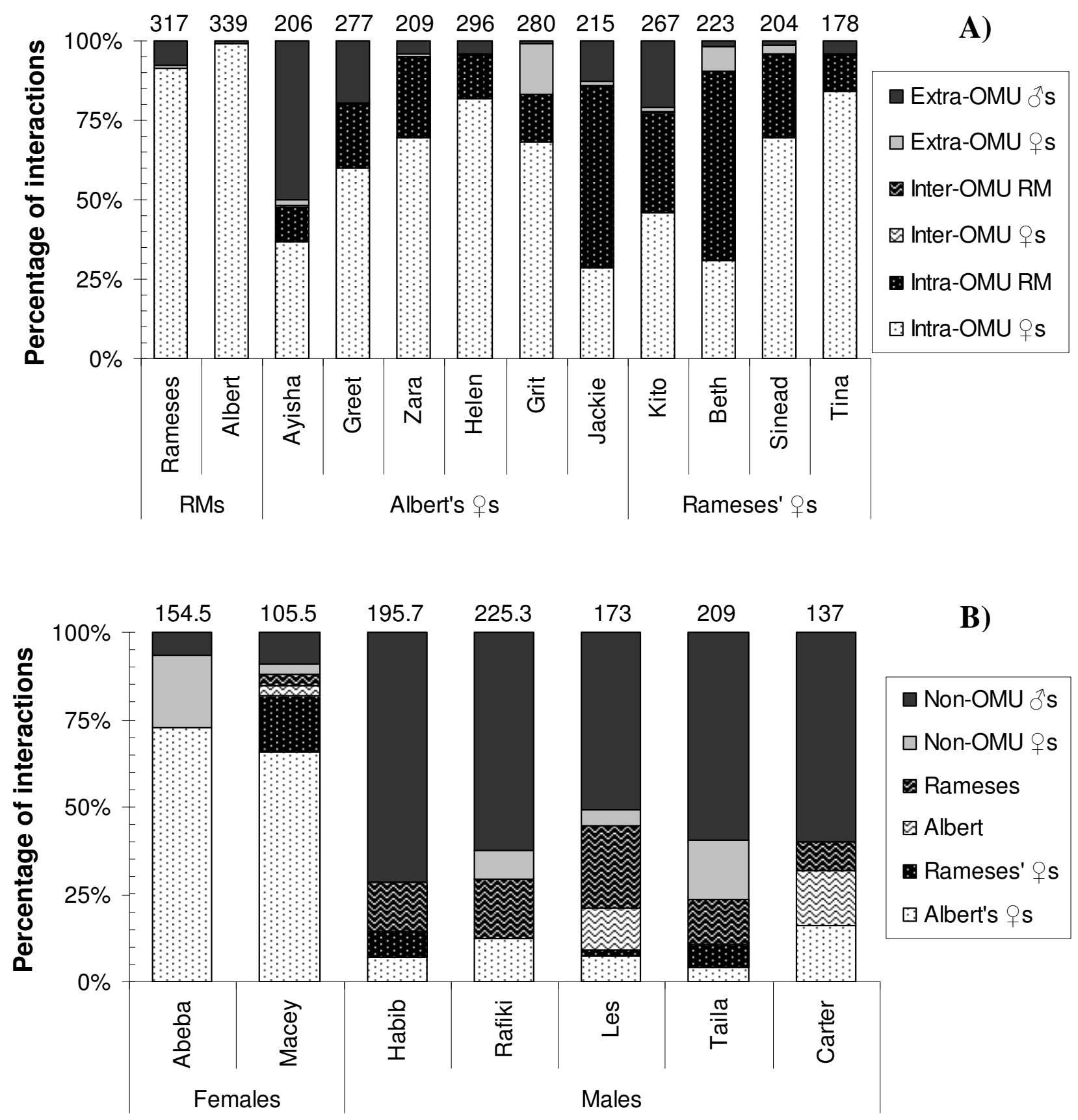

Figure 7. Distribution of affiliative interactions for A) OMU affiliated and B) non-OMU affiliated individuals in the Wellington Zoo hamadryas colony. The number of observed interactions per individual is listed above each bar. Individuals are arranged from youngest to oldest from left to right within each social category. 

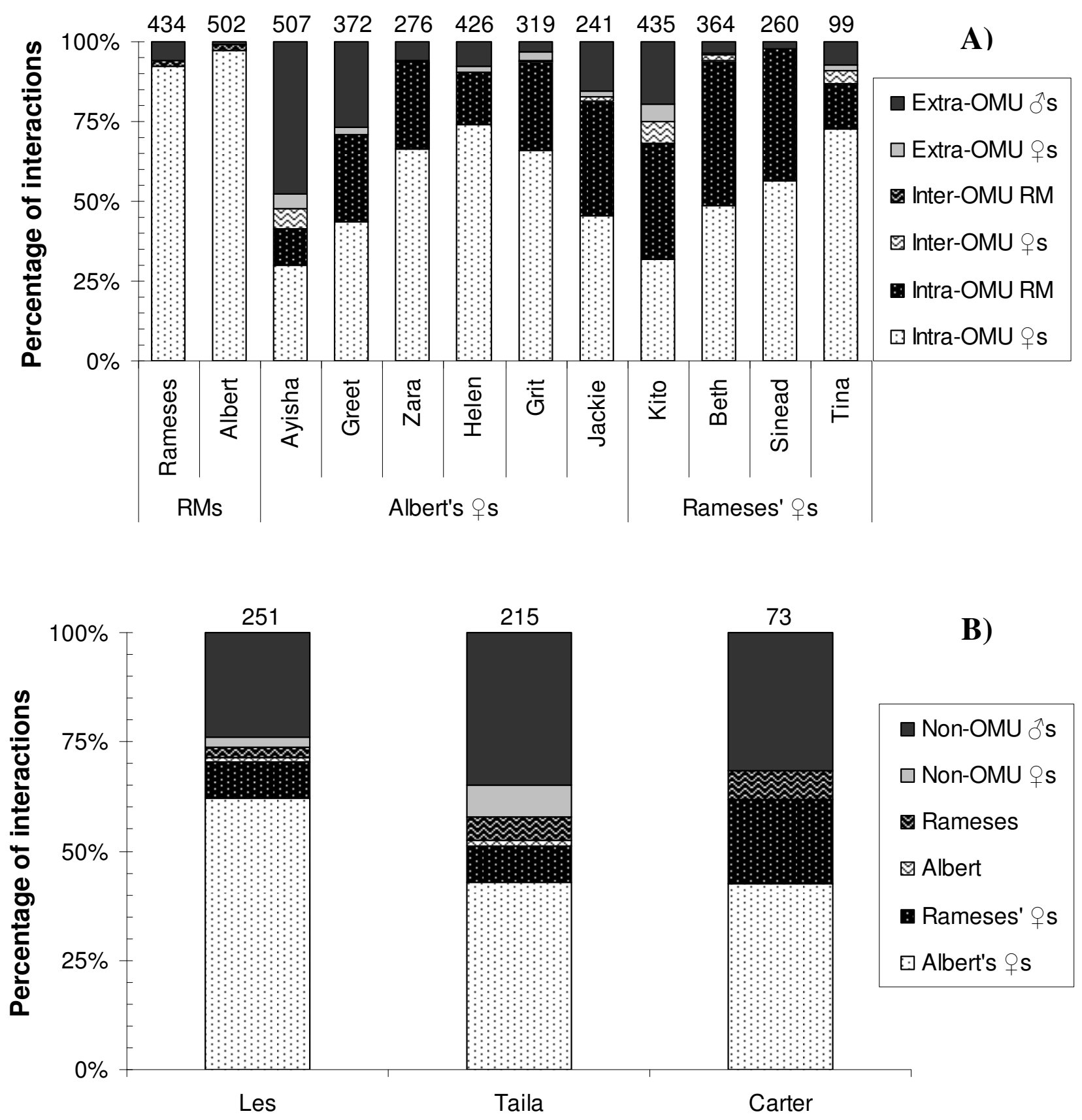

Figure 8. Distribution of approaches for A) OMU affiliated and B) non-OMU affiliated individuals (excluding non-sampled individuals) in the Wellington Zoo hamadryas colony. The number of observed interactions per individual is listed above each bar. Individuals are arranged from youngest to oldest from left to right within each social category. 
was involved in a greater proportion of social interactions with females from his own OMU, and a lower proportion of social interactions with individuals outside of his OMU, than Rameses (intra-OMU social interactions: Albert: 83.7\%, Rameses: 68.7\%; $\left.\chi_{1}^{2}=26.6, p<0.001\right)$. The most common extra-OMU interactees for both RMs were non-OMU affiliated males $(10.5 \%$ of all social interactions and $76.6 \%$ of extra-OMU social interactions), followed by one another (2.8\% of all social interactions and $20.4 \%$ of extra-OMU social interactions). The majority of extra-OMU interactions for RMs involved agonistic (Figure 9A), and to a lesser extent conciliatory (Figure 10A), behaviours. Finally, RM sexual interactions (Figure 11A) were conducted almost exclusively with females from within their own OMU (99.7\%). No sexual encounters occurred with female members from the other OMU, and no mounts or attempted mounts were initiated by RMs with females from the other OMU.

\section{OMU members - females}

Female OMU members had the majority of their social interactions $(82.5 \%)$ with other members from within their OMU. Females from Albert's OMU were involved in a larger proportion of intra-OMU social interactions than females in Rameses OMU (Rameses' females $=79.2 \%$, Albert's females $\left.=84.7 \% ; \chi_{1}^{2}=7.6, p=0.006\right)$. Females in Rameses' OMU tended have a higher proportion of social interactions with their RM (Rameses' females $=25.9 \%$, Albert's females $=17.6 \%)$ and less with other female OMU members (Rameses' females $=53.3 \%$, Albert's females $=67.1 \%$ ) than females in Albert's OMU $\left(\chi_{1}^{2}=202.4, p<0.001\right)$. Females also showed marked differences in the proportion of affiliative interactions they shared with their RM (ranges: Albert's OMU: 10.7\% - 59.2\%, Rameses' OMU: 11.2\% - 59.6\%). Four out of six females in Albert's 

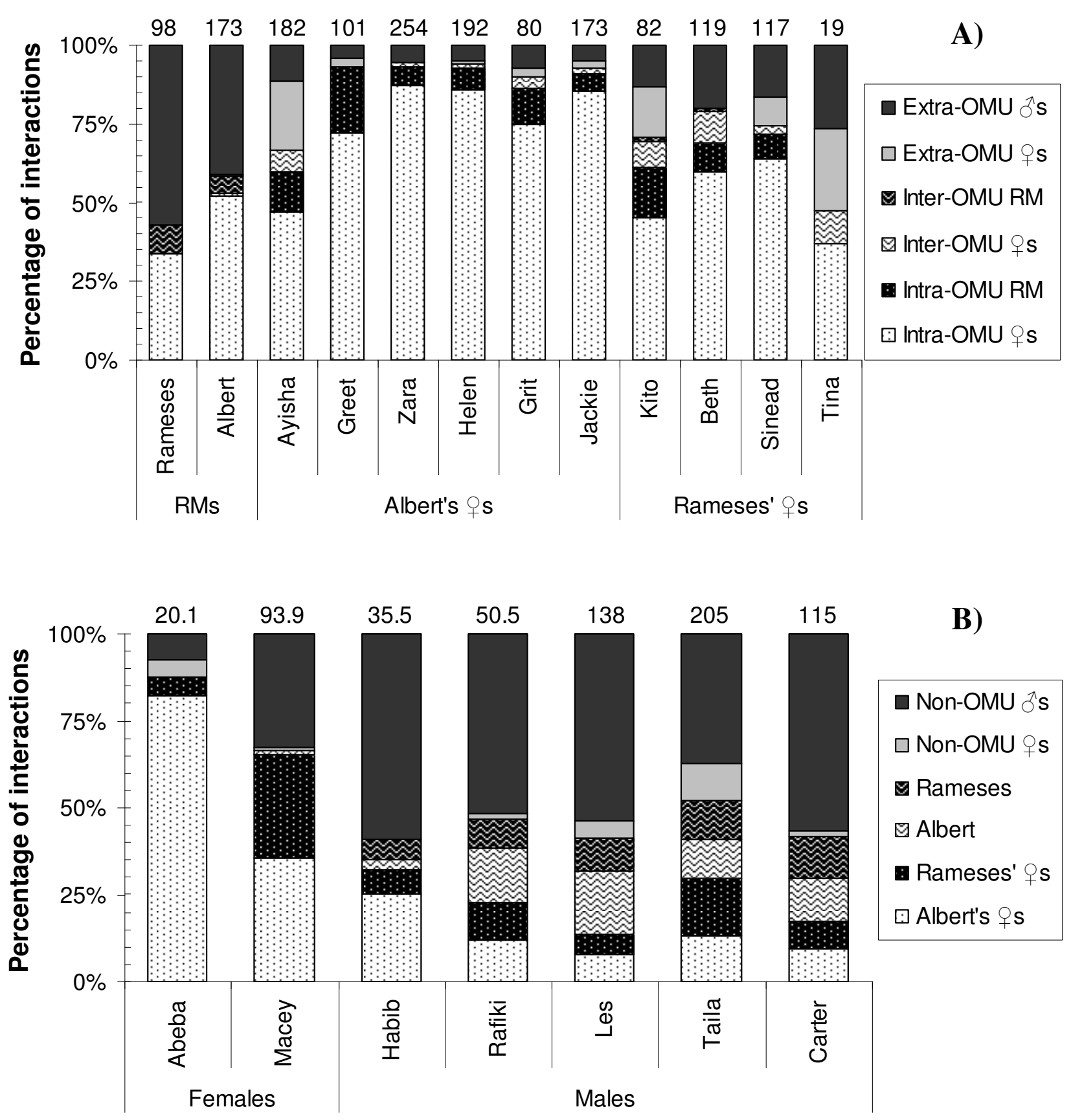

Figure 9. Distribution of agonistic interactions A) OMU affiliated and B) non-OMU affiliated individuals in the Wellington Zoo hamadryas colony. The number of observed interactions per individual is listed above each bar. Individuals are arranged from youngest to oldest from left to right within each social category. 

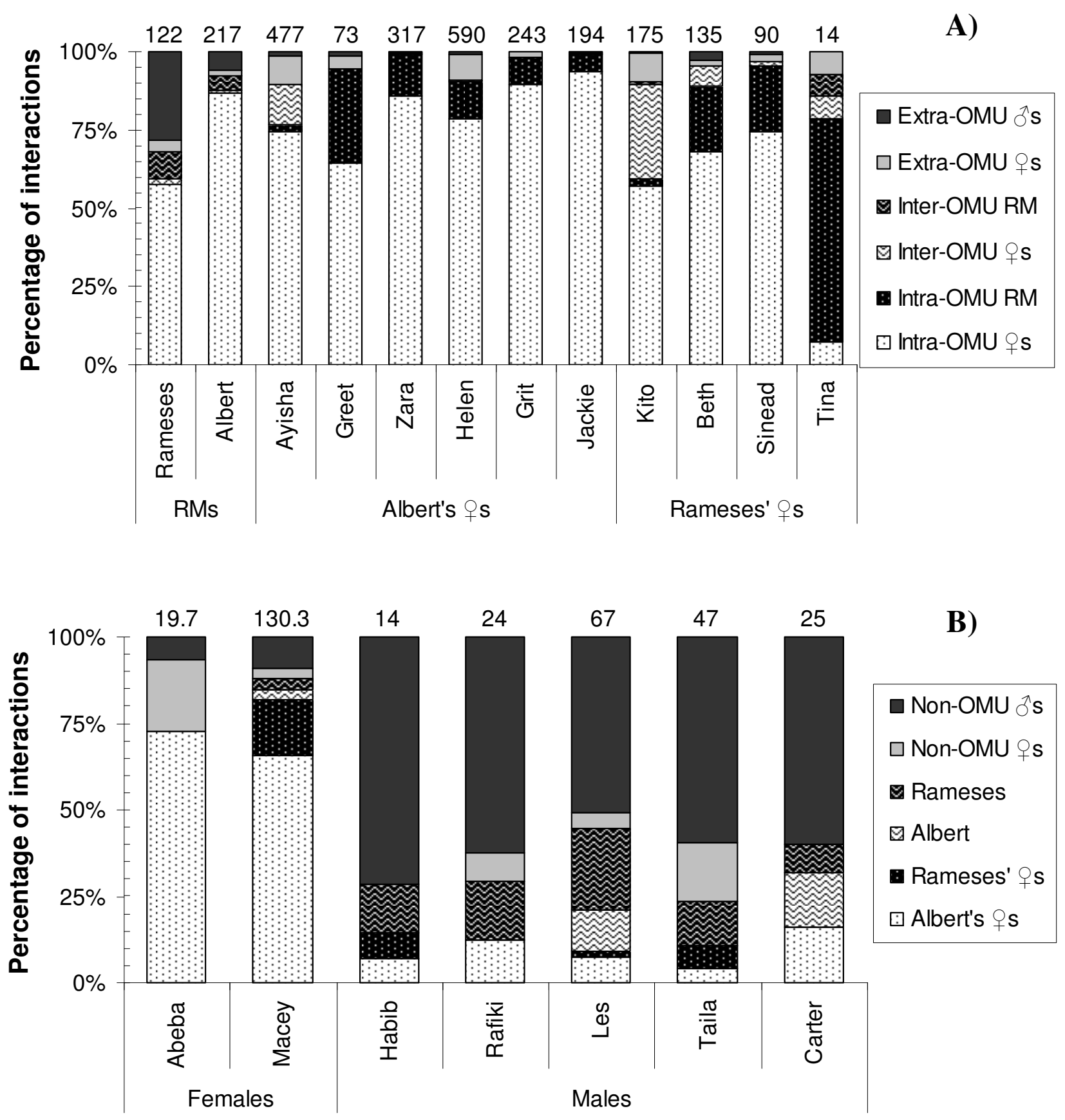

Figure 10. Distribution of conciliatory interactions A) OMU affiliated and B) nonOMU affiliated individuals in the Wellington Zoo hamadryas colony. The number of observed interactions per individual is listed above each bar. Individuals are arranged from youngest to oldest from left to right within each social category. 

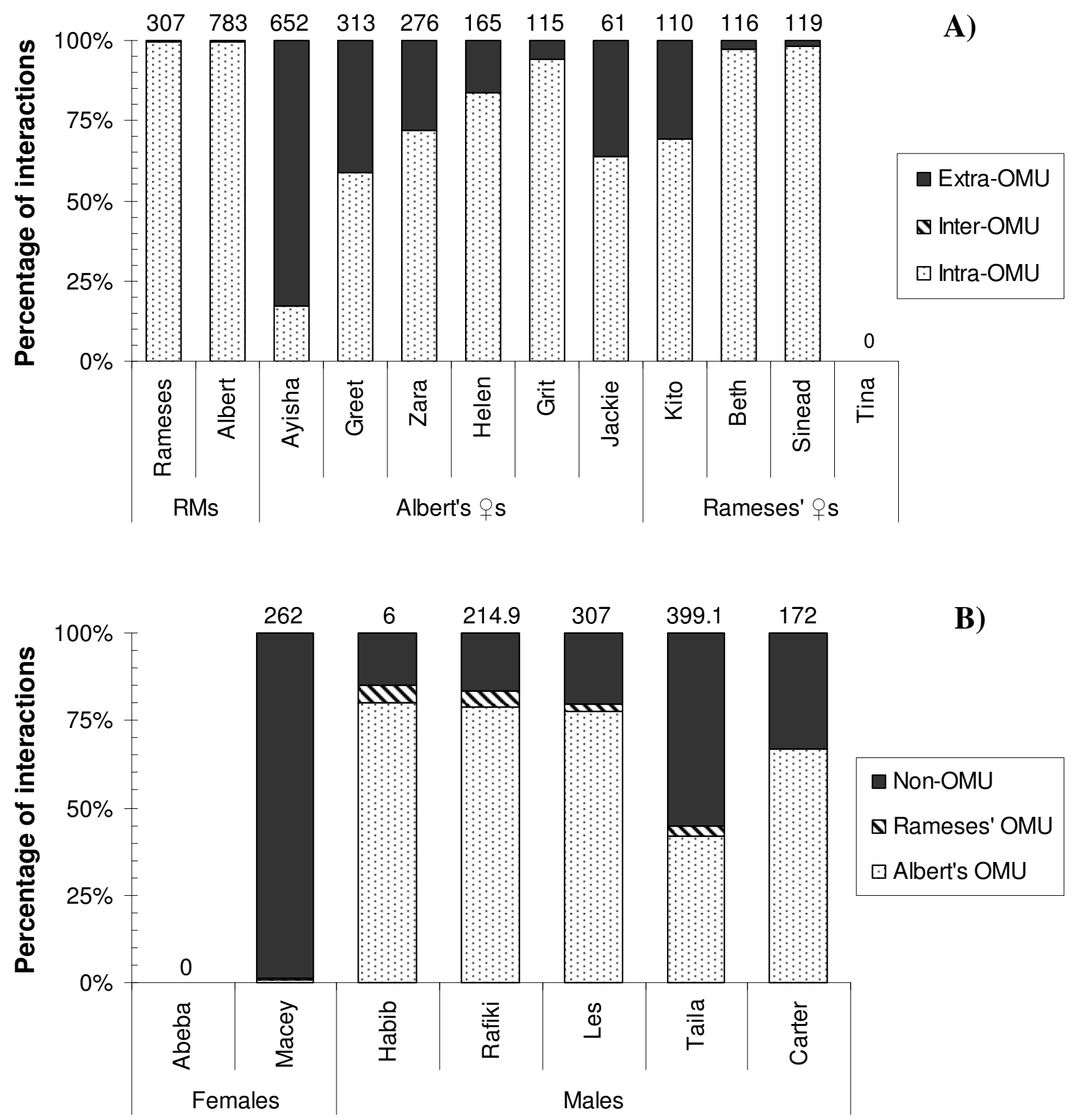

Figure 11. Distribution of sexual interactions A) OMU affiliated and B) non-OMU affiliated individuals in the Wellington Zoo hamadryas colony. The number of observed interactions per individual is listed above each bar. Individuals are arranged from youngest to oldest from left to right within each social category. 
OMU and two out of four females in Rameses' OMU had other female OMU members, rather than their RM, as their predominant affiliative interactees (Figure 7A).

Similar to RMs, female OMU members were involved in relatively few social interactions with members from the other OMU (3.5\%) and the majority of their social interactions outside the OMU involved non-OMU individuals (14.1\% of all social interactions and $80.4 \%$ of all social interactions outside the OMU). The tendency to interact with individuals outside their own OMU, however, varied greatly between females (ranges: Albert's OMU: 4.7\% - 43.7\%, Rameses OMU: $9.7 \%$ 33.5\%). The most common interactions between female OMU members and individuals outside their OMU included those between the youngest female members of each OMU (i.e.: Ayisha and Kito), and those involving extra-OMU males. The latter interactions were more common amongst females in Albert's OMU (proportion of social interactions outside of the OMU involving extra OMU males: Albert's OMU $=65.6 \%$, Rameses OMU $\left.=42.5 \%, \chi_{1}^{2}=28.6, p<0.001\right)$.

Affiliative interactions between mothers and their daughters were also common. With the exception of Greet and Kito (who were not involved in any affiliative interactions), between 7 to $17 \%$ of the affiliative interactions of individuals that had either a mother or daughter (i.e., Grit-Abeba, Beth-Macey, Zara-Ayisha) involved one another (average 14.1\%, cf. $27.7 \%$ with their RM for female OMU members), making them one of the top four affiliative partners for each female.

Female members of Rameses' OMU were also more likely to confine their sexual interactions to their RM (Rameses' females $=88.7 \%$, Albert's females $=$ $49.4 \% ; \chi_{1}^{2}=178.2, p<0.001$, Figure 11A). However, much of the difference 
between OMUs in sexual interactions was due to a solitary female, Ayisha, who accounted for a third of the total sexual interactions for female OMU members, of which only $17.3 \%$ were with her RM. When Ayisha's results are removed, the proportion of intra-OMU sexual interactions rise to $71.8 \%$ in Albert's OMU (although this value is still significantly lower than for females in Rameses' OMU; $\chi_{1}^{2}=39.7, p$ $<0.001$ ) and to $76.4 \%$ for female OMU members overall.

\section{Non-OMU members}

Non-OMU females (Macey and Abeba) most regularly interacted with female OMU members $(61.9 \%)$, followed by non-OMU males (30.1\%). These two groups were also the most common interactees for non-OMU males, albeit in the reverse order (nonunit affiliated males $=50.0 \%$, Female OMU members $=27.7 \%$ ). A large proportion of each non-OMU female's affiliative interactions were spent with their respective mothers $($ Abeba $=27.7 \%$; Macey $=16.7 \%)$. However, the majority of their affiliative interactions were spent with non-OMU males $($ Abeba $=61.7 \%$; Macey $=63.4 \%)$, which suggests that they were largely socially independent of their mothers (Figure 7B). In contrast, the pre-adult non-OMU males (i.e., Habib, Rafiki, Les and Taila, Table 1) did not show a similar degree of maternal affinity (average for all 4 pre-adult males $=4.1 \%$ ). As outlined above, non-OMU members interacted more frequently with females from Albert's OMU than females in Rameses' OMU, and Rameses was the more common interactee of the two RMs.

Most of the sexual interactions of non-OMU males involved females from Albert's OMU (72.9\%), with Ayisha being the most their most common sexual interactee amongst the female OMU members overall $(49.0 \%$ of all non-OMU male 
sexual interactions). Despite only being sexually active for around half the study period, Macey was involved in $23.6 \%$ of all sexual interactions involving non-OMU males. This made Macey the second most common sexual interactee for non-OMU males overall, although Taila was the only male for whom Macey was the majority sexual partner (Figure 11B). Non-OMU males represented 98.9\% of Macey's total sexual interactions, with only 3 of her sexual interactions involving RMs (2 with Albert and 1 with Rameses).

\section{DISCUSSION}

\section{Social Structure}

The social structure of the colony largely coincided with expectations, comprising two OMUs and a composite group of individuals that were not affiliated with any particular OMU. OMU sizes in the Wellington Zoo colony were commensurate with the OMU sizes reported for other captive populations (Kummer and Kurt, 1965; Smith et al. 1999; Zinner et al. 2006), but tended to be larger than the typical OMU size in wild populations (between 1 to 3 females; Kummer, 1968; Kummer et al., 1981; Swedell, 2006; Zinner et al. 2001). Notably, 7 months prior to the start of this study there were 3 OMUs in the Wellington Zoo colony, none of which contained more than 4 females. The death of one of the RMs led to the subsequent redistribution of his females amongst the two established OMUs, presumably as the young males present in the colony at that time were incapable of competing directly with either RM for 'possession' of these females. The relatively large OMU sizes in the Wellington Zoo colony, therefore, appear to be a consequence of the artificially large femalebiased adult sex ratio at the time of the study. Similar female-biased sex ratios have 
also been reported in some wild hamadryas populations, again resulting in OMUs that were larger than normal (Biquand et al., 1992; Mori et al., 2007; Zinner et al., 2001). These differences appear to be due to a variety of factors, including higher predation pressure, the selective killing of adult males, differential maturation of the sexes (hamadryas males maturing slower than females) and recent drought periods (Mori et al., 2007; Zinner et al., 2001).

The non-OMU group has no obvious analogue in wild populations, and appears to be byproduct of captivity. In the wild, males that have not formed their own OMU generally attach themselves to another OMU as 'follower' males, or, less frequently, they may remain unattached to any particular OMU (i.e.: as 'solitary' males). Solitary males have been observed to form loose aggregates in one wild population (Mori et al., 2007), however, this was not similar the more permanent types of all-male groups seen in other primate species and is not typical of hamadryas populations in general. Similarly, females may also spend time unattached to any OMU as so-called 'floaters'. This practice is rare in most populations and is unknown in mature females, and typically involves prepubescent females who are presumably still loosely attached to their natal OMUs (Kummer et al., 1981). Alternatively, young males and females may form 'initial' units, which become full OMUs once females reach sexual maturity. The formation of initial OMUs generally involves males coaxing young females away from their natal OMUs, and therefore do not require them having to usurp females from physically superior adult males. Hence, even though there was the potential to form initial units in the Wellington Zoo colony, young males and females apparently preferred to remain as 'solitary' males and 'floater' females. The possible reasons underlying these decisions will be examined further in the section on social organisation. 
Finally, a single female (Ayisha) was grouped amongst the non-OMU members even though she was observed being herded by Albert throughout the study and, therefore, was probably a member of his OMU. Furthermore, Ayisha also had a core range which was considerably larger than any other OMU member and the $5^{\text {th }}$ largest in the colony overall. According to Wellington Zoo staff, Albert began herding Ayisha around 15 months prior to the start of the present study, several months after she began exhibiting perineal swellings. At that time Albert's OMU contained 3 other female members. Two further adult females (Greet and Zara) joined Albert's OMU 8 months before the start of the present study, following the dissolution of their previous OMU. Hence, while the more recent arrivals appear to have been fully integrated into the social fabric of the OMU, Ayisha remained only loosely attached at the time of the study. The reasons for her semi-detached status will also be examined in the section on social organisation.

\section{Spatial organisation}

Two clear patterns emerged from the spatial analysis. Firstly, while there were distinct social subgroups within the colony (i.e., Albert and Rameses OMUs and the nonOMU group), there was a lack of spatial differentiation amongst the individual members of the colony. The most frequently inhabited areas of the enclosure, specifically the areas adjacent to the sleeping den and public viewing area, were the same for each member of the colony. Notably, foraging opportunities were limited in these areas and the primary activities that took place there were social interactions and resting. It is likely that these areas provided the best location from which to observe activities that took place outside of the enclosure, which would allow individuals to monitor the arrival of zoo keepers (e.g. for feeding times). The presence of the glass 
viewing wall and sleeping den meant that these areas also provided a good source of shade and shelter from the elements, as well as being the location of the sole source of water within the enclosure. These features may have led to these sites being preferred as the loci for social activities and resting within the enclosure for all colony members.

Secondly, the core range size of non-OMU members tended to be much larger than those of OMU members, who tended to have similar range sizes. The difference between OMU and non-OMU members may have been due to two main factors. Firstly, female OMU members were subject to RM herding, and so had ranges which closely mapped that of their RM. Non-OMU members, however, were not subject to any form of herding and subsequently displayed much more intra-group variation in range size. Secondly, non-OMU members were involved in more play and foraging, and less grooming, than OMU members. Both play and foraging typically involved moving around most of the enclosure, whereas grooming is largely sedentary in comparison. Hence, it is likely that the larger ranges of non-OMU members arise from a relative lack of constraint on their activities and an inclination to engage in behaviours which involve more movement.

\section{Activity Budget}

\section{Longitudinal}

In general, there was little change in the activity budget of the colony across the study period. However, time spent on grooming and conciliatory behaviour tended to decrease over the first two months before stabilizing, whereas inactivity and, to a lesser extent, sitting-near showed a general tendency to increase over the interval. As 
the weather became consistently warmer across the study period, these findings suggest that less energy intensive behaviours may have been increasingly favoured as the average daily temperatures increased, but that grooming might not decrease below some minimum threshold that is necessary for maintaining group cohesion. Hence, as well as being an important cohesive mechanism, grooming may also have a function in controlling thermoregulation in hamadryas baboons. Grooming frequency was found to be unrelated to air temperature changes in studies with Japanese macaques, however, which suggests that it does not play a significant role in thermoregulation in this species (Troisi and Schino, 1986; Ventura et al., 2005). While these findings do not rule out the possibility of a link between grooming and ambient temperatures in hamadryas baboons, the data here are insufficient to make a more substantive assessment.

\section{General}

Grooming was the by far the most common social activity for all individuals in the Wellington Zoo colony, a result which is consistent with reports from other freeranging (Kummer, 1968; Kummer and Kurt, 1963; Swedell, 2006) and captive (Kummer and Kurt, 1965) populations. The next most common social behaviour in the colony was sit-near (i.e.: maintaining close spatial proximity to another individual), which was five times lower overall. Play fighting was also a regular activity amongst non-OMU members, particularly males, and showed a general tendency to decrease with age. Notably the adult castrate male, who was not affiliated to any OMU, still engaged in small amounts of play, whereas play was almost entirely absent in OMU members (only the two youngest females, Ayisha and Kito, occasionally engaging in play with non-OMU members). This suggests that grooming 
gradually replaces play fighting as the primary social activity for hamadryas baboons, particularly once OMU membership is obtained. Furthermore, this transition appears to happen more slowly in females, potentially because of the increased importance of physical prowess and fighting ability amongst males. Kummer and Kurt (1965) also observed that play fighting amongst captive males continued to a later age than was typical for males in wild populations. Therefore, it appears that the loss of play behaviour can become delayed in captivity, presumably because of the continuous availability of playmates, enriched diet, and lack of predators and daily foraging requirements that is afforded by the confined environment.

OMU members also spent a greater proportion of their time in social interactions than non-OMU members. This suggests that servicing social relationships may become more important upon attaining OMU membership for hamadryas baboons. Dunbar (1992) argued that affiliative interactions play a central role in maintaining group cohesion in baboon societies, with larger groups requiring that individuals spend more time engaging in affiliative behaviours. Indeed, female OMU members were involved in a higher proportion of affiliative activities in the larger OMU. However, while RMs had virtually identical activity budgets, there was considerable variability amongst the female members of both OMUs. Swedell (2006) reported similar inter-female variability in a wild population that contained several OMUs of variable sizes ( 1 to 9 females per OMU), and found an association between OMU size and the time females spent sitting near other OMU members, but no correlation was found with time spent grooming. Similarly, RMs in larger OMUs tended to spend more time in grooming interactions, but this was not statistically significant. This suggests that factors other than OMU size may be more important in determining the time OMU members spend in social activities in hamadryas baboons. 
Indeed, that RMs assiduously herd females throughout their tenure suggests that affiliative interactions are likely to be less important in maintaining group cohesion in hamadryas baboons than in other baboon subspecies where male herding is largely absent.

Foraging, which largely consisted of the consumption of readily available grass and weeds, was the most common activity in the Wellington Zoo hamadryas colony overall, accounting for over a third of each individual's time on average. This is somewhat surprising, given that the colony received daily meals which were designed to meet their nutritional needs. Foraging-like behaviour has also been observed in juvenile hamadryas baboons in captive environments where vegetation was entirely absent (Kummer and Kurt, 1965). This finding, combined with the knowledge that foraging is the predominant activity engaged in by wild hamadryas baboons during daylight hours, suggests that foraging may be an innate component of hamadryas behaviour that continues to be expressed in captive populations despite provisioning. Notably, foraging was absent amongst adults in the same captive colony (Kummer and Kurt, 1965), which suggests that the expression of this behaviour may eventually be eschewed through a lack of positive reinforcement.

\section{Social Organisation}

How individuals allotted their social and sexual interactions was strongly dependent on whether they were members of an OMU or not. In general, non-OMU members interacted with members from both OMUs but tended to spend most of their time interacting with one another. In contrast, OMU members tended to perform the 
majority of their social and, to a lesser extent, sexual interactions with their OMUmates, with interactions with members of the opposite OMU being exceedingly rare.

Indeed, neither RM at the Wellington Zoo showed any interest in maintaining relationships with individuals other than their female OMU members. While RMs were occasionally approached and groomed by young males, the only affiliative interactions that they initiated outside of the OMU involved the occasional presentations made to one another. Moreover, RMs did not approach, nor were they ever approached by, females from another OMU, and the only extra-OMU sexual incidents involving RMs were the few occasions in which they were presented to by a recently pubescent female (Macey). In each case neither RM responded, going so far as to look away from Macey until she had moved on. Overall, both RMs appeared more interested in policing the activities of female OMU members than in pursuing extra-OMU copulations. This agrees with other published reports and appears to be a species-typical behaviour that purportedly allows RMs to maintain OMU cohesion and to protect their sexual monopoly (Abbeglen, 1984; Kummer, 1968, 1990). Hence, the social and sexual behaviour of both RMs at the Wellington Zoo colony appears to be largely unaltered post-vasectomy. Presumably, this is because the physiological processes that regulate herding and copulatory behaviour are not affected by this procedure.

Female OMU members also interacted predominantly with their fellow OMUmates and largely avoided inter-OMU interactions. Notably, the RM was a prominent social partner for all female OMU members, although not the predominant partner in most cases. Females in the larger OMU tended to engage in more frequent affiliative episodes with individuals other than their RM than females in the smaller OMU. Indeed, females from the larger OMU were observed to fight more frequently over 
grooming access to the RM than females in the smaller OMU, indicating that competition for access to the RM was more intense in the larger OMU. However, two or more females were observed simultaneously grooming their RM on numerous occasions, with instances of up to four females doing so in the larger OMU. Moreover, females in both OMUs were also frequently observed grooming individuals other than their RM when he was socially available (i.e.: sitting alone). Therefore, it appears that females may have preferred the company of individuals other than the RM in some cases.

In her study of a wild Ethiopian hamadryas population, Swedell (2006) also observed that female OMU members often interacted with individuals other than their RM when he was socially available. This led her to conclude that females will invest in relationships with individuals other than the RM where these are available. Swedell goes on to suggest that intra-OMU female bonds may help to reduce competition for access to the RM and lower stress levels amongst female OMU members, such that these relationships may have an adaptive function in hamadryas baboons.

Swedell further postulated that the operation of kin selection should favour the formation of relationships with close female kin where possible. While the incomplete genealogical records prohibit a thorough investigation of kin interactions within the Wellington Zoo colony, affiliative bonds were found to be strong for three out of the four mother-daughter dyads (Zara-Ayisha, Grit-Abeba and Beth-Macey). Moreover, both Ayisha and Grit spent more time in affiliative interactions with their mother and daughter, respectively, than they did with their RMs. Notably, Greet and Kito were the only mother-daughter dyad that were members of separate OMUs, and were also the only pair that were never observed in any affiliative interactions. Several other studies have also pointed out the willingness of hamadryas females to maintain 
contacts with close kin (Abegglen, 1984; Chalyan et al., 1994; Kummer, 1968; Sigg et al., 1982; Swedell, 2002a; Swedell, 2006) and mother-daughter grooming dyads were found to be significantly more common than expected in another captive colony (Colmenares, 2004). Hence, it appears that females will maintain relationships with individuals other than their RM, particularly with close female kin, where these are available. However, because RM herding actively restricts inter-female relationships from taking place outside of the OMU, the scope for such relationships is particularly limited in smaller OMUs.

Perhaps the most interesting finding in this study concerns the uncharacteristically large degree of promiscuity exhibited by female OMU members in the Wellington Zoo colony. The only available quantitative data for a wild hamadryas baboon population showed that RMs were involved in $83.5 \%$ (76 of 91) of observed copulations (Swedell, 2006), and there is a general consensus that extraOMU sexual interactions are extremely rare in this species in general (Abegglen, 1984; Kummer, 1968; Stammbach, 1987). In contrast, Female OMU members at the Wellington Zoo had only $56.4 \%$ of their sexual interactions, and $51.8 \%$ of copulations (these include all cases of observed intromission, i.e.: mounts and aborted mounts), involving RMs. However, when Ayisha's data are excluded the average proportion of intra-OMU copulations increases to $74.3 \%$. Hence, while this value is closer to that observed in the wild population, it appears that females were more promiscuous in the Wellington Zoo colony than is typical in wild populations.

Whereas non-OMU males are potentially accessible throughout the day in captivity, this is not the case in wild populations where groups separate into their individual OMUs during the daily foraging forays. This suggests that the opportunity for extra pair copulations may generally be greater in captive colonies than in their 
wild counterparts. However, this does not explain how females were able to engage in more extra-OMU copulations. A possible explanation is suggested by the presence of two factors in the Wellington Zoo colony that are rare in wild hamadryas populations. Firstly, OMUs containing four or more females are uncommon in most wild populations (see Zinner et al, 2001 for a recent list), such that both OMUs were relatively large by wild hamadryas standards. Secondly, because of RM contraception, all sexually mature females were experiencing repeated ovarian cycling in the colony at the time of the study. Consequently, the likelihood that several females were concurrently experiencing oestrus within each OMU was high and intra-OMU operational sex ratios (OSR, the ratio of sexually available males to females; Emlen and Oring, 1977) were abnormally low in the Wellington Zoo colony. As hamadryas females generally conceive within their first three cycles (Asanov, 1972; Sigg, 1982) and breeding tends to be non-seasonal in most wild populations, the intra-OMU OSRs at the Wellington Zoo are likely to be exceptionally low compared to what is customary for wild groups. Under such conditions, RMs may struggle to control the activities of all their female OMU members, particularly in larger OMUs. As a result, opportunities for extra-OMU mating are expected to increase as the intra-OMU OSR decreases, such that, everything else being equal, female promiscuity is likely to increase with OMU size.

Indeed, 5 out of 6 females in Albert's OMU, which consistently had the lower OSR of the two OMUs, had more than $20 \%$ of their copulations with extra-OMU males, whereas only 1 out of 3 females did so in Rameses' OMU (excluding the noncycling female). Kummer (1968) also reported that extra-OMU mating was particularly common in a wild population when intra-OMU OSR was low. Similarly, RM paternity probability was found to be low in a Saudi Arabian population where 
the OMU sizes were large due to an abnormally high female-biased adult sex ratio (caused by the selective killing of sub-adult and adult males; Yamane et al., 2003), while young males regularly sired offspring in a captive population where all RMs were also vasectomised (Zinner et al., 2006). Notably, as the likelihood of multiple concurrently oestrus females in an OMU increases in proportion with the number of females per OMU, intra-OMU OSRs were likely to have been periodically low in both of these scenarios (Zinner et al., 2006). Hence there is indirect evidence from both wild and captive sources which suggests that an RMs ability to monopolise sexual access to his female OMU members is negatively affected by changes in the intra-OMU OSR.

Ayisha's apparent detachment from her OMU also appears to have been a consequence the large OMUs and artificially low intra-OMU OSRs in the colony. Two related factors appear to have contributed to this situation. Firstly, female hamadryas baboons generally do not conceive until one year after menarche (Caljan et al., 1987; Swedell, 2006), which suggests that they are infertile over the majority of this period. Therefore, as a recently pubescent and nulliparous female, Ayisha may have been less preferred as a sexual partner by her RM relative to her parous female OMU-mates, all of whom were in their reproductive prime. Indeed, young females became pregnant later than their prime-age counterparts in a free ranging population where intra-OMU OSRs were temporarily low because of a compressed breeding season (Asanov, 1972), a situation in which RM choosiness is expected to increase. Hence, given the low OSR in her OMU at the time of the study, Ayisha's RM (Albert) may have preferentially concentrated on herding the prime-age females in his OMU (who are expected to represent better investments of herding time), thereby increasing the opportunities for Ayisha to pursue extra-OMU relationships. Secondly, young 
females are unlikely to have had developed relationships with their fellow OMU members prior to their recruitment into an OMU, and may initially seek to maintain relationships with members of their age cohort and natal OMU. Hence, Ayisha may also have been more inclined to seek out extra-OMU interactions than females who had been part of their OMU for several years.

Taken together, Ayisha's dubious fertility status and relatively recent recruitment into an OMU that contained several prime-age females, all of whom happened to be cycling at the time of the study, suggests that she was probably freer and more motivated to pursue relationships with individuals outside of her OMU than her fellow female OMU members. Indeed, females up to 5 years of age were observed 'floating' between males in Saudi Arabian populations - a situation that had not been observed in females older than 3 years of age in populations where the adult sex ratios are more even (Kummer et al., 1981; Kummer et al., 1985) - which is also explicable through a combination of a low RM interest in young females and a desire on the behalf of these females to maintain extra-OMU relationships. Notably, the youngest member of Rameses' OMU, Kito, also interacted with non-OMU members much more frequently than the prime-age females in her OMU did. However, Kito exhibited stronger socio-spatial ties to her OMU and weaker relationships with non-OMU members than Ayisha, despite being 15 months younger than Ayisha and having been recruited into her OMU more recently (based on observations by zoo staff). This may be explained by the fact the OSR in Kito's OMU was $2^{1 / 2}$ times higher than that in Ayisha's OMU on average, such that Kito's ability to engage in extra-OMU interactions was likely to have been much lower than that exhibited by Ayisha.

Finally, the absence of any initial units and the existence of floater females in the Wellington Zoo colony also appeared to be a byproduct of large OMUs and low 
intra-OMU OSRs. Initial unit formation is often a lengthy process, typically requiring that males spend several months slowly coaxing females away from their natal OMU (Abegglen, 1984; Kummer, 1968). Moreover, males may then have to wait several more years before females obtain sexual maturity. Hence, young males may eschew forming initial units in favour of pursuing copulations with fertile females when they are relatively accessible, as is expected in populations with female-biased adult sex ratios and low intra-OMU OSRs. Additionally, the subsequent lack of male interest means that young females are likely to obtain a greater degree of autonomy than is customary. Indeed, initial units were also found to be less common, and floater females more common, in Saudi Arabian populations where the adult sex ratio and OMU sizes were similar to those found in the Wellington Zoo (Kummer et al., 1981; Kummer et al., 1985; Mori et al., 2007). Therefore, these findings strongly suggest that changes in the adult sex ratio and the intra-OMU OSR leads to the adoption of more opportunistic mating strategies by non-OMU males and increased freedom for young females in hamadryas baboon populations.

\section{Conclusion}

The behavioural and social characteristics of the Wellington Zoo hamadryas baboon colony are largely commensurate with what has been previously described for wild hamadryas baboons. The naturalistic enclosure has meant that foraging is the predominant activity in the Wellington Zoo colony, despite daily provisioning by zoo staff. Grooming was the most important social activity within the colony, particularly once OMU membership had been obtained. Colony members seemed to prefer the same areas of the enclosure, potentially as these areas provided the best loci to observe external events as well as providing the best protection from the elements. 
Non-OMU members also tended to use larger tracts of the enclosure than OMU members, presumably because of their penchant for play fighting and the lack of behavioural constraints that accompany life in an OMU.

Notably, the basic integrity of both OMUs has persisted despite their RMs having previously been vasectomised. This was also found in other captive (Deleu et al., 2003; Zinner et al., 2006) and commensal (Biquand et al., 1994) groups, suggesting that OMU integrity is robust to this type of contraception. The archetypal social patterns of OMU members also appeared to be largely unaltered; affiliative activities were highly concentrated within OMUs and intra-OMU contact was exceedingly rare. However, while RMs were indifferent to relationships outside of their OMU, female OMU members appeared to be interested in maintaining relationships with individuals other than their RM, particularly with close kin. Hence, this study provides further support for the recent argument that the extent of crossbonding in hamadryas baboons may have been overemphasized in previous studies, potentially because these studies focused mostly on male, rather than female, behaviour (Colmenares, 2004; Swedell, 2002a, 2006).

While social activity was largely unaltered by RM contraception, however, the high degree of female promiscuity in the Wellington Zoo colony appears to have been a direct result of it. Hence, the existence of multiple simultaneously oestrus females in the colony, in combination with large OMU sizes, is hypothesised to have compromised RM herding practices and subsequently resulted in increased opportunities for extra-OMU copulations. As a result, extra-OMU mating was more frequent in the larger OMU, where the OSR was lower, and a recently mature female in the largest OMU was able to maintain a degree of spatial and social freedom from her RM which is unusual in wild populations. Additionally, the subsequent increase in 
sexually active females is thought to have led to the absence of initial units and the presence of floater females in the Wellington Zoo colony. Low RM paternity certainty, a lack of initial units and high numbers of floater females have also been found in Saudi Arabian populations which have similarly female-biased adult sex ratios (Kummer et al., 1981; Kummer et al., 1985; Mori et al., 2007; Zinner et al., 2006). Hence, these findings provide indirect evidence that increases in OMU size and the subsequent decreases in the intra-OMU OSR lead to a decrease in the exclusivity of intra-OMU sexual relations, and may potentially enable the expression of more opportunistic mating strategies of female and non-RM male hamadryas baboons.

A pertinent question left unaddressed by this study concerns how different individuals negotiate changes in RM herding patterns to their own benefit. Notably, inter-female variation in promiscuity was large both within and between OMUs, suggesting that females may differ in their desire or ability to pursue extra-OMU copulations. Furthermore, despite of the high degree of promiscuity, no pregnancies had been reported in the colony by the end of the study, although there were adolescent males that were presumably able to do so (Zinner et al., 2006). This implies that RMs may have utilised alternative techniques to protect their sexual monopoly, or, alternatively, that females may use extra-OMU copulations for nonconceptive purposes. The investigation of these questions will form the basis of the forthcoming chapters. 


\section{REFERENCES}

Abegglen JJ. 1984. On Socialization in Hamadryas Baboons. London: Associated University Presses.

Altmann J. 1974. Observational study of behaviour: Sampling methods. Behaviour 49:227-267.

Asanov SS. 1972. Comparative features of the reproductive biology of hamadryas baboons (Papio hamadryas), grivet monkeys (Cercopithecus aethiops) and rhesus monkeys (Macaca mulatta). Acta Endocrinologica Supplementum $166: 458-471$.

Beehner JC, Bergman TJ. 2006. Female behavioral strategies of hybrid baboons in the Awash National Park, Ethiopia. In: Swedell L, Leigh SR, editors. Reproduction and Fitness in Baboons: Ecological, Behavioral and life History Perspectives: Springer. p 53-79.

Bergman TJ. 2006. Hybrid baboons and the origins of the hamadryas male reproductive strategy. In: Swedell L, Leigh SR, editors. Reproduction and Fitness in Baboons: Ecological, Behavioral and life History Perspectives: Springer. p 81-103.

Biquand S, Biquand-Guyot V, Boug A, Gautier JP. 1992. Group composition in wild and commensal hamadryas baboons: A comparative study in Saudi Arabia. International Journal of Primatology 13:533-543.

Biquand S, Boug A, Biquand-Guyot V, Gautier JP. 1994. Management of commensal baboons in Saudi Arabia. Revue d'écologie 49:213-222.

Byrne RW, Whiten A, Henzi SP. 1989. Social relationships of mountain baboons: Leadership and affiliation in a non-female bonded monkey. American Journal of Primatology 18:191-207. 
Caljan VG, Meishvili NV, Vancatova MA. 1987. Sexual behaviour of hamadryas baboons. Anthropologie 25:183-187.

Chalyan VG, Lapin BA, Meishvili NV. 1994. Kinship and troop structure formation in baboon in Gumista Reserve. Congress of the International Primatological Society 15:238.

Colmenares F. 1992. Clans and harems in a colony of hamadryas and hybrid baboons: Male kinship, familiarity and the formation of brother-teams. Behaviour 121:61-94.

Colmenares F. 2004. Kinship structure and its impact on behavior in multilevel societies. In: Chapais B, Berman C, editors. Kinship and Behavior in Primates: Oxford University Press, USA. p 242-270.

Deleu R, Leinfelder I, Nelissen M. Irreversible birth control methods in captive populations of hamadryas baboons. In: Gilbert T, editor. Proceedings of the Fifth Annual Symposium on Zoo Research; 2003; Maxwell Park. Federation of Zoological Gardens of Great Britain and Ireland. p 241-251.

Dunbar RIM. 1992. Time: A hidden constraint on the behavioural ecology of baboons. Behavioral Ecology and Sociobiology 31:35-49.

Emlen ST, Oring LW. 1977. Ecology, sexual selection, and the evolution of mating systems. Science 197:215-223.

Gore MA. 1994. Dyadic and triadic aggression and assertiveness in adult female rhesus monkeys, Macaca mulatta, and hamadryas baboons, Papio hamadryas. Animal Behavior 48:385-392.

Kaumanns W, Rohrhuber B, Zinner D. 1989. Reproductive parameters in a newly established colony of hamadryas baboons (Papio hamadryas). Primate Report 24:25-33. 
Kummer H. 1968. Social Organization of Hamadryas Baboons: A Field Study. Chicago: University of Chicago Press.

Kummer H. The social system of hamadryas baboons and its presumed evolution. In: Mello MT, Whiten A, Byrne RW, editors. Baboons: Behaviour and Ecology. Use and Care. Selected Proceedings of the XIIth Congress of the International Primatological Society; 1990; Brasilia, Brazil.

Kummer H. 1995. In Quest of the Sacred Baboon: A Scientist's Journey. Princeton, NJ: Princeton University Press.

Kummer H, Banaja AA, Abo-Khatwa AN, Ghandour AM. 1981. A survey of hamadryas baboons in Saudi Arabia. In: Wittmer W, Buttiker W, editors. Fauna of Saudi Arabia. Basel: Pro Entolologica, c/o Natural History Museum. p 441-471.

Kummer H, Banaja AA, Abo-Khatwa AN, Ghandour AM. 1985. Differences in social behavior between Ethiopian and Arabian hamadryas Baboons. Folia Primatologica 45:1-8.

Kummer H, Kurt F. 1965. A comparison of social behavior in captive and wild hamadryas baboons. In: Vagtborg H, editor. The Baboon in Medical Research. Austin: University of Texas Press. p 1-16.

Milligan GW. 1996. Clustering validation: results and implications for applied analysis. In: Arabie P, Hubert LJ, de Soete G, editors. Clustering and Classification: World Scientific. p 341-376.

Mori A, Yamane A, Sugiura H, Shotake T, Boug A, Iwamoto T. 2007. A study on the social structure and dispersal patterns of hamadryas baboons living in a commensal group at Taif, Saudi Arabia. Primates 48:179-189. 
Nagel U. 1973. A comparison of hamadryas baboons, anubis baboons, and their hybrids at a species border in Ethiopia. Folia Primatologica 19:104-165.

Sigg H, Stolba A, Abegglen JJ, Dasser V. 1982. Life history of hamadryas baboons: Physical development, infant mortality, reproductive parameters and family relationships. Primates 23:473-487.

Silverman BW. 1986. Density Estimation for Statistics and Data Analysis. Chapman and Hall/CRC.

Smith GS, Sreetharan K, Disbrow M, Wagner JL. 1999. Reconstruction of parentage in a band of captive hamadryas baboons. International Journal of Primatology 20:415:429.

Stammbach E. 1987. Desert, forest and montane baboons: Multilevel-societies. In: Smuts BB, Cheney DL, Seyfarth RM, Wrangham RW, Struhsaker TT, editors. Primate Societies: University of Chicago Press.

Sugawara K. 1988. Ethological study of the social behavior of hybrid baboons between Papio anubis and P. hamadryas in free-ranging groups. Primates 29:429-448.

Swedell L. 2002a. Affiliation among females in wild Hamadryas baboons (Papio hamadryas hamadryas). International Journal of Primatology 23:1205-1226.

Swedell L. 2002b. Ranging behavior, group size and behavioral flexibility in Ethiopian hamadryas baboons (Papio hamadryas hamadryas). Folia Primatologica 73:95-103.

Swedell L. 2006. Strategies of sex and survival in hamadryas baboons: through a female lens. Sussman RW, Vasey N, editors. Upper Saddle River, NJ: Pearson Prentice Hall. 
Troisi A, Schino G. 1986. Diurnal and climatic influences on allogrooming behaviour in a captive group of Java monkeys. Animal Behaviour 34:1420-1426.

Ventura R, Majolo B, Schino G, Hardie S. 2005. Differential effects of ambient temperature and humidity on allogrooming, self-grooming, and scratching in wild Japanese macaques. American Journal of Physical Anthropology 126:453-457.

Wood RL, 2003. Investigation of the behavioural response of group-housed hamadryas baboons to relocation to a more 'naturalistic' enclosure. [Master of Science]: Victoria University.

Yamane A, Shotake T, Mori A, Boug AI, Iwamoto T. 2003. Extra-unit paternity of hamadryas baboons (Papio hamadryas) in Saudi Arabia. Ethology, Ecology and Evolution 15:379-387.

Zinner D, Krebs E, Schrod A, Kaumanns W. 2006. Early sexual maturity in male Hamadryas Baboons (Papio hamadryas hamadryas) and its reproductive implications. American Journal of Physical Anthropology 129:584-590.

Zinner D, Pelaez F, Torkler F. 2001. Group composition and adult sex-ratio of hamadryas baboons (Papio hamadryas hamadryas) in central Eritrea. International Journal of Primatology 22:415-430. 


\title{
Chapter 3: The pattern and function of sexual behaviour in
}

\section{relation to the ovarian cycle in hamadryas baboons}

\begin{abstract}
Little is known about the relationship between sexual activity and the ovarian cycle in hamadryas baboons (Papio. h. hamadryas). Here I investigate the timing and frequency of mounts, ejaculations, presents, inspections and approaches in relation to the ovarian cycle of female one-male unit (OMU) members in a captive colony of hamadryas baboons. The timing and frequency of sexual activities with resident males (RM) and non-OMU males were compared and various hypotheses on the function of extra-OMU mating examined. Females were found to be receptive throughout the turgescent and deturgescent phases, whereas their attractiveness and proceptivity only peaked over the final days before perineal deturgescence. RMs were found to concentrate their sexual interactions over the period where ovulation was expected to be highest, whereas non-OMU males tended to have most of their interactions on the days either side of this period. NonOMU males appeared to target sexual activities with females that had most recently joined an OMU, presumably because these females were more accessible. The majority of females rarely solicited copulations with nonOMU males and were most likely to reject mounts from them around the optimal conceptive period. Overall, the patterns suggest females sought to enhance the conceptive probabilities of their RM and that extra-OMU mating was more likely to serve an anti-infanticide strategy than facilitating female choice or fertility insurance strategies.
\end{abstract}




\section{INTRODUCTION}

Female baboons are one of several species of old world primates whose ovarian status is signalled by conspicuous changes in the turgescence of their perineal and anogenital regions (see Dixson, 1998 and Nunn, 1999 for recent lists). Various studies indicate that the likelihood of ovulation is positively, but imperfectly, correlated with perineal turgescence in female baboons, with the majority of ovulations occurring on or shortly before the first day of perineal deturgescence (Aranda et al., 2006; Gillman and Gilbert, 1946; Hendrickx and Kraemer, 1969; Higham et al., 2007; Shaikh et al., 1982; Stevens, 1997; Wildt et al., 1977). This means that males can use the degree of turgescence as a signal to coordinate the timing of their sexual activities with females during optimal conceptive periods. Hence, the expression of sexual behaviour for both sexes tends to be strongly correlated with the degree of perineal turgescence in species that display this trait (Dixson, 1983, 1998). Furthermore, changes in perineal turgescence alone has been shown to be sufficient to stimulate male sexual arousal in baboons (Girolami and Bielert, 1987).

The majority of studies investigating the relationship between the ovarian cycle and sexual behaviour thus far have focused on subspecies of baboons which live in temporally stable societies, where males actively compete for access to oestrus females (i.e.: multimale-multifemale mating systems) and only consort with females over the oestrus period. In contrast, only limited data are available on the patterning of sexual behaviour across the ovarian cycle amongst hamadryas baboons $(P . h$. hamadryas), which live in modular societies that comprise several one male units (OMU; i.e., a single adult male, resident male (RM), and one or more adult females and their dependent offspring) and have a mating system that is based upon female defence polygyny (Kummer, 1968; Stammbach, 1987). 
Adult male hamadryas baboons maintain sexually exclusive relationships with females in their OMU which typically last several years. RMs employ a combination of agonistic herding and active vigilance to ensure their sexual monopoly over these females. Competition between RMs for sexual access to oestrus females is virtually unknown (Abegglen, 1984; Kummer, 1968; Sigg et al., 1982; Swedell, 2006) and experimental data suggest that RMs are actually 'inhibited' from mating with females outside their own OMU (Kummer, 1995; Kummer et al., 1974). Hence, the majority of observed extra-OMU copulations have involved sub-adult and older juvenile males that have attached themselves to a particular OMU (i.e., 'follower' males). RMs tend to exhibit a high degree of tolerance towards follower males, potentially because these males are close kin or because their relatively young age means that they are more likely to be perceived as a relatively low paternity risk by RMs (Abegglen, 1984; Kummer, 1968; Zinner et al., 2006). Higher RM tolerance is expected to increase the opportunities for follower males to 'sneak' copulations with female OMU members (Abegglen, 1984; Kummer, 1968). Indeed, sexual maturity occurs earlier in hamadryas baboons than other baboons (Jolly and Phillips-Conroy, 2003, 2006; Zinner et al., 2006), which suggests that extra-OMU mating may have been sufficiently frequent for selection to favour accelerated sexual development in young hamadryas males.

Observations of extra-OMU copulations are relatively rare in hamadryas baboons, such that there is little information regarding their frequency and timing. Consequently, the potential benefits of extra-OMU mating for hamadryas females are still largely unknown. Extra-OMU mating may reflect female choice, should females prefer males other than their RM, or it might be used to facilitate a post-copulatory strategy such as sperm competition or cryptic female choice. Alternatively, females 
may use extra-OMU mating to ensure conception in situations where RM sperm depletion is likely (i.e., a fertility insurance strategy). Indeed, the probability of conception was found to be negatively correlated with the number of simultaneously turgescent females per OMU in a captive hamadryas population (Zinner et al., 1994), presumably because of RM sperm depletion. Finally, male hamadryas baboons have been observed to commit infanticide (Swedell, 2006), such that females may pursue extra-OMU copulations as part of a paternity confusion strategy to deter infanticide.

The data presented here were collected from the Wellington Zoo hamadryas baboon colony between June and December 2007. The objectives of this chapter are threefold: 1) to describe the patterning of sexual behaviour for both sexes of hamadryas baboons with respect to changes in the ovarian cycle, 2) to examine the differences, if any, in the timing of sexual events involving RMs and non-OMU males across the ovarian cycle of female OMU members, and 3) to use this information to investigate whether female hamadryas baboons utilise extra-OMU mating for one or more of the following functions: female choice, fertility insurance or paternity confusion.

\section{METHODS}

\section{Subjects}

At the time of the study the Wellington Zoo colony comprised 3 adult males, 10 adult females, and 7 pre-adult members (Table 3). All adult females were members of one of the two OMUs, which comprised 6 and 4 females respectively. Membership in these OMUs remained unchanged throughout the study period. Additionally, another female, Macey, began exhibiting regular perineal swellings from August 2007, and 
Table 3. The demographic profile of the Wellington Zoo hamadryas baboon colony at the time of the study. Resident males are indicated by bold text. The list is organised by OMU affiliation, with OMU-affiliated females and individuals not affiliated to an OMU arranged from oldest to youngest in descending order. All animals were born in Wellington Zoo unless otherwise noted. See Appendix 1 for description of age and sex classes.

\begin{tabular}{lcccc}
\hline \multicolumn{1}{c}{ Name } & Sex & D.O.B. & OMU & Age Class \\
\hline Rameses & M & 11.Oct.95 & Rameses & Adult \\
Tina $\dagger$ & F & 18.Apr.79 & Rameses & Adult \\
Sinead & F & 29.Jan.93 & Rameses & Adult \\
Beth & F & 4.Jun.94 & Rameses & Adult \\
Kito & F & 21.May.02 & Rameses & Adult \\
Albert & M & 24.Jun.95 & Albert & Adult \\
Jackie† & F & 17.Oct.86 & Albert & Adult \\
Grit* & F & 1.Jan.88 & Albert & Adult \\
Helen* & F & 3.Oct.92 & Albert & Adult \\
Zara & F & 21.Sep.94 & Albert & Adult \\
Greet* & F & 16.Sep.96 & Albert & Adult \\
Ayisha & F & 4.Sep.01 & Albert & Adult \\
Carter & M & 14.May.93 & None & Adult \\
Taila & M & 2.Oct.01 & None & Subadult \\
Les & M & 19.Sep.02 & None & Large juvenile \\
Rafiki & M & 24.Sep.03 & None & Medium juvenile \\
Macey & F & 13.Mar.04 & None & Medium-large juvenile \\
Habib & M & 7.Dec.04 & None & Medium juvenile \\
Abeba & F & 24.Dec.04 & None & Medium-large juvenile \\
\hline
\end{tabular}

* Introduced from Melbourne Zoo, Australia, on $12^{\text {th }}$ January 1988.

$\dagger$ Introduced from Dierenpark Emmen, the Netherlands, on $7^{\text {th }}$ June 2001. 
had undergone four complete cycles by the completion of this study. However, despite being post-menarchal, Macey had not been incorporated into either of the existing OMUs by the end of the study, nor had she formed a new OMU with an unattached male. Additionally, an adult female member of Rameses' OMU, Tina, had not exhibited any signs of perineal tumescence since initial observations began in November 2006 and was, therefore, presumed to have been post-menopausal. Consequently, both Tina and Macey are omitted from all subsequent analyses.

\section{Housing}

Since March 2000 the colony has resided in a purpose-built 0.25 ha naturalistic outdoor enclosure. This enclosure contains a number of trees, rocks, logs and open grassed areas, and is surrounded on all sides by a 3 metre tall chain-link wire fence. A $6 \times 4$ metre sleeping den adjoins the northern-western section of the enclosure. Access to the sleeping den was restricted between the daily feeding times, which occurred at approximately 10 a.m. and 3 p.m., unless it was wet or cold. The public viewing area is located on the western side of the enclosure, with a 7 metre long glass wall forming part of the perimeter fence at this point to assist in viewing. The eastern perimeter of the enclosure adjoins a public park, with the remainder being bordered by other zoo exhibits. In August 2007 an electric fence that ran parallel with the northern and eastern sections of the perimeter fence was installed inside the enclosure in order to protect several newly planted saplings. This reduced the area of the enclosure that is accessible to the baboons to approximately 0.2 hectares. 


\section{Contraceptive treatments}

In order to control population growth within the colony the two RMs (along with another RM who died in November 2006) were vasectomised in October 2004. A further adult male (Carter, Table 3) was castrated as a juvenile and had not developed the characteristic mantle of adult hamadryas males, nor acquired an OMU of his own. Additionally, a subadult male (Taila) received a hormonal castration treatment (Suprelorin ${ }^{\circledR}$, a gonadotrophin-releasing hormone agonist produced by the Peptech corporation) in October 2006, after he was observed mating with females. No pregnancies or births had been observed in the colony from March 2005 until the completion of the study in February 2008. Hence, 3 out of the 4 females in Rameses OMU (excluding Tina), and all 6 females in Albert's OMU, had been undergoing repeated ovarian cycling from at least March 2005 until the end of the present study (including Macey from late August).

\section{Behavioural data collection}

Behavioural data was collected through focal sampling techniques which involved a mixture of focal animal and focal behaviour sampling (Altmann, 1974). During each focal sample all approach events that involved the focal individual (i.e., focal animal sampling) as well as all occurrences of sexual behaviour for the entire colony (i.e.: focal behaviour sampling) were recorded. Up to five focal samples were collected each day, with samples separated by periods lasting between 1 to 30 minutes. A stratified random sampling procedure was used to select the subject of each focal animal sample, with males (excluding Carter, Rafiki and Habib) and females (excluding Tina, Macey and Abeba) separated into two different strata. At least one 
male and three females were sampled every day, unless data collection had to be terminated early because of inclement weather. RMs received double weighting over other males, such that each RM was sampled every 3 days, and other males every 6 days, on average. Females had equal weightings, whereby each female was sampled every 3 days on average. If a fifth sample took place it was assigned to a female with a maximum perineal swelling in order to increase the sample size for females in this state. If no female existed in this condition then the 5th sample was assigned to either Carter or Tina, because data collection was prioritised for adult over pre-adult colony members.

In order to minimise observer effects, all observations were made from the public viewing area where the baboons were accustomed to people being present. Furthermore, because the enclosure slopes upward from west to east, most parts of the enclosure can be observed from this location. The majority of data was collected daily between the hours of 10 a.m. and 3 p.m., coinciding with the period of time in which sleeping den access was restricted and individuals were confined to the outdoor enclosure and subsequently readily observable. Sampling occasionally continued after 3 p.m. on days where the dens remained closed beyond that time. No sampling occurred on days when it was raining or unusually cold since the sleeping den was freely accessible on these days and the baboons spent the majority of their time inside the den where they could not be observed.

Eight different types of behaviour were recorded during the study (Table 4). These were reallocated to the following 7 categories for all subsequent analyses in this chapter: attempted mounts (which include all mounts, aborted mounts and rejected mounts), successful mounts (i.e., mounts), ejaculatory mounts, approaches initiated (by females), approaches received (by females), inspections, and presents. 
Table 4. List of the behaviours analysed in the study, and their definitions. 'A' and 'B' represent instigator and recipient interactees respectively. Behaviours were collected through a mixture of focal animal (approach) and focal behaviour (all other behaviours) sampling.

Behaviour Definition

Presentation

Female A directs her hindquarters toward Male B with tail upright and both front and rear limbs unflexed.

Perineal inspection

Male A looks, smells, touches or licks (or combination thereof) the genital area of Female B.

Male A climbs onto hindquarters of Female $\mathbf{B}$ by placing his feet

Sexual mount on her upper calves and grasping her hip area before intromitting. Mount is not interrupted by a third party.

Prior to or shortly after intromitting Female B, Male A ceases a Mount abort mount due to discovery by participating female's RM (only nonOMU males) or incorrect body positioning (RM).

Male A attempts to climb onto the hindquarters of Female B, but Mount reject Female B moves in such a way as to inhibit Male A from doing so.

Ejaculatory pause

After initiating several thrusts, Male A pauses for several seconds before dismounting Female B. Indicative of ejaculation.

Approach

A moves to within 1 body length of $\mathbf{B}$ after being further than 1 body length away from $\mathbf{B}$. 


\section{Ovarian cycles}

Perineal turgescence data was recorded daily for all mature, fertile females in the colony. Ovarian cycles were scored by assigning each cycle day a value as determined by its position relative to the first day of perineal deturgescence (DoD). The DoD was scored as day 0 , while the first day following the DoD was scored as day +1 , the day coming two days after the $\mathrm{DoD}$ as +2 and so on, until every day of deturgescence and the absence of turgescence for a given cycle was assigned a non-negative value. Likewise, the day that fell immediately prior to the DoD was scored as day -1 , the day falling two days before the DoD as day -2 and so on, until every day of turgescence for a given cycle was assigned a negative value.

One complete ovarian cycle was defined to be the interval that begins on the DoD and ends on the day prior to the DoD for the subsequent ovarian cycle. This interval was preferred above inter-menses and inter-turgescence intervals because deturgescence was a clearly demarcated event amongst the Wellington Zoo females, whereas external signs of menses were not always observed and the early stages of tumescence were difficult to distinguish. Furthermore, previous studies on savannah baboons have demonstrated that the time between consecutive DoDs closely matches that for the inter-menses period (Hausfater, 1975; Wildt et al., 1977). Thus, this interval provides an accurate measure of ovarian cycle length for baboons.

\section{Statistical analyses}

A permutation model was employed to test whether the frequency of sexual events involving RMs and non-OMU males (all males not affiliated to a known OMU, see Table 3) was significantly different for each day of the ovarian cycle. The permutation 
model was used to control for possible autocorrelation between samples, as independence of data is not a prerequisite criterion for these models (Manly, 2006). The permutation test was conducted as follows:

\section{Test statistic}

- For a given behaviour, all events were allocated to one of the $n$ 'days' of the ovarian cycle according to the day of the cycle on which the event took place.

- For each cycle day $n$, the difference between the number of events involving RMs and non-OMU males (i.e., the paired difference, PD) was calculated for each sample taken. Because no sexual interactions were observed between females and the RM from the other OMU, all sexual interactions either involved the RM form their own OMU or one of the bachelor males (i.e. Carter, Taila, Les, Rafiki or Habib), such that all extra-OMU mating involved non-OMU males. Hence, this value is positive whenever RMs were involved in more events than other nonOMU males, and negative otherwise.

- The average PD for cycle day $n$ was then calculated by summing the PD for each sample and then dividing by the total number of samples taken on that day. This value is the observed PD, or test statistic, for cycle day $n$.

- This process was repeated for each day of the cycle, such that each cycle day was assigned an observed PD for a given behaviour.

\section{Null distribution}

- For a given behaviour, an expected PD for cycle day $n$ was generated by randomly reallocating the data in each sample (i.e., only two permutations; either the data remain allocated to the original male grouping or are exchanged), then calculating the PD for each sample and the subsequent average PD as above. 
- This procedure was repeated 1000 times such that a distribution of expected PDs for cycle day $n$ was created. This procedure was repeated for each day in a given cycle.

\section{Hypothesis testing}

- For cycle day $n$, a significant result occurred whenever the observed PD is greater than the most extreme upper expected PDs or less than the most extreme lower expected PDs. All tests are two tailed (either RMs may be involved in more events than non-OMU males or vice versa), with $\alpha=0.05$ (i.e., a significant result occurred whenever the observed value was amongst the most extreme $2.5 \%$ of values at either end of the null distribution). This was repeated for each cycle day within the cycle.

For each of the 7 behavioural categories (attempted mounts, successful mounts, ejaculatory mounts, inspections, presents, approaches initiated by females, approaches received by females), separate tests were run on each individual female and all female OMU members combined. In order to minimise the computation time taken to run each analysis, days beginning on and preceding day -10 and days beginning on and following day 4 were grouped together, such that there were 15 cycle 'days' analysed overall (i.e., $\leq-10,-9,-8, \ldots, 0,1,2,3, \geq 4$ ). These categories were chosen because the majority of all sexual events took place within this interval for each behaviour. Additionally, because the number of samples for approach data were smaller than those for sexual behaviours (approach data were collected for the focal animal only, whereas all sexual behaviour within the colony was collected during each sample), merged cycle day categories were used for tests involving approach data from individual females $(\leq-10,-9$ to $-7,-6$ to $-4,-3$ to $-1,0$ to 2 , $\geq 3$; i.e., 6 cycle 'days' overall). The original categorisations were retained for the combined 
female analysis. Finally, in order to control for the effects of multiple testing (which increases the probability of type 1 statistical error), a sequential Bonferroni correction was used (Holm, 1979), such that for a given behaviour and female or group of females the $p$-values from each cycle day were ranked from smallest to largest, with the smallest $p$-value tested at $0.05 / c$, the second smallest value at $0.05 / c-1$ on so on, where $c$ is the number of comparisons. The permutation model was written by Shirley Pledger, and run on $\mathbf{R}$ 2.6.2 mathematical software.

\section{RESULTS}

Overall, 560 focal animal and focal behaviour samples, equalling 280 hours of observations, were gathered over 191 days between the 6th of June 2007 and the 13th of December 2007. The number of samples per female ranged from 42 to 51 (Table 5). Information from 48 complete ovarian cycles was collected over the study period, with a minimum of 4 and a maximum of 6 cycles being recorded for each female. The average cycle length for all 9 female OMU members was $31.3 \pm 0.78$ days during this period, with the turgescent phase averaging $14.0 \pm 0.69$ days and the non-turgescent phase $17.4 \pm 0.46$ days (average phase lengths calculated using data from both complete and incomplete cycles). Additionally, the adult castrate (Carter) was only observed in 4 sexual interactions with female OMU members during the study, such that almost all non-OMU male sexual activity involved Taila, Les, Rafiki and Habib. 


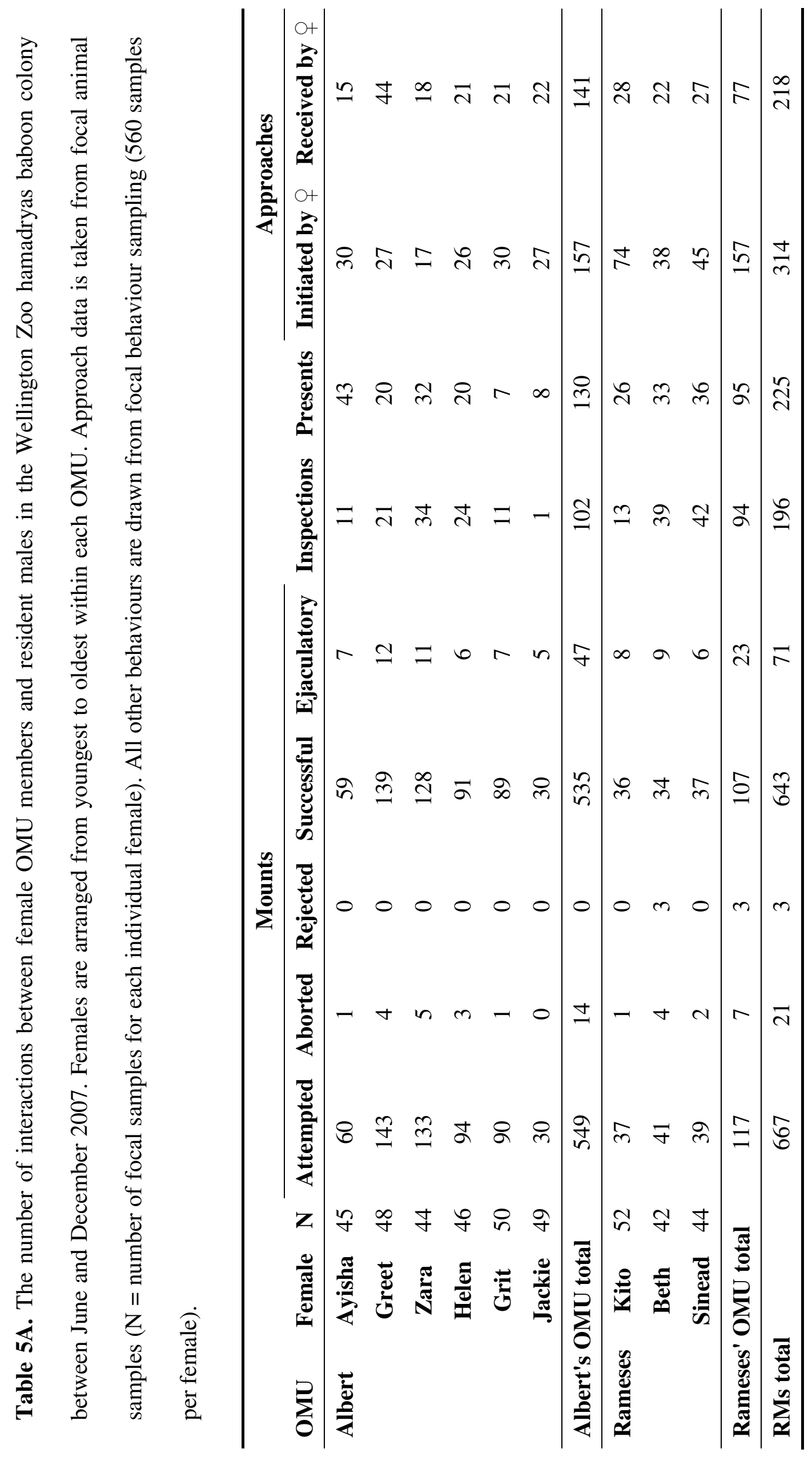




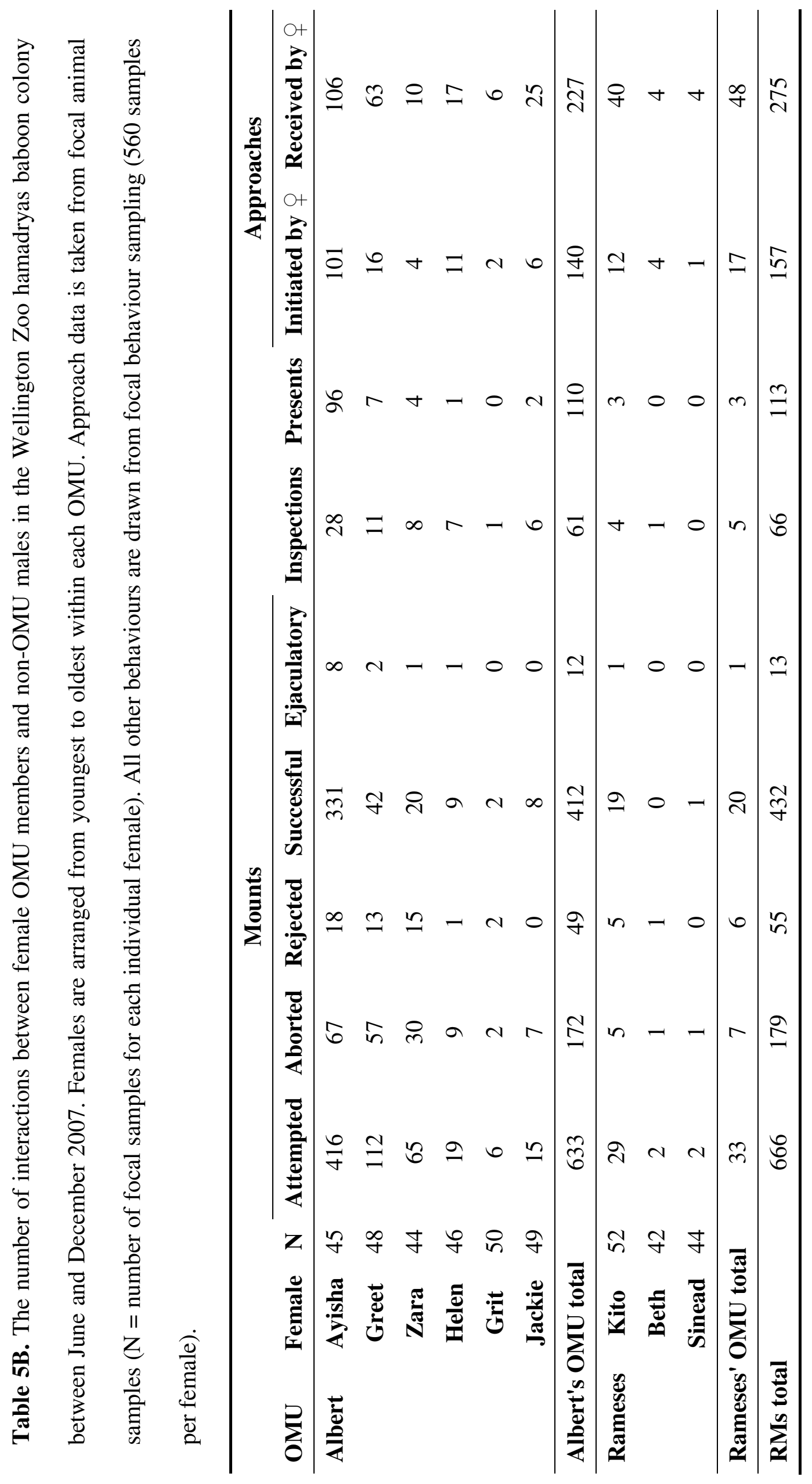




\section{Mounts and ejaculations}

Both RMs and non-OMU males attempted an almost identical number of mounts with female OMU members (Tables 5A and 5B). However, non-OMU males had far fewer successful mounts than RMs (success rate: $64.9 \%$ vs. 96.4\%). RMs tended to concentrate their copulatory activities over a 4 day period between cycle days -4 and -1 , with $82.6 \%$ of all attempted mounts, and $84.1 \%$ of all successful mounts, occurring during this period (Figure 12A). Both RMs displayed similarly concentrated copulatory patterns, however, Albert was involved in nearly 4 times as many mounts as Rameses overall. In contrast, the copulatory activity of non-OMU males had a bimodal pattern. The peak mating periods for non-OMU males occured over cycle days -6 to -4 and on cycle day 0 (Figure 12B), with mount events decreasing markedly between these two periods and more gradually on either side. Day 0 represented the greatest single day for copulatory activity for non-OMU males, with $64.3 \%$ more attempted mounts and $66.0 \%$ more all successful mounts taking place on this day relative to the next most frequent day (day 5 in both cases, Figure 5B).

Non-OMU males had a sharp increase in the proportion of unsuccessful mount attempts they made around cycle days -1 and -2 . Of all the mounts attempted by nonOMU males over these two days, $49.6 \%$ were aborted and $24.3 \%$ were rejected, whereas the average over the rest of the turgescent period was $21.4 \%$ and $4.0 \%$ respectively (Figure 13). In other words, 3 out of 4 mounts attempted by non-OMU males were unsuccessful over this period, compared to 1 in 4 mounts over the rest of the turgescent period. Consequently, RMs were significantly more likely to attempt and successfully mount females over cycle days -1 to -3 , whereas non-OMU males 

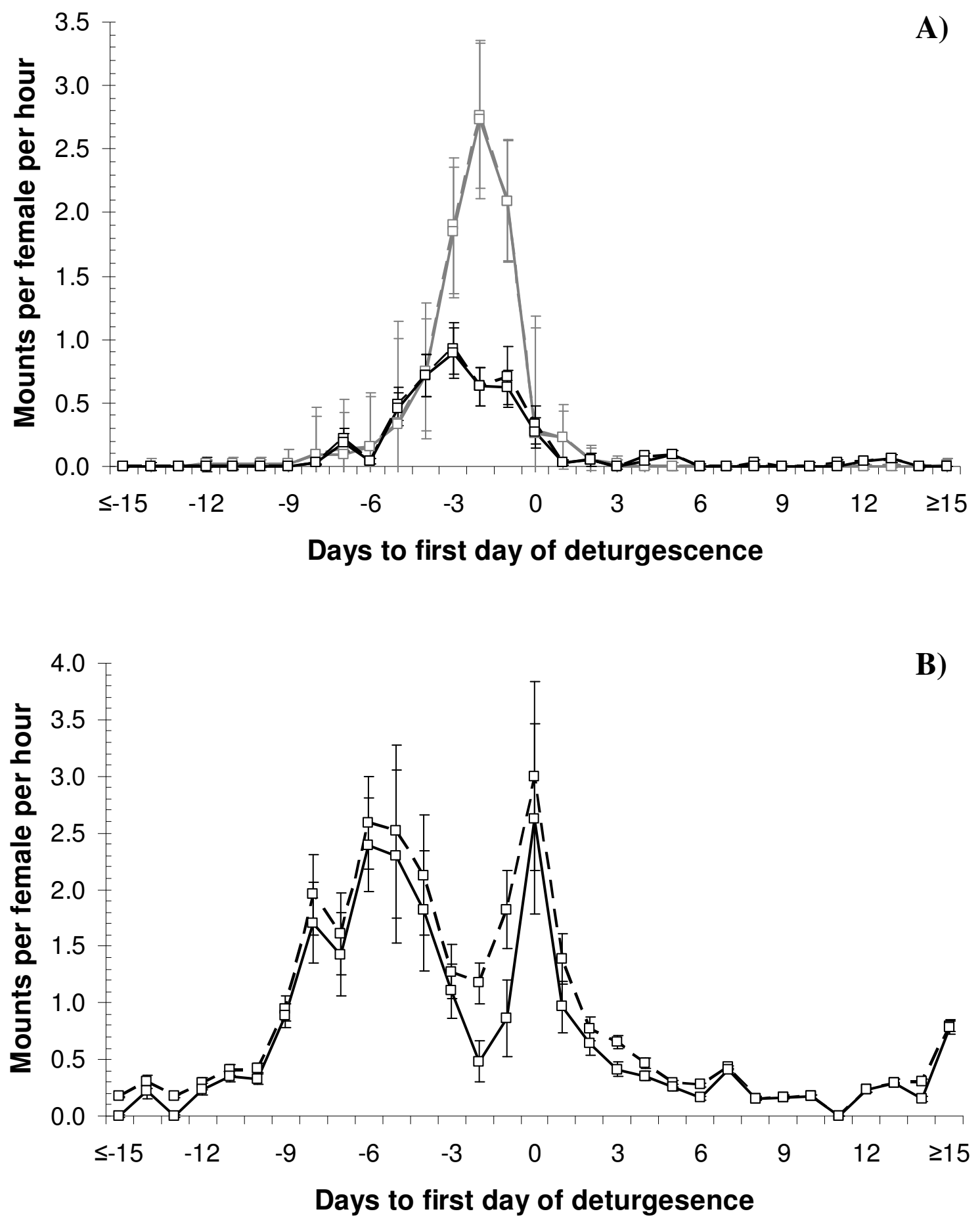

Figure 12. Average ( $\pm 1 \mathrm{SE}$ ) rate (per hour) of mounts received by female OMU members from A) their resident male $($ Albert = grey line, Rameses $=$ black line $)$ and B) non-OMU males against time of ovarian cycle measured relative to the first day of perineal detumescence (day 0). Attempted mounts are indicated by broken lines and successful mounts (i.e.: uninterrupted mounts with intromission) by unbroken lines. 


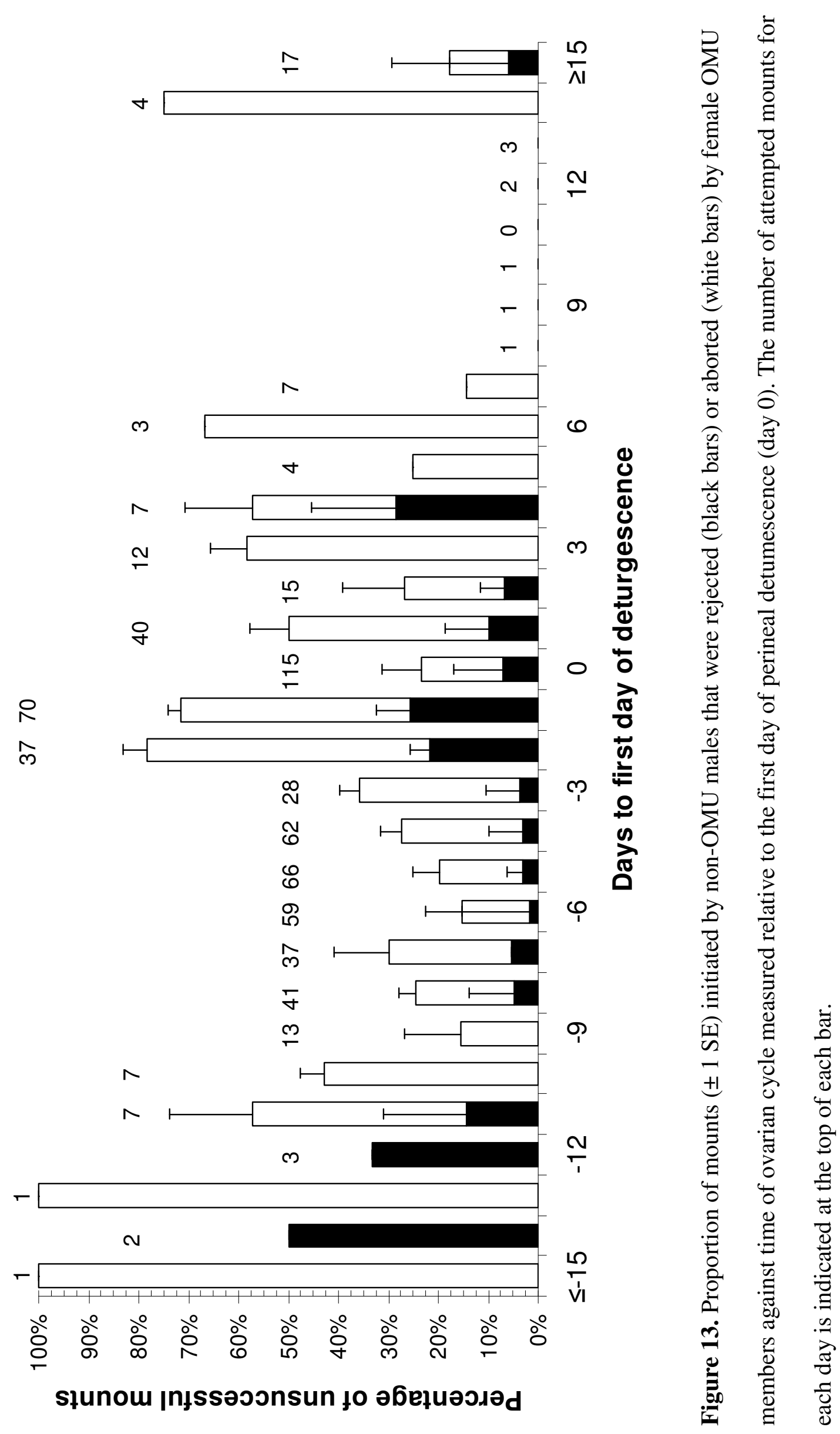


were significantly more likely to attempt and be successful in mounting females on cycle days outside the interval between cycle days -5 and -1 (Tables 6 and 7). RMs were also most likely to have an ejaculatory mount during cycle days -4 to $-1,(78.6 \%$ of all ejaculations; Figure 14A), and were significantly more likely to do so than nonOMU males over this interval (15.4\% of all ejaculations, Table 8). Overall, non-OMU males were only able to achieve 2 ejaculatory mounts, compared to 55 in the case of RMs, with female OMU members over this period. The patterning of the ejaculatory mounts for non-OMU males followed their general copulatory patterns (Figure 14B). However, non-OMU males had approximately 5 times fewer ejaculatory mounts than RMs overall, such that they did not have a significantly higher ejaculatory frequency on any of the cycle days compared to RMs. Furthermore, both RMs had a similar ejaculatory rate when averaging over the number of females in an OMU, such that Albert had roughly double the ejaculatory rate of Rameses. Albert also ejaculated on a considerably lower proportion of mounts than Rameses overall (8.7\% vs. $21.5 \%)$, although this proportion was still much higher than that for non-OMU males (3.2\%).

The general mating patterns of RMs and non-OMU males were largely reiterated for individual female OMU members. Only Ayisha was involved in significantly more attempted, successful and ejaculatory mounts with non-OMU males on any of the cycle days between -1 and -6 , and there was no female for whom this occurred over cycles days -3 to -1 (Tables 6 to 8 ). However, there were instances where neither RMs nor non-OMU males were involved in significantly more copulatory activities for at least one day within this interval for nearly every female OMU member, with Beth being the only exception. Non-OMU males were also significantly more likely to attempt and successfully mount each individual female for at least one day outside of interval between cycle days -6 to -1 , with Beth again being 


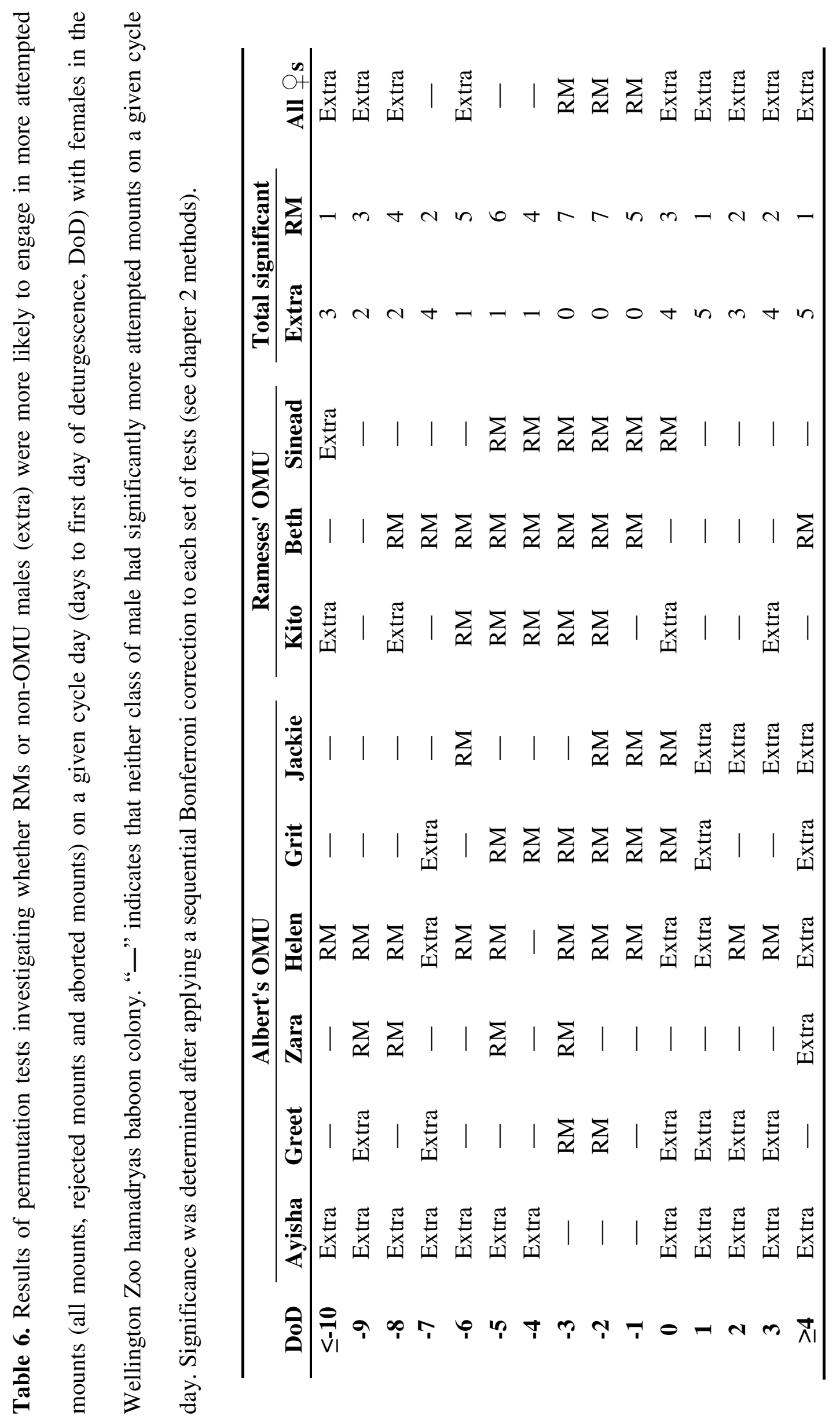




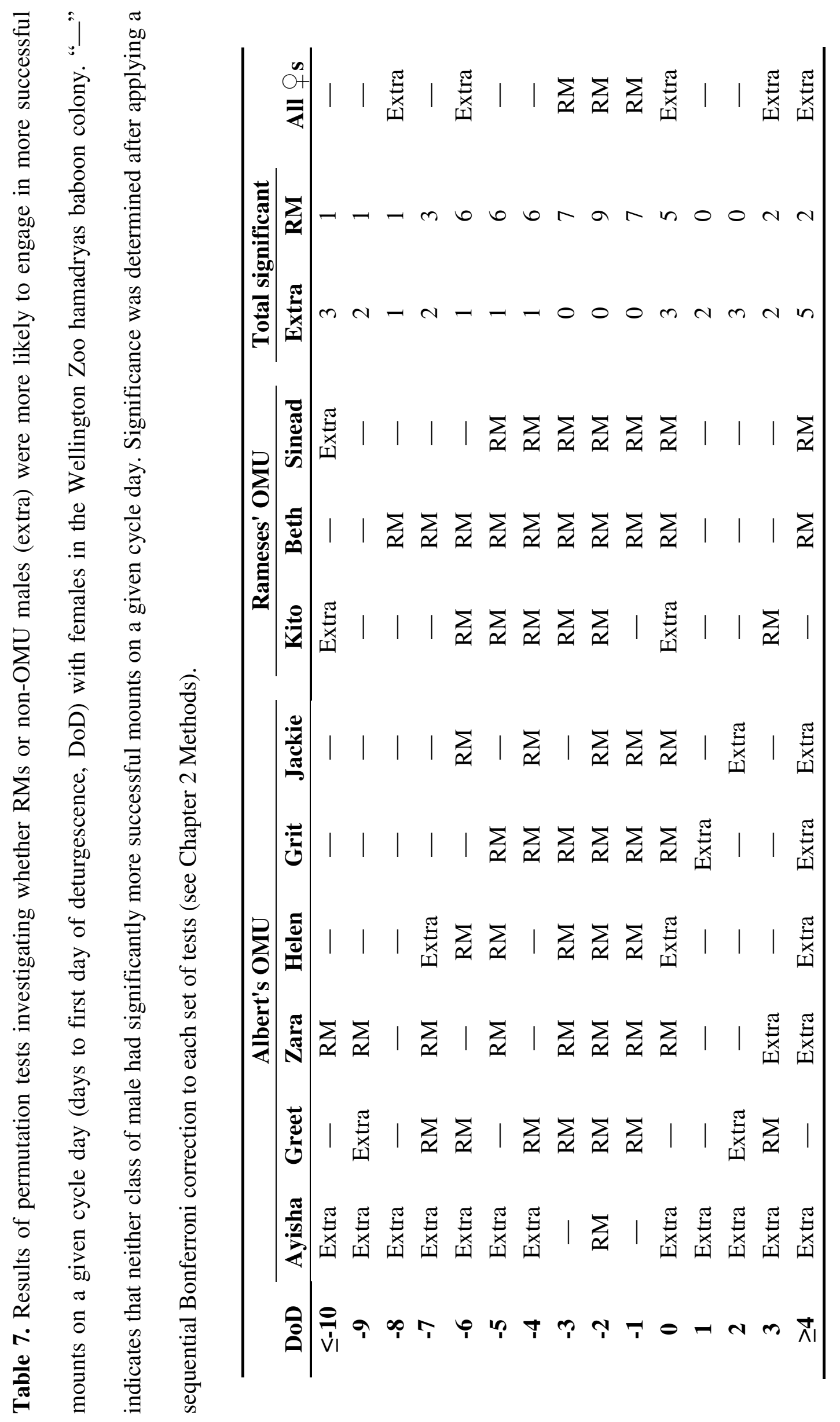



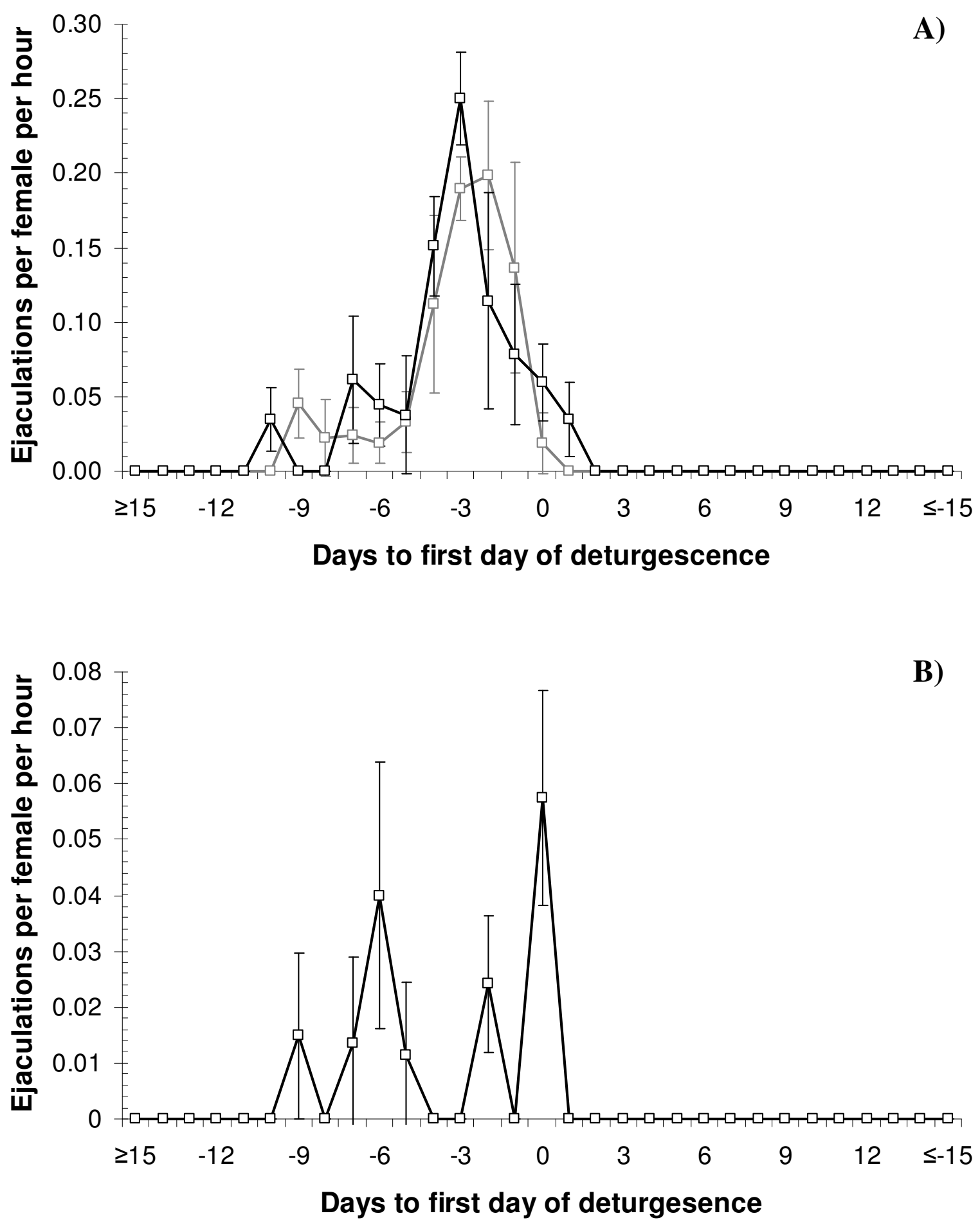

Figure 14. Average ( $\pm 1 \mathrm{SE}$ ) rate (per hour) of ejaculations received by female OMU members from A) their resident male $($ Albert = grey line, Rameses = black line $)$ and B) non-OMU males against time of ovarian cycle measured relative to the first day of perineal detumescence (day 0$)$. 


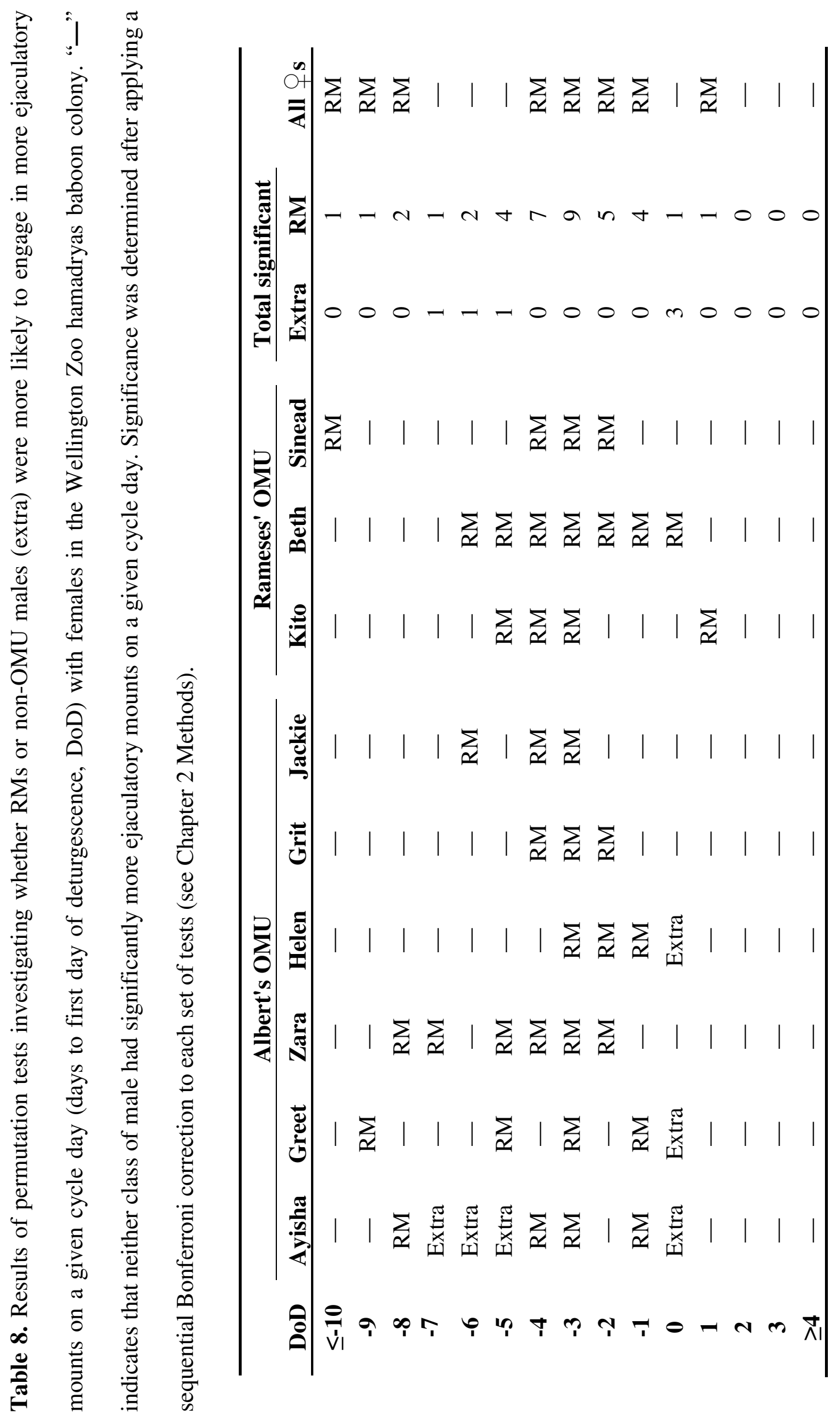


the only exception. Only three females (Ayisha, Greet and Helen) had cycle days on which non-OMU males were involved in significantly more ejaculatory mounts; specifically cycle day 0 for each female. Additionally, non-OMU males conducted the vast majority of their copulatory activities with 3 females (Ayisha, Greet and Zara); with $89.0 \%$ of attempted mounts, $91.0 \%$ of all successful mounts, and $84.6 \%$ of all ejaculations concentrated on these females. Moreover, Ayisha accounted for $62.7 \%$, $74.9 \%$ and $61.5 \%$ of all attempted, successful and ejaculatory mounts respectively, or at least 3 times more interactions for each of these behaviours than any other female in the colony. As a result, Ayisha had more attempted, successful and ejaculatory mounts with non-OMU males than with RMs, and was the only female in each instance to do so. This made Ayisha easily the most promiscuous female in the colony.

\section{Presents and perineal inspections}

Females tended to present to RMs (Figure 15A), and RMs inspect female perinea (Figure 15B), more frequently in the latter part of the turgescent phase, with the respective peaks of both behaviours occurring between cycle days -4 and -2 . NonOMU males also made the majority of their perineal inspections on cycle day -2 , and made only a third of total number of inspections made by RMs overall (Tables 5A and 5B). Females were most likely to present to non-OMU males on cycle days -6 and -8 , and did so at an intermediate level between days -5 and -1 . Additionally, females only made half the number of presents to non-OMU males than they did to their RM (Tables 5A and 5B). Overall, RMs received significantly more presents from females over cycle days -4 to -2 , and again on cycle day 3 , with neither group of males being favoured on the remaining cycle days (Table 9). Likewise, RMs made significantly 

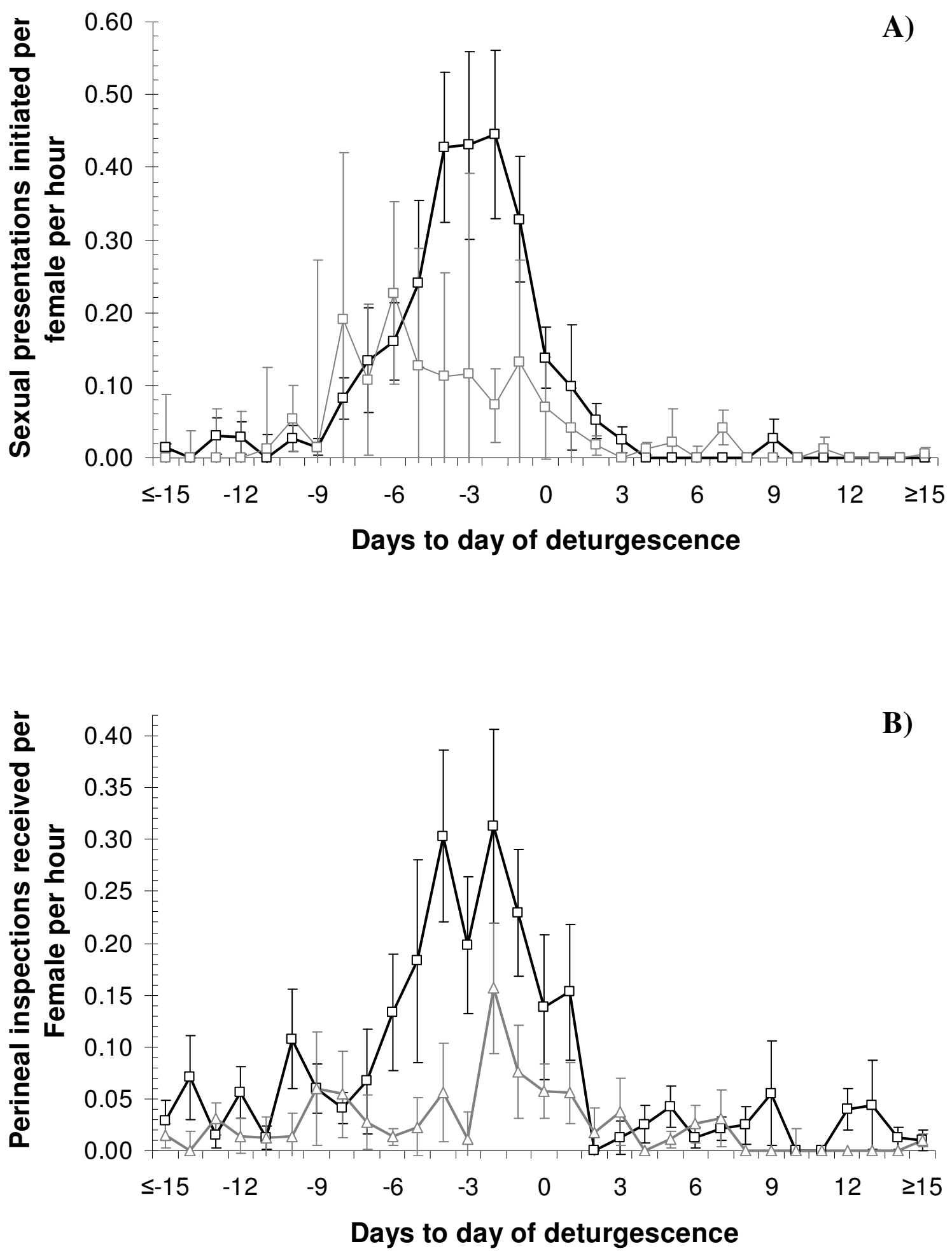

Figure 15. Average ( $\pm 1 \mathrm{SE})$ rate (per hour) of $\mathrm{A})$ sexual presentations initiated and B) perineal inspections received by female OMU members to/from their resident male (black lines) and non-OMU males (grey lines) per hour against time of ovarian cycle measured relative to the first day of perineal detumescence (day 0 ). 


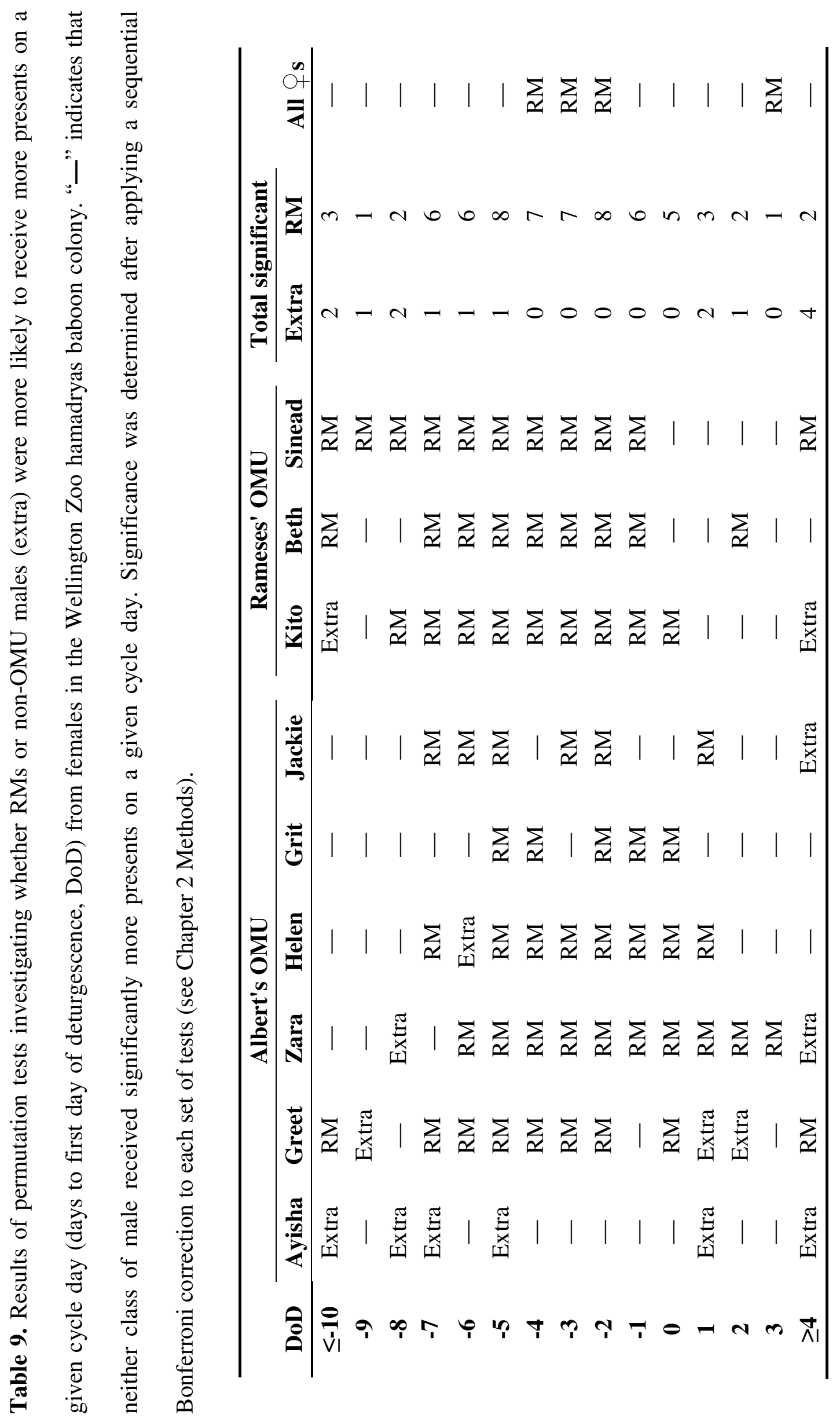


more perineal inspections during days -6 to -4 , whereas non-OMU males only did so on day 2 , with neither being preferred on all other cycle days (Table 10).

These patterns were largely borne out in individual females. At least 6 females were significantly more likely to present to their RM on each of the cycle days between -7 and -1 , with only Helen (day -6 ) and Ayisha (days -5 and -7 ) being more likely to present to non-OMU males on one or more days within this period. Similarly, at least 4 females were significantly more likely to receive perineal inspections from their RM on each of the 6 cycle days between -6 and -1 , with only Jackie (day -4), Kito (day -2) and Ayisha (days -6, -5 and -1) being more likely receive inspections from to non-OMU males on one or more days within this period. Additionally, the vast majority of presents (85.0\%) and a large proportion of perineal inspections (42.4\%) involving non-OMU males involved a single female, Ayisha. Indeed, while all other females were nearly 11 times more likely to present their RM, and nearly 5 times more likely to be inspected by their RM relative to non-OMU males on average, Ayisha was about twice as likely to present to and be inspected by non-OMU males relative to her RM.

\section{Approaches}

The number of approaches made by female OMU members to their respective RMs increased steadily towards a peak on cycle days -3 and -2 , and declined sharply thereafter (Figure 16A). Similarly, females received the majority of approaches from RMs over cycle days -3 to -1 , with a sharp peak occurring on cycle day -2 , before declining relatively rapidly either side of this period (Figure 16B). In contrast, approaches both to and from non-OMU males displayed a more bimodal pattern, with 


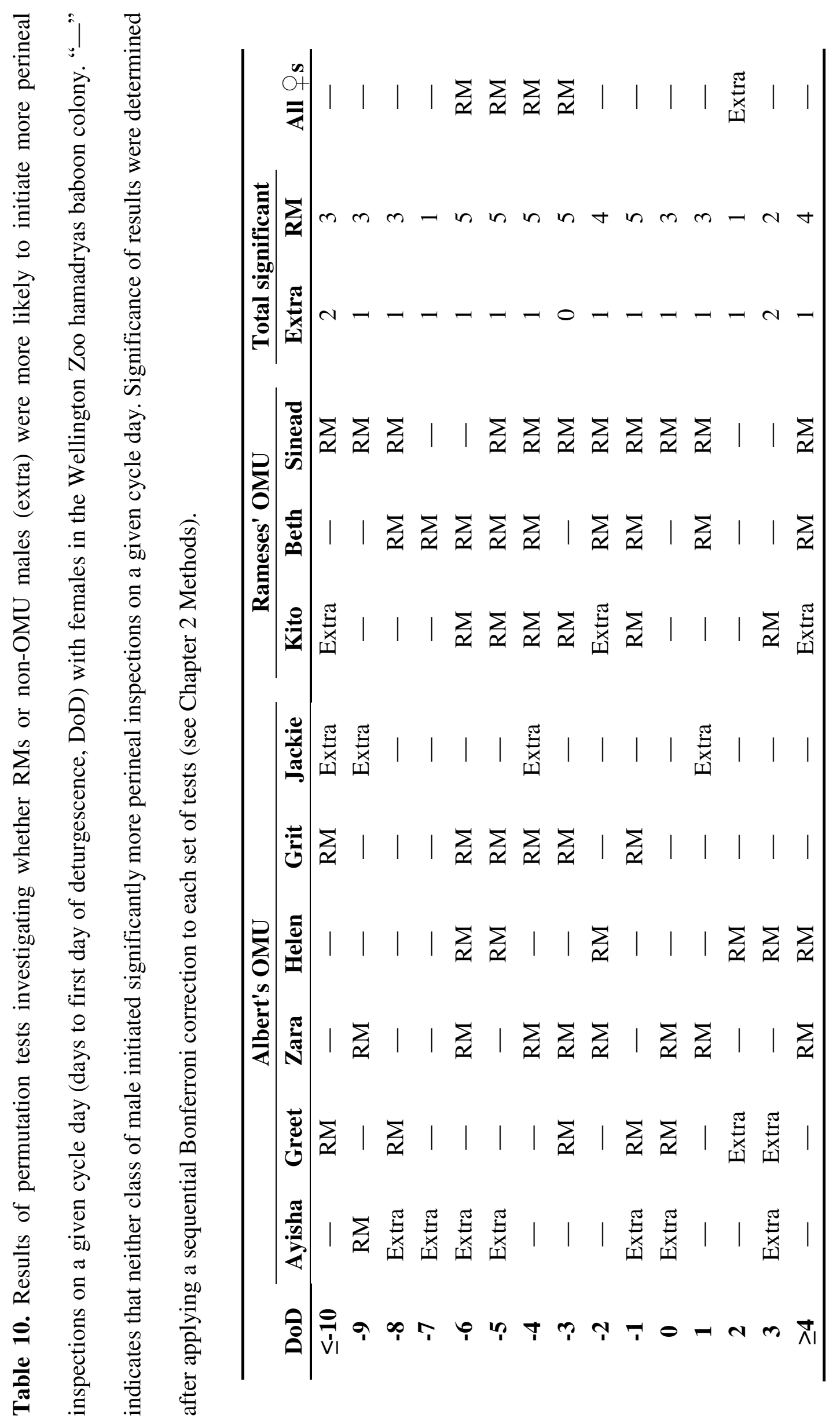



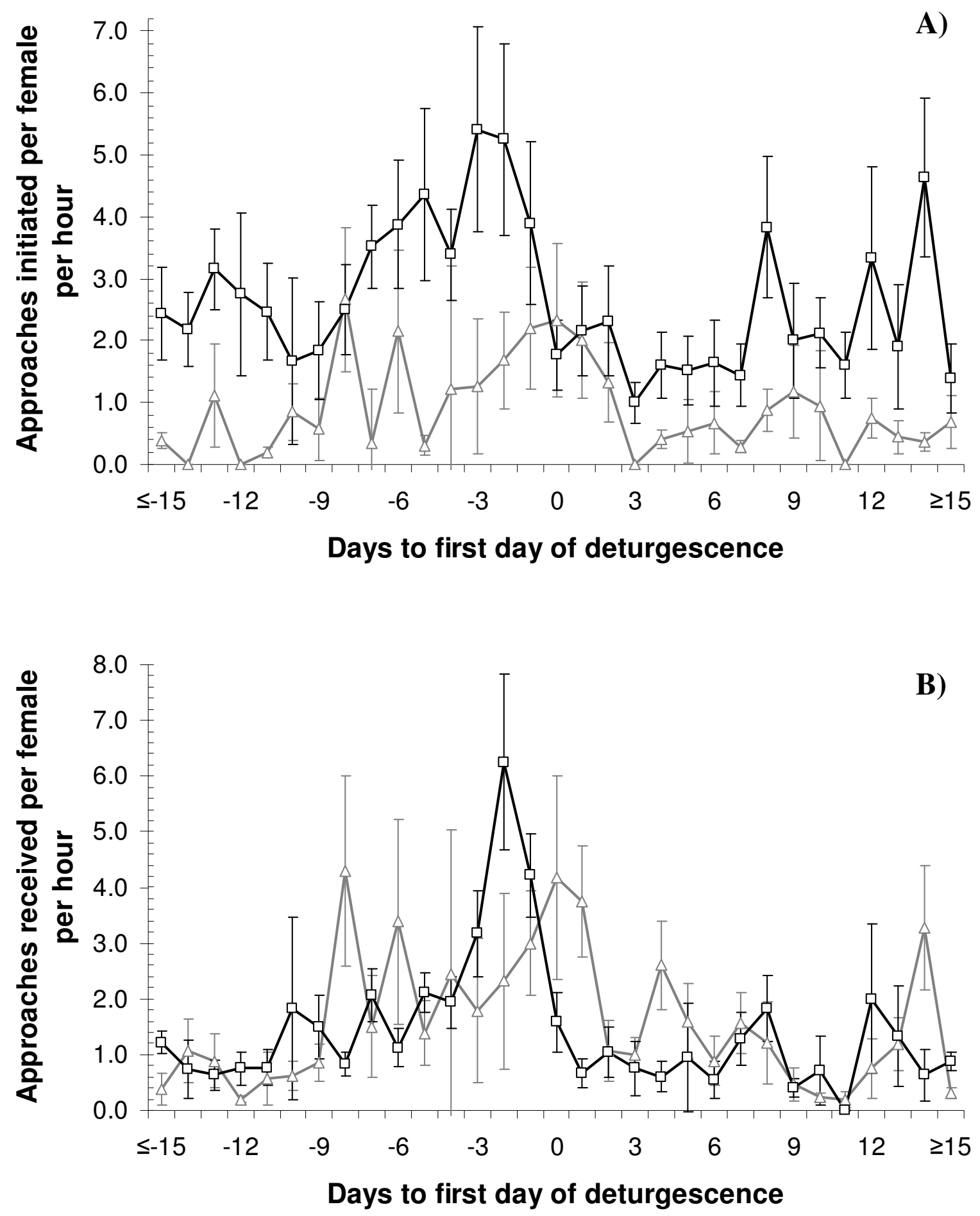

Figure 16. Average ( $\pm 1 \mathrm{SE}$ ) rate (per hour) of approaches A) initiated and B) received by female OMU members to/from their resident male (black lines) and nonOMU males (grey lines) per hour against time of ovarian cycle measured relative to the first day of perineal detumescence (day 0 ). 
sharp peaks on cycle days -8 and -6 , and a more gradual peak on day 0 (Figures 16A and 16B). Additionally, non-OMU males received exactly half the number of approaches from females as did RMs, though they were responsible for initiating more approaches than RMs overall (Tables 5A and 5B). Hence, whereas RMs received more approaches from female OMU members than they initiated, non-OMU males initiated more than they received. Overall, females were significantly more likely to approach RMs on cycle days $-5,-3$ and -2 , and RMs and non-OMU males were each more likely to approach females on a single cycle day either side of the DoD (cycle days - 9 and 3 respectively), with neither RMs nor non-OMU males being more likely to approach or be approached by females over the rest of the ovarian cycle (Tables 11 and 12);

When looking at individual females, at least 5 females approached their RM significantly more frequently over each of the four cycle day categories of the turgescent phase. Only a single female (Ayisha) was found to do so with non-OMU males, and only for the terminal category in this period (i.e.: $\leq-10$ ). The situation is similar, though less pronounced, for approaches received by females. RMs initiated significantly more approaches with at least 3 females on each cycle day during the turgescent period, with only Ayisha and Kito having significantly more approaches from non-OMU males over the same period. Additionally, a subset of females were involved in a disproportionate amount of approaches with non-OMU males, with Ayisha, Greet and Kito contributing $85.4 \%$ of all approaches to, and $76.0 \%$ of all approaches from, non-OMU males (Table 5B). Ayisha was the single largest contributor in each case, with her contribution being particularly marked for the approaches made to non-OMU males $(64.3 \%$ overall, or nearly 14 times more than any other female). 


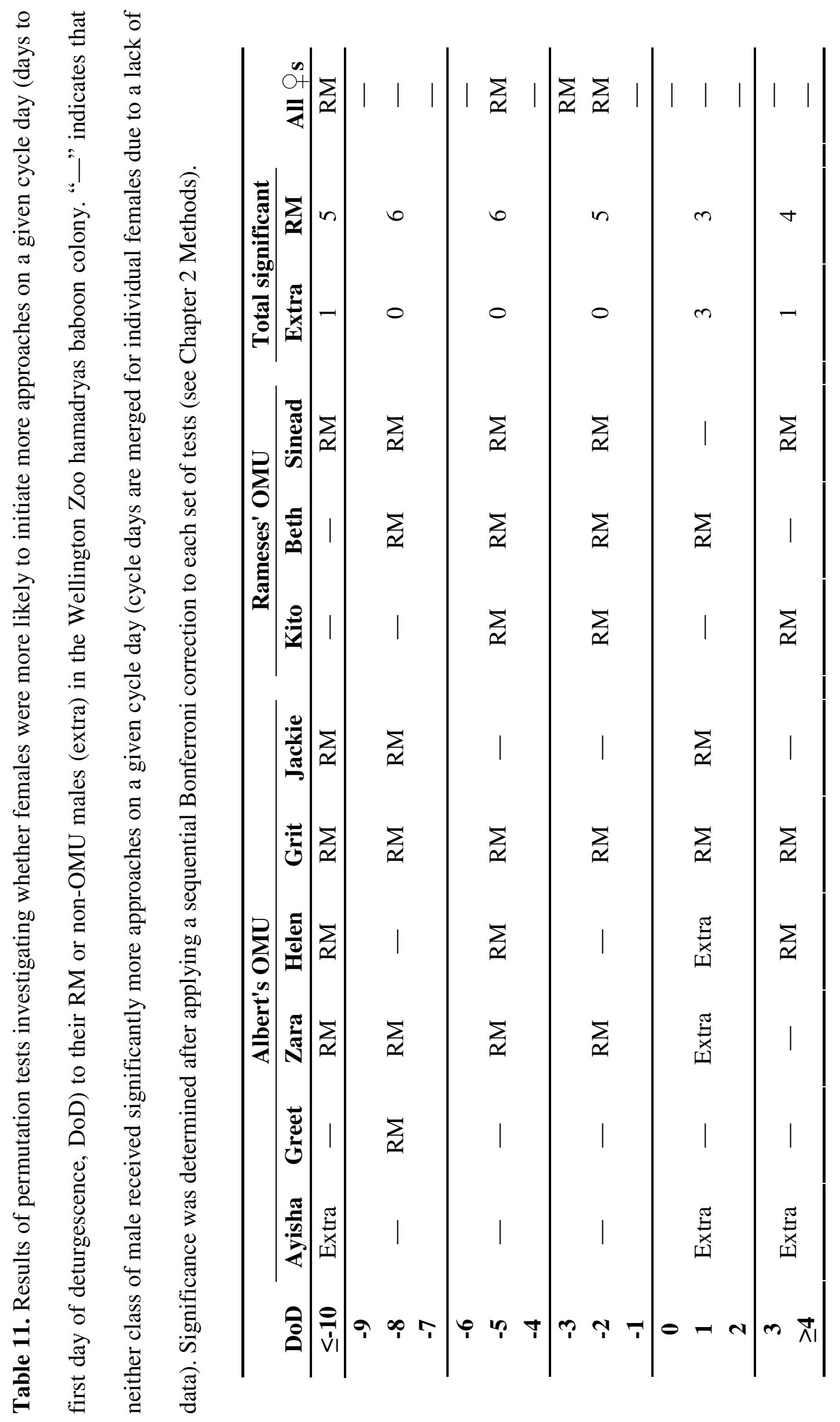




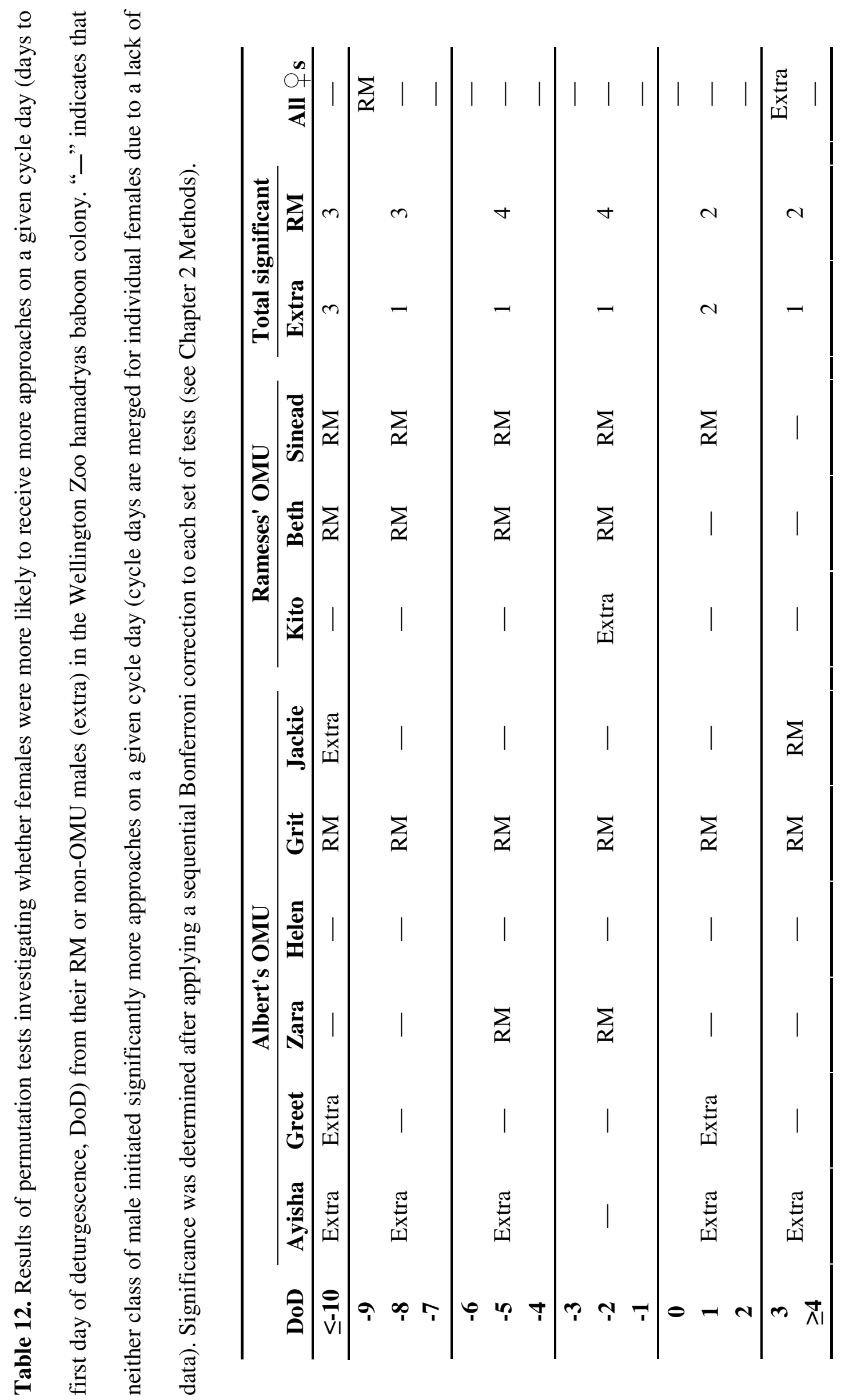




\section{DISCUSSION}

The frequency of both approach and sexual behaviours underwent consistent changes across the ovarian cycle for both sexes in the Wellington Zoo hamadryas baboon colony. The number of approaches, inspections and mounts made by males tended to increase across the turgescent phase with RMs having a distinct peak in their interactions over the final four days prior to the DoD, whereas non-OMU males tended to have majority of their interactions on the days that fell either side of this four day interval. Similarly, females were found to increase the number of approaches and presentations over the latter stages of the turgescent phase, with RMs again being the focus of most interactions over the final few days before perineal deturgescence, and non-OMU males being favoured on the days either side of this period. These patterns indicate that female receptivity (willingness of females to be engaged in sexual activity) remained steady throughout the turgescent and deturgescent phases of the cycle, whereas their attractiveness (degree of sexual stimulus to males) and proceptivity (inclination of females to seek out sexual activity) only peaked during the latter part of the turgescent period (Beach, 1976).

The patterning of sexual behaviour for both sexes in the Wellington Zoo colony is consistent with what has been reported for other baboon subspecies in both wild (Hausfater, 1975; Saayman, 1970; Seyfarth, 1978) and experimental settings (Bielert, 1986). Furthermore, Hendrikx and Kraemer (1969) reported that $48 \%$ of conceptions occurred 3 days prior to the DoD in a group of yellow and olive baboons, and Gilman and Gilbert (1946) inferred that most conceptions occurred 2 days prior to ovulation in a population of chacma baboons $(P . h$. ursinus $)$ based on backdating conceptive events. Assuming that the ovulatory patterns found in other papionin subspecies is similar for hamadryas baboons, therefore, it appears that the Wellington 
Zoo RMs were able to effectively monopolise sexual interactions with females over their optimal conceptive period (i.e.: cycle days -3 and -2 ), whereas the non-OMU males were generally only able to mate during periods where conception was less likely. Indeed, RMs were also found to dominate copulations over the period of maximal perineal turgescence, relegating non-OMU males to mating before and after this period, in a free ranging hamadryas population (Caljan et al. 1987). A similar situation is known to occur in other papionin baboons, where access to oestrus females is largely determined by inter-male competition (i.e., the priority-of-access model; Altmann, 1962). In these subspecies dominant males typically form consorts with females only towards the end of the turgescent phase, and therefore monopolise sexual activity over the optimal conceptive period, whilst the copulatory activities of subordinates are generally restricted to the non-optimal conceptive periods (Alberts et al., 2003; Altmann et al., 1996; Bulger, 1993; Gesquiere et al., 2007; Hausfater, 1975; Packer, 1979; Weingrill et al., 2003).

\section{Non-OMU male mate selection}

That non-OMU males attempted fewer mounts and had more mounts aborted and rejected over the latter part of the turgescent period suggests that the mating success of non-OMU males was simultaneously hindered by an increase in RM vigilance and a decrease in female preference for non-OMU males during this period. Moreover, Ayisha aside, females rarely solicited extra-OMU copulations and were particularly unlikely to do so during the optimal conceptive period (whole cycle average: approaches initiated $=7.00 \pm 1.90$, presents $=2.13 \pm 0.86$; average over cycle days -4 to -1 : approaches initiated $=1.38 \pm 0.84$, presents $=0.38 \pm 0.26$ ). Rather, the females that were involved in the most extra-OMU copulations tended to be the same females 
that were also approached most frequently by non-OMU males. This suggests that the majority of females were not actively seeking out extra-OMU copulations, rather, certain females appeared to have been targeted as potential copulatory partners by non-OMU males. In this case, non-OMU males may have chosen females based on their accessibility and the likelihood of their acquiescence toward extra-OMU copulations.

Non-OMU males may have preferentially targeted females that had been most recently recruited to their OMU as potential copulatory partners. Recently recruited females have been observed to be regularly threatened by pre-existing female OMU members (Gore, 1994; Kummer, 1968), and to be resistant to the herding of a new RMs (Swedell, 2006). Thus, it may take time before females are fully spatially and socially integrated into a new OMU, particularly in OMUs with more pre-existing female members. Additionally, younger females may seek to maintain bonds with members of their natal OMU and former playmates over the initial part of their OMU membership, and they are likely to be less attractive to RMs than females in their reproductive primes (females typically having low fertility in the year following menarche; Caljan et al., 1987; Swedell, 2006). Hence, both younger and more recently recruited females are likely to be more amenable, and more available, to interactions with individuals outside of their OMU than are established female OMU members in their reproductive primes.

The accessibility of female OMU members is also likely to have been affected by their repeated ovarian cycling during the study. Repeated ovarian cycling increases the probability of multiple females from the same OMU will simultaneously enter the turgescent phase of their cycle (i.e., the oestrous period), creating abnormally low intra-OMU operational sex ratios (OSR, the number of sexual available males to 
females; Emlen and Oring, 1977). Consequently, RM control is expected to be reduced and, all else being equal, extra-OMU mating opportunities are expected to increase, as the number concurrently oestrus females per OMU increase.

The findings support these ideas. Females in Albert's OMU tended to receive more approaches and mounts from non-OMU males than those in Rameses' OMU. Similarly, recently recruited and young females were the recipients of more extraOMU approaches and mounts than their prime-age and more established counterparts. Hence, the female that received the most extra-OMU approaches and mounts in the colony, Ayisha, was a young female member and a recent recruit of Albert's OMU, which also maintained the lower average OSR of the two OMUs. Similarly, the recipient of the most extra-OMU approaches and mounts in Rameses' OMU was Kito, who also happened to be its youngest member and a recent recruit (both Ayisha and Kito were recruited less than 12 months prior to the commencement of behavioural sampling according to observations from Zoo staff). After Ayisha, the next most promiscuous female OMU members in the colony were Zara and Greet, who were both recruited into Albert's OMU following the death of their previous RM eight months before the commencement of behavioural sampling (November 2007). Notably, Sinead, who was also a former member of the dissolved OMU that contained Zara and Greet, was the recipient of very few approaches or mounts by non-OMU males, despite being recruited at the same time as these females. That Sinead was one of only two prime-age females in Rameses' OMU, however, suggests that she was probably less able, and potentially less inclined, to seek out extra-OMU copulations than either Zara or Greet. In contrast, all other female OMU members were of prime reproductive age (or post-reproductive in Tina's case) and had been part of their OMUs for at least 4 years (Fletcher, 2003). Hence, it appears that non-OMU males 
sought sexual interactions with females based on their degree of accessibility in the Wellington Zoo hamadryas colony.

\section{Non-OMU male mating success}

Despite the best efforts of non-OMU males, there had been no recorded pregnancies or births in the Wellington Zoo hamadryas colony for at least 3 years prior to the end of the present study. Hence, the vasectomisation of all RMs in the Wellington Zoo colony appears to have been an effective population control measure. In contrast, Zinner et al. (2006) found that extra-OMU mating was highly successful in the Cologne Zoo hamadryas population, where all RMs, and several non-OMU males, had also been vasectomised to control population growth. Non-OMU males were thought to be responsible for 121 conceptions in 14 out of the 18 OMUs that were present during the 10 year study period, with males as young as 3 years of age being implicated in some of these conceptions.

All ejaculatory mounts made by non-OMU males at the Wellington Zoo colony either involved Taila, Les or Rafiki (4, 5 and 4 ejaculatory mounts respectively), each of whom were old enough to be producing viable sperm at the time of the study (Zinner et al., 2006). Rafiki and Les were both observed having ejaculatory mounts in and around optimal conceptive period, all involving either Ayisha or Kito. Both of these females were nulliparous at the time of the study and were likely to have undergone menarche approximately 33 months and 25 months prior to the start of behavioural sampling respectively (based on average age of menarche being 3 years old in captive populations (Asanov, 1972; Kaumanns et al., 1989). In most cases captive female hamadryas baboons are able to conceive within a 
year of menarche, though inevitably their first few observed pregnancies die perinatally (Asanov, 1972; Kaumanns et al., 1989; Sigg et al., 1982). Therefore, while both Ayisha and Kito are likely to be fertile, they are also more likely than mature females to have failed pregnancies, and may be aborting foeti before they could be detected. Taila, on the other hand, did have ejaculatory mounts with parous females (Greet and Zara), one of which occurred inside of the optimal conceptive period. However, it is possible that Taila's sperm production may have been affected by the implant he received shortly before the study commenced - this being one of the documented effects of the implant in dogs (Junaidi et al., 2003) - effectively rendering him infertile during the study.

Another possibility is suggested by several recorded observations of RMs mounting females immediately after having detected an extra-OMU mount. This may allow RMs to remove any previous ejaculatory deposits from other males, or prevent the formation of a copulatory plug. Alternatively, should RMs go on to ejaculate, this would then allow RMs to engage in sperm competition. Although this was not observed to happen during the initial mount, this may have occurred on subsequent mounts. Taken together, it appears that a combination of female infertility, a lack of sexual access to females during their peak receptive period, and the copulatory countermeasures of RMs were sufficient to prevent extra-OMU conceptions in the Wellington Zoo colony.

\section{Function of extra-OMU mating}

The high number of simultaneously oestrus females in an OMU at any given time in the Wellington Zoo colony is expected to negatively affect the ability of RMs to 
monopolise females and to create opportunities for extra-OMU copulations. This is expected to allow females to express alterative reproductive strategies, such as female choice (both pre- and post-copulatory), should these exist. However, female OMU members tended to be passive participants, rather active solicitors, of extra-OMU copulations. This indicates that females did not generally seek to exploit the expected increase in extra-OMU copulatory opportunities (Ayisha being a notable exception). Moreover, the finding that females were most likely to reject males during the optimal conceptive period suggests that they may have been actively inhibiting, as opposed to enhancing, the opportunities for extra-OMU paternity. Even Ayisha was more likely to reject non-OMU males over this period, albeit at a lower rate than other females. Hence, female choice does not appear to have been the primary function of extraOMU mating in the colony.

These patterns also appear inconsistent with a fertility insurance strategy, which entails that females engage in extra-OMU copulations to ensure conception when RMs are likely to be experiencing sperm depletion. Notably, the RM who had twice as many cycling females in his OMU (Albert) also had twice the number of ejaculatory mounts. This suggests that the RMs in the Wellington Zoo colony may have been modifying their copulatory activities in direct response to the number of concurrently oestrus females in their OMU. Whether this would have resulted in all female OMU members being successfully fertilised by their respective RMs were they not vasectomised, however, is unknown. Moreover, in addition to the general apathy exhibited by females towards extra-OMU mating, the females that received the fewest ejaculatory mounts from their RM also tended to make fewer approaches and presents to, and have fewer attempted mounts with, non-OMU males. Consequently, it appears 
unlikely that extra fertility insurance was an important determinant of extra-OMU mating in the Wellington Zoo hamadryas colony.

Alternatively, the offspring of female hamadryas baboons are known to be vulnerable to infanticide (Kaumanns et al., 1989; Swedell, 2000, 2006; Swedell and Tesfaye, 2003; Zinner et al., 1993), particularly following the usurpation of the RM by another male (Swedell, 2000, 2006). Thus, the extra-OMU copulations may have represented a possible female counterstrategy to male-induced infanticide. Indeed, the copulatory patterns observed in the colony bear some resemblance to the dual paternity concentration/confusion anti-infanticide strategy outlined by van Schaik et al. (2000): RMs gained the majority of copulations over the conceptive period, favouring them to protect any resultant offspring (i.e., paternity concentration), whilst copulations with potentially infanticidal non-OMU males mostly occurred outside of this period, thereby conferring these males with some chance of paternity (i.e., paternity confusion).

That both RMs were in their physical prime, however, whilst all non-OMU males in the colony were yet to reach physical maturity, raises questions about why females were prepared to risk RM retaliation by mating with males that presumably posed little threat as potential usurpers in the near future. Notably, unpredictable events such as predation, illness, and injury may lead to the subsequent usurpation or replacement of a previously healthy RM. Such cases have been reported in wild hamadryas populations, with a suspected infanticide having followed one such instance (Swedell 2006). This suggests that extra-OMU copulations will typically always have some value for hamadryas females. Thus, while the apparently low infanticide risk in the Wellington Zoo colony implies that females should have been less inclined to risk RM reprisal by actively soliciting extra-OMU copulations, they 
should still be willing to engage in extra-OMU copulations when the risk of detection from their RM was low. Indeed, this appears to have been the case in the colony, where the presence of multiple concurrently cycling females meant that the chances of a RM detecting extra-OMU copulations was likely to have been considerably lower than that expected in wild populations. Moreover, this scenario also suggests that extra-OMU mating frequency in the colony was largely determined by how often females were 'targeted' as a mate by non-OMU males and, therefore, may help explain the large variation in inter-female extra-OMU mating rate within the colony.

\section{Conclusion}

The present study adds to the limited information that is currently available on the patterning of hamadryas sexual behaviour in relation to the ovarian cycle. Overall, there were three main findings that emerged from this study; 1) that both sexual and approach behaviours were strongly correlated with the current status of the ovarian cycle for both sexes of hamadryas baboons, 2) that RMs and non-OMU males had differential sexual access to females that was dependent on the stage of the ovarian cycle, and 3) that these patterns favour RMs having the majority of conceptions and were consistent with an anti-infanticide strategy, but not female choice and fertility insurance. Furthermore, the vasectomisation of RMs appeared to be an effective strategy for controlling population growth in the Wellington Zoo. However, because this type of treatment results in all mature females undergoing uninterrupted ovarian cycling, there is ample scope for extra-OMU conceptions in the future, as was the case in the Cologne Zoo colony (Zinner et al., 2006). Finally, while I have attempted to interpret the data with the broader reproductive patterns of hamadryas baboons in mind, the small size of the group and artificial setting place serious constraints on the 
general applicability of these interpretations. Hence, there remains a great need for data to be collected from wild populations in the future so that complexities of hamadryas reproductive behaviour can continue to be elucidated.

\section{REFERENCES}

Abegglen JJ. 1984. On Socialization in Hamadryas Baboons. London: Associated University Presses.

Alberts SC, Watts HE, Altmann J. 2003. Queuing and queue-jumping: long-term patterns of reproductive skew in male savannah baboons, Papio cynocephalus. Animal Behaviour 65:821-840.

Altmann J. 1974. Observational study of behaviour: Sampling methods. Behaviour 49:227-267.

Altmann J, Alberts SC, Haines SA, Dubach J, Muruthi P, Coote T, Geffen E, Cheesman DJ, Mututua RS, Saiyalel SN. Behavior predicts genetic structure in a wild primate group; 1996. National Academy of Sciences. p 5797-5801.

Altmann SA. 1962. A field study of the sociobiology of rhesus monkeys, Macaca mulatta. Annals of the New York Academy of Sciences 102:338-435.

Aranda JD, Brindle E, Carey KD, Rice K, Tatar M, O'Connor KA. 2006. Sexual swelling relative to occurrence and timing of ovulation in Papio sp. American Journal of Physical Anthropology (Supplement) 42:57.

Asanov SS. 1972. Comparative features of the reproductive biology of hamadryas baboons (Papio hamadryas), grivet monkeys (Cercopithecus aethiops) and rhesus monkeys (Macaca mulatta). Acta Endocrinologica Supplementum $166: 458-471$. 
Beach FA. 1976. Sexual attractivity, proceptivity, and receptivity in female mammals. Hormones and Behavior 7:105-138.

Bielert C. 1986. Sexual interactions between captive adult male and female chacma baboons (Papio Ursinus) as related to the females menstrual cycle. Journal of Zoology 209:521-536.

Bulger JB. 1993. Dominance rank and access to estrous females in male savanna baboons. Behaviour 127:67-103.

Caljan VG, Meishvili NV, Vancatova MA. 1987. Sexual behaviour of hamadryas baboons. Anthropologie 25:183-187.

Dixson AF. 1983. Observations on the evolution and behavioral significance of “sexual skin" in female primates. In: Rosenblatt JS, Hinde RA, Beer C, Busnel M-C, editors. Advances in the Study of Behaviour. New York: Academic Press. p 63-106.

Dixson AF. 1998. Primate Sexuality: Comparative Studies of the Prosimians, Monkeys, Apes, and Human Beings. Oxford University Press.

Fletcher N. 2003. An analysis of aggressive behaviour in the hamadryas baboons at Wellington Zoo. [Bachelor of Science (Honours)]: Massey University.

Gesquiere LR, Wango EO, Alberts SC, Altmann J. 2007. Mechanisms of sexual selection: Sexual swellings and estrogen concentrations as fertility indicators and cues for male consort decisions in wild baboons. Hormones and Behavior $51: 114-125$.

Gillman J, Gilbert C. 1946. The reproductive cycle of the chacma baboon (Papio ursinus) with special reference to the problems of menstrual irregularities as assessed by the behaviour of the sex skin. South African Journal of Medical Science (Supplement) 11:1-54. 
Girolami L, Bielert C. 1987. Female perineal swelling and its effects on male sexual arousal - an apparent sexual releaser in the chacma baboon (Papio ursinus). International Journal of Primatology 8:651-661.

Gore MA. 1994. Dyadic and triadic aggression and assertiveness in adult female rhesus monkeys, Macaca mulatta, and hamadryas baboons, Papio hamadryas. Animal Behavior 48:385-392.

Hausfater G. 1975. Dominance and Reproduction in Baboons (Papio cynocephalus): A Quantitative Analysis. Basel, New York: S. Karger.

Hendrickx AG, Kraemer DC. 1969. Observations on the menstrual cycle, optimal mating time and pre-implantation embryos of the baboon, Papio anubis and Papio cynocephalus. Journal of Reproduction and Fertility (Supplement) 6:119-128.

Higham JP, MacLarnon AM, Ross C, Heistermann M, Semple S. 2007. Baboon sexual swellings: Information content of size and color. Hormones and Behavior 53: 452-462.

Holm S. 1979. A simple sequentially rejective multiple test procedure. Scandinavian Journal of Statistics 6:65-70.

Jolly CJ, Phillips-Conroy JE. 2003. Testicular size, mating system, and maturation schedules in wild anubis and hamadryas Baboons. International Journal of Primatology 24:125-142.

Jolly CJ, Phillips-Conroy JE. 2006. Testicular size, developmental trajectories, and male life history strategies in four baboon taxa. In: Swedell L, Leigh SR, editors. Reproduction and Fitness in Baboons: Behavioral, Ecological, and Life History Perspectives: Springer. 
Junaidi A, Williamson PE, Cummins JM, Martin GB, Blackberry MA, Trigg TE. 2003. Use of a new drug delivery formulation of the gonadotrophin-releasing hormone analogue Deslorelin for reversible long-term contraception in male dogs. Reproduction, Fertility and Development 15:317-322.

Kaumanns W, Rohrhuber B, Zinner D. 1989. Reproductive parameters in a newly established colony of hamadryas baboons (Papio hamadryas). Primate Report 24:25-33.

Kummer H. 1968. Social Organization of Hamadryas Baboons: A Field Study. Chicago: University of Chicago Press.

Kummer H. 1995. In quest of the sacred baboon: a scientist's journey. Princeton, NJ: Princeton University Press.

Kummer H, Götz W, Angst W. 1974. Triadic differentiation: An inhibitory process protecting pair bonds in baboons. Behaviour 49:62-87.

Manly BFJ. 2006. Randomization, Bootstrap and Monte Carlo Methods in Biology. Chapman \& Hall/CRC.

Nunn CL. 1999. The evolution of exaggerated sexual swellings in primates and the graded-signal hypothesis. Animal Behaviour 58:229-246.

Packer C. 1979. Male dominance and reproductive activity in Papio anubis. Animal Behavior 27:37-45.

Saayman GS. 1970. The menstrual cycle and sexual behaviour in a troop of free ranging chacma baboons (Papio ursinus). Folia Primatologica 12:81-110.

Seyfarth RM. 1978. Social relationships among adult male and female baboons. 1. behavior during sexual consortship. Behaviour 64:205-226. 
Shaikh AA, Shaikh SA, Celaya CL, Gomez I. 1982. Temporal relationship of hormonal peaks to ovulation and sex skin deturgescence in the baboon. Primates 23:444-452.

Sigg H, Stolba A, Abegglen JJ, Dasser V. 1982. Life history of hamadryas baboons: Physical development, infant mortality, reproductive parameters and family relationships. Primates 23:473-487.

Stammbach E. 1987. Desert, forest and montane baboons: Multilevel-societies. In: Smuts BB, Cheney DL, Seyfarth RM, Wrangham RW, Struhsaker TT, editors. Primate Societies: University of Chicago Press.

Stevens VC. 1997. Some reproductive studies in the baboon. Human Reproduction Update 3:533-540.

Swedell L. 2000. Two takeovers in wild hamadryas baboons. Folia Primatologica 71:169-172.

Swedell L. 2006. Strategies of Sex and Survival in Hamadryas Baboons: Through a female lens. Sussman RW, Vasey N, editors. Upper Saddle River, NJ: Pearson Prentice Hall.

Swedell L, Tesfaye T. 2003. Infant mortality after takeovers in wild Ethiopian hamadryas baboons. American Journal of Primatology 60:113-118.

van Schaik CP, Hodges JK, Nunn CL. 2000. Paternity confusion and the ovarian cycles of female primates. In: Janson $\mathrm{CH}$, Van Schaik CP, editors. Infanticide by Males and its Implications. Cambridge: Cambridge University Press. p $361-387$.

Weingrill T, Lycett JE, Barrett L, Hill RA, Henzi SP. 2003. Male consortship behaviour in chacma baboons: The role of demographic factors and female conceptive probabilities. Behaviour 140:405-427. 
Wildt DE, Doyle LL, Stone SC, Harrison RM. 1977. Correlation of perineal swelling with serum ovarian hormone levels, vaginal cytology, and ovarian follicular development during the baboon reproductive cycle. Primates 18:261-270.

Zinner D, Kaumanns W, Rohrhuber B. 1993. Infant mortality in captive hamadryas baboons (Papio hamadryas). Primate Report 36:97-113.

Zinner D, Krebs E, Schrod A, Kaumanns W. 2006. Early sexual maturity in male Hamadryas Baboons (Papio hamadryas hamadryas) and its reproductive implications. American Journal of Physical Anthropology 129:584-590.

Zinner D, Schwibbe MH, Kaumanns W. 1994. Cycle synchrony and probability of conception in female hamadryas baboons Papio hamadryas. Behavioral Ecology and Sociobiology 35:175-183. 


\title{
Chapter 4: No evidence for ovarian synchrony or
}

\section{asynchrony in hamadryas baboons}

\begin{abstract}
The tendency for females to synchronise some part of their ovarian cycles, i.e., ovarian synchrony, has been reported in several species, including hamadryas baboons. However, ovarian synchrony remains contested on several grounds and its benefits have yet to be demonstrated for hamadryas baboons, although significant fitness costs have been reported. Here I present 12 months of ovarian cycle data for 10 females in a captive hamadryas baboon colony that have been undergoing repeated cycling due to male contraception. A permutation test was used to examine whether ovarian cycles were more synchronous or asynchronous than expected due to chance for each pair of females, and females grouped by their one-male unit (OMU) and across the colony as a whole. No pairing or group of females were found to synchronise or asynchronise their ovarian cycles. Rather females oscillated between pseudo-synchronous and pseudo-asynchronous states due to intra- and interfemale variability in ovarian cycle length. Previous reports of ovarian synchrony appear to have been due to females resuming cycling at the same time as other female OMU members, short co-cycling periods amongst female OMU members and lengthy turgescent phases. I suggest that the nature of hamadryas social and breeding systems have meant that mathematically 'true' synchrony over multiple ovarian cycles is unlikely to have evolved in this species. Hamadryas females still appear to be able to coordinate their ovarian cycles over shorter time scales, however, which may benefit females by facilitating a paternity confusion strategy.
\end{abstract}




\section{INTRODUCTION}

Ovarian synchrony, the tendency for group-living females to coordinate the timing of ovarian cycle events, has been reported in a number of species including human (e.g.: McClintock, 1971; Weller and Weller, 1993, 1997) and non-human primates (chimpanzees, Pan troglodytes, Wallis, 1985; and gold lion tamarins, Leontopithecus rosalia, French and Stribley, 1987). Unlike breeding synchrony, which is suggested to benefit females by synchronising the subsequent timing of births, ovarian synchrony is purported to benefit females by synchronising their receptive periods and thereby limiting the degree to which they can be monopolised by dominant males (Colinshaw and Dunbar, 1991; Emlen and Oring, 1977; Kutsukake and Nunn, 2006; Paul, 1997; Ridley, 1986; Shuster and Wade, 2003; Soltis et al., 2001). This may enable females to pursue alternative mate choices, facilitate an anti-infanticide strategy or cryptic female choice, or increase paternal investment by decreasing the probability of males obtaining multiple mates (Eberhard, 1996; Hrdy, 2000; Knowlton, 1979).

However, ovarian synchrony may also lead to situations where males become the limiting sex (i.e.: a female-biased operational sex ratio, OSR; Emlen and Oring, 1977), whereby male choice and female-female competition are expected to determine which females are able to mate (Kvarnemo and Ahnesjo, 1996; Trivers, 1972). In these situations less competitive and less attractive females may be restricted from mating with high quality males or from acquiring multiple mates, thereby compromising female mate choice as well as paternity confusion and cryptic choice strategies. Additionally, female-biased OSRs may also result in higher incidences of coercive copulations involving lower ranked males because such males are less likely 
to be excluded from the breeding pool by dominant males under these conditions (Matsumoto-Oda et al., 2007).

Females may actually be better served, therefore, by avoiding ovarian synchrony in situations where the number of adult males is low (Dixson, 1998; Ims, 1990; Schank, 2004). Indeed, ovarian asynchrony (the staggering of receptive periods) has been reported in a handful of species (e.g.: Golden Hamsters, Mesocricetus auratus, Gattermann et al., 2002; Chimpanzees, Pan troglodytes schweinfurthii, Matsumoto-Oda et al., 2007; Ringtailed Lemurs Lemur catta, Pereira, 1991), and may be more common than previously supposed. Furthermore, it has been suggested that relatively lengthy and variable ovarian cycles that are typical of mammalian species may have evolved primarily to allow females to avoid ovarian synchrony and the high costs associated with it (Schank, 2001b, 2004; Yang and Schank, 2006).

Adult female baboons exhibit cyclic changes in perineal turgescence during the ovarian cycle which is positively correlated the timing of ovulation (Hendrickx and Kraemer, 1969; Shaikh et al., 1982; Wildt et al., 1977) and coincides with the oestrus period (Chapter 2). Females hamadryas baboons (Papio h. hamadryas) from the same one-male unit (OMU; i.e.; a single adult male, resident male (RM) and one or more adult females) were found to have a higher degree of overlap in the turgescent phase of their ovarian cycles (i.e., ovarian synchrony) than could be explained by chance alone in one captive (Schwibbe et al., 1992; Zinner et al., 1994) and one wild (Kummer, 1968) population. That ovarian synchrony was only found amongst females from the same OMU, which is the smallest grouping within a larger hierarchical society, suggests that its potential function occurs at the OMU level. Ovarian synchrony may assist hamadryas females by counteracting the ability of RMs 
to monopolise them, thereby enabling them to pursue intra-OMU mating opportunities (Kummer, 1995; Smith et al., 1999; Zinner et al., 2006; Zinner et al., 1994).

Increases in number of simultaneously oestrus females in an OMU have also been found to result in lower rates of conception (Zinner et al., 1994) and higher rates of aggression (Plowman et al., 2005) in hamadryas populations. Female competition for access to the RM is expected be positively correlated with the number of simultaneously oestrus females in an OMU, as the RM and his sperm supply become increasingly limited resources (hamadryas baboons having smaller testes than other baboons (Jolly and Phillips-Conroy, 2003, 2006)). Therefore, the relative merits of ovarian synchrony may decrease as the number of simultaneously oestrus females in an OMU increases and asynchrony may represent a better strategy for hamadryas females in large OMUs.

Here I present 12 months of ovarian cycle data taken from a captive hamadryas baboon population in which all adult females have undergone repeated cycling since March 2005 due to RM vasectomisation. A purpose-built permutation model is used to test whether females had significantly synchronised or asynchronised ovarian cycles at the colony, OMU and pair-wise level. In the light of these findings, I discuss the potential for ovarian synchrony or asynchrony to have evolved within hamadryas baboons and the potential function that this trait may serve.

\section{METHODS}

\section{Subjects}

At the time of the study the Wellington Zoo colony comprised 3 adult males, 10 adult females, and 7 pre-adult members (Table 13). All adult females were members of one 
Table 13. The demographic profile of the Wellington Zoo hamadryas baboon colony at the time of the study. Resident males are indicated by bold text. The list is organised by OMU affiliation, with OMU-affiliated females and individuals not affiliated to an OMU arranged from oldest to youngest in descending order. All animals were born in Wellington Zoo unless otherwise noted. See Appendix 1 for description of age and sex classes.

\begin{tabular}{lcccc}
\hline \multicolumn{1}{c}{ Name } & Sex & D.O.B. & OMU & Age Class \\
\hline Rameses & M & 11.Oct.95 & Rameses & Adult \\
Tina $\dagger$ & F & 18.Apr.79 & Rameses & Adult \\
Sinead & F & 29.Jan.93 & Rameses & Adult \\
Beth & F & 4.Jun.94 & Rameses & Adult \\
Kito & F & 21.May.02 & Rameses & Adult \\
Albert & M & 24.Jun.95 & Albert & Adult \\
Jackie† & F & 17.Oct.86 & Albert & Adult \\
Grit* & F & 1.Jan.88 & Albert & Adult \\
Helen* & F & 3.Oct.92 & Albert & Adult \\
Zara & F & 21.Sep.94 & Albert & Adult \\
Greet* & F & 16.Sep.96 & Albert & Adult \\
Ayisha & F & 4.Sep.01 & Albert & Adult \\
Carter & M & 14.May.93 & None & Adult \\
Taila & M & 2.Oct.01 & None & Subadult \\
Les & M & 19.Sep.02 & None & Large juvenile \\
Rafiki & M & 24.Sep.03 & None & Medium juvenile \\
Macey & F & 13.Mar.04 & None & Medium-large juvenile \\
Habib & M & 7.Dec.04 & None & Medium juvenile \\
Abeba & F & 24.Dec.04 & None & Medium-large juvenile \\
\hline
\end{tabular}

* Introduced from Melbourne Zoo, Australia, on $12^{\text {th }}$ January 1988.

$\dagger$ Introduced from Dierenpark Emmen, the Netherlands, on $7^{\text {th }}$ June 2001. 
of the two OMUs, which comprised 6 and 4 females respectively. Membership in both OMUs remained unchanged throughout the study period. Additionally, another female, Macey, began exhibiting regular perineal swellings on the 26th of August 2007, and had undergone four complete cycles by the end of the study. However, despite being post-menarchal, Macey had not been incorporated into either of the existing OMUs by the end of the study, nor had she formed a new OMU with an unattached male. Because Macey remained unattached to any OMU during the study, she is omitted from subsequent analyses where OMU membership is included as a factor. Additionally, an adult female member of Rameses' OMU, Tina, had not exhibited any signs of perineal turgescence since initial observations began in November 2006 and was, therefore, presumed to have been post-menopausal. Hence, Tina is also omitted from all subsequent analyses.

\section{Housing}

Since March 2000 the colony has resided in a purpose-built 0.25 ha naturalistic outdoor enclosure. This enclosure contains a number of trees, rocks, logs and open grassed areas, and is surrounded on all sides by a 3 metre tall chain-link wire fence. A $6 \times 4$ metre sleeping den adjoins the northern-western section of the enclosure. Access to the sleeping den was restricted between the daily feeding times, which occurred at approximately 10 a.m. and 3 p.m., unless it was wet or cold. The public viewing area is located on the western side of the enclosure, with a 7 metre long glass wall forming part of the perimeter fence at this point to assist in viewing. The eastern perimeter of the enclosure adjoins a public park, with the remainder being bordered by other zoo exhibits. In August 2007 an electric fence that ran parallel with the northern and eastern sections of the perimeter fence was installed inside the enclosure in order to 
protect several newly planted saplings. This reduced the area of the enclosure that is accessible to the baboons to approximately 0.2 hectares.

\section{Contraceptive treatments}

In order to control population growth within the colony the two RMs (along with another RM who died in November 2006) were vasectomised in October 2004. A further adult male (Carter, Table 3) was castrated as a juvenile and had not developed the characteristic mantle of adult hamadryas males, nor acquired an OMU of his own. Additionally, a subadult male (Taila) received a hormonal castration treatment (Suprelorin ${ }^{\circledR}$, a gonadotrophin-releasing hormone agonist produced by the Peptech corporation) in October 2006, after he was observed mating with females. No pregnancies or births had been observed in the colony from March 2005 until the completion of the study in February 2008. Hence, 3 out of the 4 females in Rameses OMU (excluding Tina), and all 6 females in Albert's OMU, had been undergoing repeated ovarian cycling from at least March 2005 until the end of the present study (including Macey from late August).

\section{Ovarian cycles}

Observations on the status of perineal turgescence (inflating, deflating or flat) were made daily for all mature, fertile females in the Wellington Zoo colony over a 366 day period between the $2^{\text {nd }}$ of February 2007 and the $2^{\text {nd }}$ of February 2008. All observations were made from the public viewing area located at the eastern side of the enclosure. Ovarian cycle parameters were categorised as follows. 
- The turgescent phase of the ovarian cycle coincided with the period beginning on the first day of perineal turgescence and ending the day prior to the subsequent first day of perineal deturgescence (DoD).

- The non-turgescent phase of the ovarian cycle coincided with the period beginning on the DoD and ending the day prior to the first day of the subsequent perineal turgescence.

- One complete ovarian cycle was defined as the period of time occurring between two consecutive DoD events, an interval which begins on the day of DoD and ending on the day prior to the DoD for the subsequent cycle. This interval was used because deturgescence was a clearly demarcated event amongst the Wellington Zoo females, whereas external signs of menses were not always observed and the early stages of turgescence were difficult to distinguish. Previous studies on savannah baboons have demonstrated that the time between consecutive DoDs closely matches that for the inter-menses period (Hausfater, 1975; Wildt et al., 1977). Thus, this interval provides an accurate measure of ovarian cycle length for baboons.

\section{Ovarian synchrony model}

A purpose-built permutation model was used to measure the degree of ovarian cycle synchrony and asynchrony amongst female colony members. Significance testing was conducted using a null model procedure. The model design is described below.

Step 1: cycle reallocation

- A female, $f_{1}$, is randomly selected from a group of $n$ females. 
- An ovarian cycle of length $x$ is chosen at random from the pool of all observed complete cycles for female $f_{1}$, and is allocated to a randomly chosen starting day ( $m$ ) from within a 366 day interval (i.e., $m$ can take on values 1 through to 366 ). The cycle is returned to the pool and made available for further selection.

- A second ovarian cycle is randomly selected from female $f_{1}$, which is allocated to begin the day immediately following the end day of last cycle (i.e.: day $m+x+1$ ). The cycle is again returned to the pool for future selection.

- This process is repeated until an ovarian cycle exceeds the upper boundary of the interval (day 366). When this occurs, the next randomly chosen ovarian cycle is allocated so the last day of the cycle falls on the day prior to the first day of the first allocated cycle (i.e.: day $m-1$ ). All subsequent cycles will be placed in this manner until the lower boundary of the interval (day 1) is exceeded.

- This process is repeated for each of the $n$ females in the group (i.e., from female $f_{l}$ to female $f_{n}$ ).

Step 2: expected overlap estimation and null distribution generation

- The interval is resized to only include days in which all $n$ females had a complete ovarian cycle (i.e., cycles which lie completely within the interval) in common. Hence, let set $\mathbf{A}$ be the collection of complete cycles whose first day is closest to day 1 for each female, and let set $\mathbf{B}$ be the collection of complete cycles with an end date closest to day 366 for each female. The new lower boundary is defined to be the latest day in which a cycle in set $\mathbf{A}$ began, and the new upper boundary the earliest day in which a cycle in set $\mathbf{B}$ ended. This ensures that the estimated overlap values are conservative, by not extrapolating beyond the minimum common period in which all observed complete cycles co-occur. 
- For each pair-wise combination of females, the total number of days within the interval that the turgescent phase of their ovarian cycles overlapped is the expected overlap, $O_{e}$, for the pair. For groups with more than 2 females, the sum of the $O_{e}$ 's for each pair-wise combination of females within the group is the expected overlap for the group of females.

- This process is repeated 10,000 times to generate a null distribution of $O_{e}$ values for each pair and group of females. Hence, the relative frequency of each $O_{e}$ value represents the probability that a pair or group of females will exhibit that extent of overlap by chance.

\section{Step 3) Test statistic and hypothesis testing}

- The observed overlap $\left(O_{o}\right)$ for $n$ females is measured in the same way as the expected overlap, except that original ovarian cycle positions are used in place of the random reallocations.

- The probability of obtaining $O_{o}$ is given by the relative frequency of $O_{e}$ values that are at least as extreme as $O_{o}$ within the null distribution. Because both synchrony and asynchrony are being tested for, all tests are 2-tailed with $\alpha=0.05$. Hence, when ovarian cycles are significantly synchronised, the degree of cycle phase overlap will be high and the $O_{o}$ value will lie within the uppermost $2.5 \%$ of $O_{e}$ values. Conversely, when ovarian cycles are significantly asynchronous, overlap will be correspondingly small and the $O_{o}$ value will lie within the bottommost $2.5 \%$ of $O_{e}$ values. All random, non-significant levels of synchrony will lie between these $O_{e}$ values.

In keeping with previous studies on hamadryas baboons (Kummer, 1968; Zinner et al., 1994), the turgescent phase of the ovarian cycle is used to determine the 
degree of overlap in the ovarian cycle. Separate tests were performed at the colony, OMU and pair-wise level. Pair-wise tests consisted of every possible pairing of cycling females, which resulted in 45 separate tests. Pair-wise tests were included on the basis that some, but not all, females within a particular group may have had a nonrandom degree of synchrony or asynchrony, which may be obscured when analysed within the context of a larger group. Because each null distribution was approximately symmetrical around its mean value, the $p$-value for each test was based on doubling the $p$-value of an equivalent one-sided test, which was taken as the smaller of the two one-sided possibilities (i.e.: $O_{o}-O_{e}>0$, or $O_{o}-O_{e}<0$ ). Additionally, a Sequential Bonferroni correction was utilised to control for each female being involved in multiple pair-wise tests (Holm, 1979). This involves ranking $p$-values from smallest to largest, with the smallest $p$-value tested at $0.05 / c$, the second smallest value at $0.05 /(c$ -

1) etc, where $c$ equals the number of comparisons (i.e.: 45). The permutation model was written by Shirley Pledger and conducted on $\mathbf{R}$ 2.6.2 mathematical software.

\section{RESULTS}

\section{Ovarian cycle characteristics}

Overall, data from 106 turgescent phases, 106 non-turgescent phases, and 100 complete ovarian cycles, were recorded for the 10 cycling females over the study period (Table 14). The average menstrual cycle length in the colony was 31.4 days. Ovarian cycle length varied within and between females. The average ovarian cycle length ranged from 29.4 to 36.0 days between females, and had a 3 to 9 day range within females (Table 14). The average length of the turgescent 


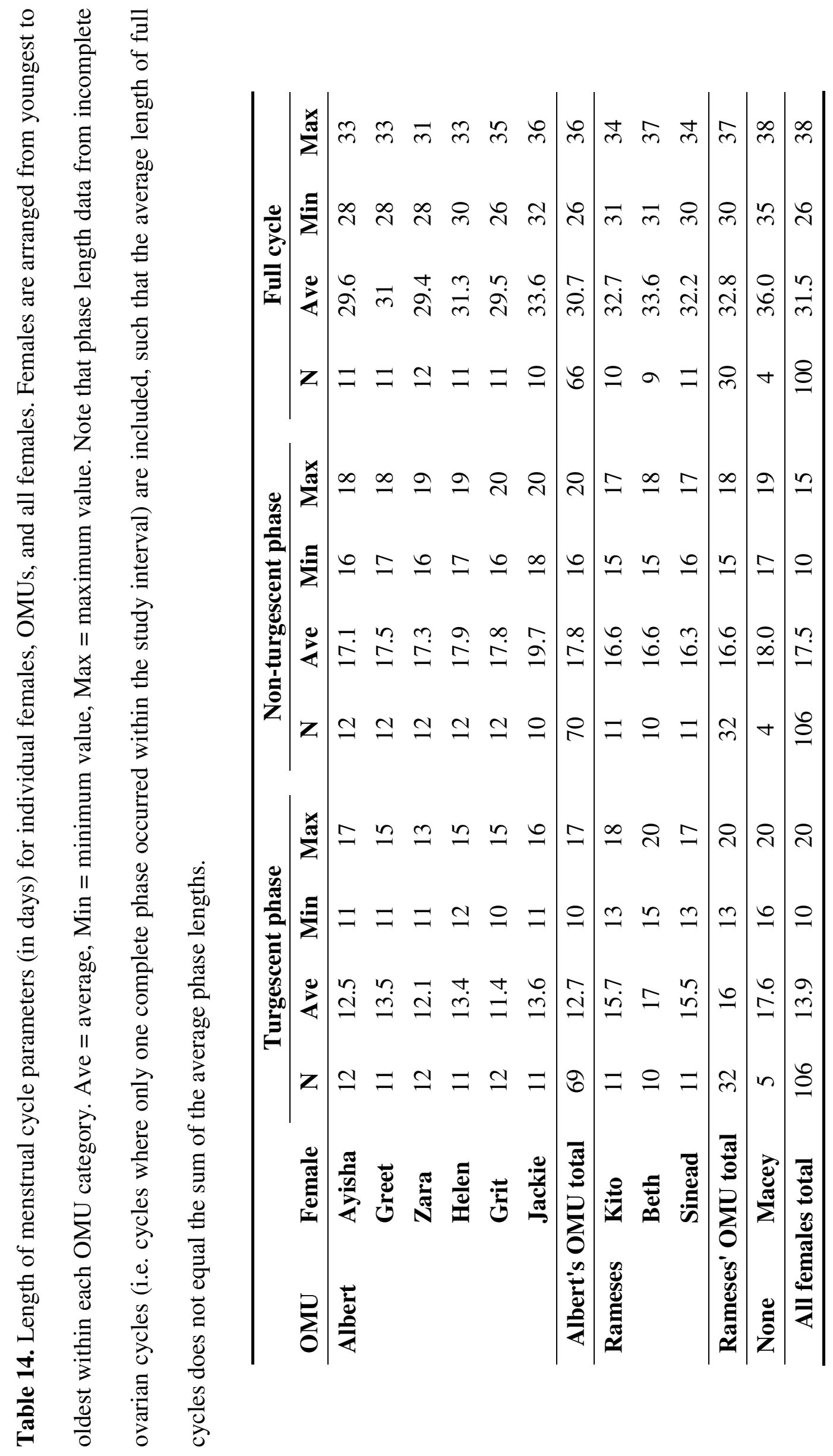


phase across the whole group was 14.6 days, with the non-turgescent phase being longer at 17.6 days. The turgescent phase was more variable both within and between females (Table 14).

\section{Ovarian synchrony}

The turgescent phase of the cycle was neither significantly synchronised, nor asynchronised, at the colony $\left(O_{o}=402, O_{e}=403.1, p\right.$-value $\left.=0.943\right)$ or $\mathrm{OMU}$ (Rameses' OMU: $O_{o}=210, O_{e}=183.1, p$-value $=0.431 ;$ Albert's OMU: $O_{o}=$ 518, $O_{e}=492.9, p$-value $\left.=0.150\right)$ level. Similarly, after making the Sequential Bonferroni adjustment for multiple testing, none of the 45 possible pair-wise combinations of females had a significant result (Table 15). One pair of females from Albert's OMU, Ayisha and Jackie, were found to have significantly asynchronised turgescent periods prior to the Sequential Bonferroni adjustment. Because this was the lowest overall $p$-value from the 45 possible pairs of females, for this result to be valid the $p$-value had to be lower than $0.05 / 45$, which it failed. Given that the magnitude of the differences between the $O_{o}$ and $O_{e}$ for this pair were not unusually large relative to other female pairings (ranked $14^{\text {th }}$ largest out of 45 pairs, Table 15), it is likely that this result represents a type one statistical error (i.e.: incorrect rejection of the null hypothesis) that arose though a fortuitous timing of cycle events and was correctly invalidated by the Sequential Bonferroni procedure. This result is examined further in the discussion. 


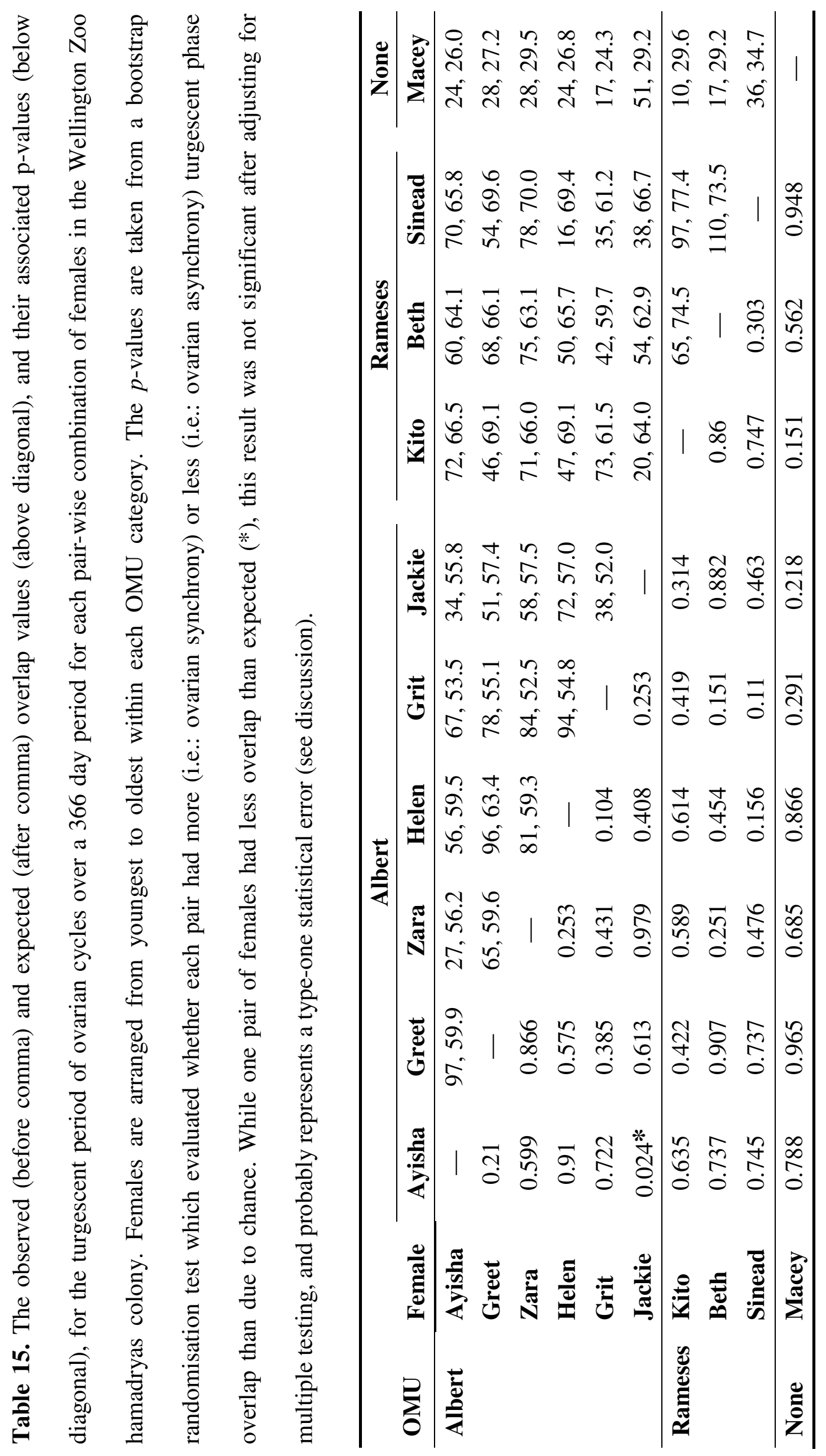




\section{DISCUSSION}

Neither ovarian synchrony nor ovarian asynchrony was detected at the colony or OMU level, nor for any pair-wise combination of females, at the Wellington Zoo hamadryas colony. Over the 366 day study period, in which females experienced between 9 to 12 consecutive cycles, inter-female overlap in the turgescent phase of the ovarian cycle did not significantly differ from levels expected by chance. As has been demonstrated in several other studies, the existence of inter and intra-female variation in cycle length makes 'true' synchrony mathematically impossible to obtain (Arden and Dye, 1998; Jarett, 1984; Schank, 2000, 2001a, 2001b, 2001c; Strassmann, 1997, 1999; Wilson, 1992; Wilson et al., 1991; Yang and Schank, 2006; Ziomkiewicz, 2006). True synchrony/asynchrony requires that females maintain stable cycle lengths that are integer multiples of one another (i.e.: the length of the longer cycle divided by the length of the shorter cycle returns a whole number quotient), so that the onset of cycle phases can continue to 'match up' across multiple cycles (Schank, 2000; Winfree, 2001). Females in the Wellington Zoo colony do not display this pattern; rather they display a general tendency to move from a state of pseudo-synchrony (i.e.: chance levels of turgescent phase overlap) to a state of pseudo-asynchrony (i.e.: chance levels of turgescent phase staggering), and vice versa, as a result of differences in inter- and intra-female cycle length (Figure 17). This oscillating pattern also indicates that females were not altering their cycle lengths in a systematic way to bring about either synchrony or asynchrony (which requires that cycle lengths stabilise once the desired arrangement has been achieved).

Notably, the females in Rameses' OMU displayed considerably more overlap across multiple consecutive cycles than did the females in Albert's OMU. This appeared to be due primarily to the combination of two factors; 1) the lengthiness of 

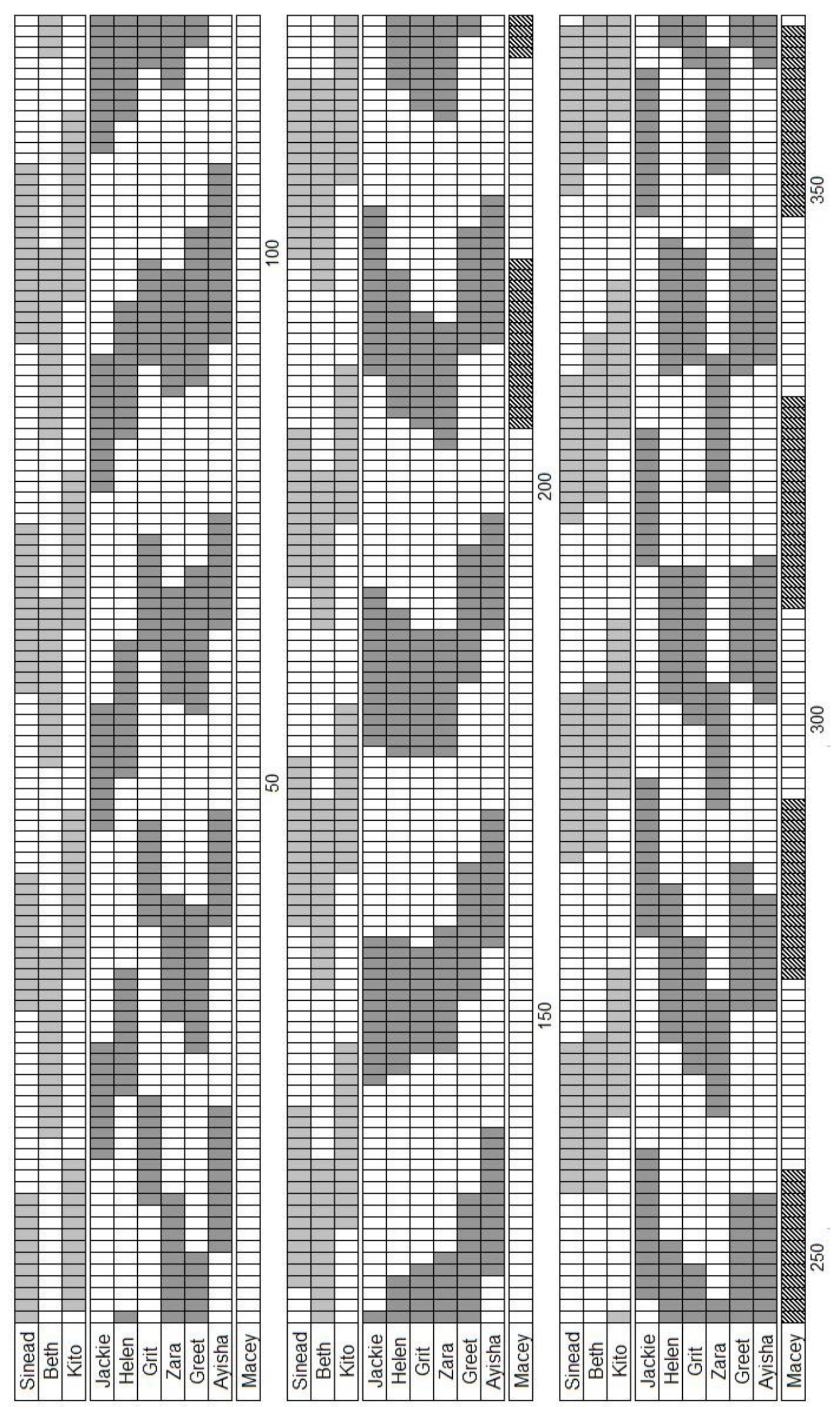
Figure 17. (previous page) Changes in ovarian cycle status across a 366 day period for females in the Wellington Zoo colony. Each cell represents one day, with each $50^{\text {th }}$ day labelled. Filled cells indicate period of perineal turgescence (light grey $=$ females from Rameses' OMU, dark grey = Albert's OMU, diagonal lines = Non-OMU), unfilled cells the deturgescent and flat period. Patterns oscillate between pseudosynchronous and pseudo-asynchronous states and do not maintain a consistent pattern amongst females in either OMU, nor for any pair-wise combination of females.

the turgescent phase relative to that of the non-turgescent phase and 2) the greater degree of similarity in the average cycle length amongst these females. Thus, that the females in Albert's OMU tended to have shorter turgescent phases and displayed greater inter- and intra-cycle length variation than the females in Rameses' OMU meant that they were also unable to maintain overlap across as many consecutive cycles as their counterparts. Consequently, females in Albert's OMU tended to display greater variation in the degree of overlap between subsequent cycles, and also moved more rapidly between states of high and low overlap, than did females in Rameses OMU. Ayisha and Jackie typify this pattern, alternating from a small degree of overlap at the start of the study interval, to a considerable degree of overlap midinterval, before reverting back to small degree of overlap by the end of the interval (Figure 1). Moreover, that this was the only pair of females that also had significantly asynchronous turgescent phases prior to the Sequential Bonferroni adjustment reinforces the conclusion that this result was a type-one statistical error that was correctly rejected following the adjustment. 


\section{Comparison of ovarian cycle data with other hamadryas populations}

The degree of cycle variability in the Wellington Zoo population was smaller than that seen in another captive population, and much smaller than that observed in a freeranging population. Zuckerman and Parkes (1932) reported a 31.4 day average cycle length and 24 day range ( 22 to 46 days) for 10 females in a captive colony based at the London Zoo (total cycles $=72$ ), while Swedell (2006) reported a 40 day average cycle length and 37 day range (23 to 60 days) for 17 females in a free-ranging population in Ethiopia (total cycles $=38$ ). After adjusting for the cycle length differences (by dividing the standard deviation by the mean cycle length) the magnitude of variation for the Wellington colony $(\mathrm{CoV}=0.07$, Table 14) is approximately three times smaller than that in the Ethiopian population $(\mathrm{CoV}=0.20$, and approximately two times smaller than that in the London Zoo colony $(\mathrm{CoV}=$ 0.16) (the latter two values were recalculated from cycle data in Zuckerman and Parkes, 1932, p. 152, and Swedell, 2006, p.139, respectively).

Notably, these inter-population differences in cycle length variation appear to be mostly due to the relative amount of long cycles in each population (percentage of cycles longer than 40 days: Wellington Zoo: 0\% (0 of 100), London Zoo: 8\% (6 of 72), Ethiopia: $55 \%$ (21 of 38); as the lower cycle length values are similar for each population (Wellington Zoo: 26 days, London Zoo 22 days, and Ethiopia: 23 days). The lack of long cycles in captive populations may be partly due to the absence of external stressors such as predation or intra-group resource competition in captive environments, as stress is known to delay ovulation and lead to longer cycles in female primates (Caperton et al., 2006; Harlow and Matanoski, 1991; Rowell, 1970). Consequently, the absence of synchrony in the Wellington Zoo colony cannot be attributed to abnormal inter- or intra-female variation in cycle lengths. On the 
contrary, cycles in captivity appear to be more stable than those in free-ranging populations, and should not provide any additional barrier to cycle coordination.

\section{The evolution and function of ovarian synchrony in hamadryas baboons}

Recently, Swedell (2006) has suggested that the presence of ovarian synchrony in some hamadryas baboon populations may be due to a tendency toward seasonal breeding patterns within these populations. Hamadryas baboons are not obligatory seasonal breeders (i.e.: they are physiologically capable of breeding throughout the year), but show a tendency to temporally cluster their breeding in populations where resources show seasonal variation in abundance (Chalyan et al., 1994; Kummer, 1968). Indeed, both Kummer (1968) and Schwibbe et al. (1992) found that ovarian synchrony was more prominent at certain times of the year in their respective study populations, while Swedell (2006) found no ovarian synchrony in another freeranging population that lacked significant seasonal variation in food resources. Thus, there is evidence that hamadryas females coordinate the resumption of ovarian cycling in more seasonal environments. This suggests that ovarian synchrony in hamadryas baboons may be a byproduct of selection on an ecologically mediated trait, and not an adaptive response to some socio-sexual context. However, this theory does not explain why only females from within the same OMU tend to be synchronised (Kummer, 1968; Zinner et al., 1994), as breeding seasonality should presumably affect all females within a common environment simultaneously.

An additional possibility is suggested by the findings of Schwibbe and colleagues (1994), who reported that menarchal and post-partum females tended to begin ovarian cycling at the same time as other females in their OMU. When 
combined with the knowledge that the majority of mature hamadryas females tend to conceive within their first 3 cycles (Asanov, 1972; Kaumanns et al., 1989; Sigg et al., 1982) and that their turgescent phase typically comprises between $45 \%$ to $55 \%$ the length of a full cycle (This study; Kaumanns et al., 1989; Zuckerman and Parkes, 1932), then considerable turgescent phase overlap, and the appearance of synchrony (though not mathematically 'true' synchrony), will ensue whenever two females begin cycling at the same time, cycle variability notwithstanding. This pattern is clearly demonstrated in the case of a menarchal female, Macey, in the Wellington Zoo colony. Macey had her first turgescent phase within 2 days of three other females (Helen, Grit and Zara) resuming their own. The degree of overlap that she maintained with each of these females declined steadily, on average, over each successive cycle. The overlap remained reasonably large over the first three cycles in each case, however, before falling away after this point, providing an impression of ovarian synchrony (Figure 17).

The presence of 'ovarian synchrony' in hamadryas OMUs, therefore, may be explained by a tendency for females to coordinate their initial ovarian cycles with other females in their OMU, which, when combined with the brief co-cycling periods and relatively long turgescent phases, makes turgescent phase overlap across a few consecutive cycles highly probable. Furthermore, the relatively brief cycling periods typical of hamadryas females mean that mechanisms for sustained cycle synchronisation are unlikely to have come under selection in this species. Therefore, the absence of ovarian synchrony in hamadryas females (at least in the strict mathematical sense) should not be regarded as a surprise but rather the expected outcome given the demographic and reproductive contexts that characterise this species. Moreover, given that selection should favour females that spend the 
minimum amount of time cycling, then it is unlikely that a mechanism for maintaining ovarian synchrony over multiple cycles has evolved in any animal species. This may explain why two recent long-term investigations of ovarian synchrony in women also reported negative results (Yang and Schank, 2006; Ziomkiewicz, 2006).

The fact remains that hamadryas females appear to be able to coordinate their ovarian cycle over shorter intervals irrespective of inter- and intra- female cycle variation, regardless of lacking a long term cycle entrainment mechanism. Short term synchronisation of ovarian cycle amongst female OMU members may have fitness benefits for females. One possibility is suggested by reports that female hamadryas baboons are prone to infanticide following the usurpation of their RM by another male (Kummer et al., 1974; Swedell, 2000, 2006; Swedell and Tesfaye, 2003). In this case, ovarian synchrony may be employed by females to confound RM control and increase their opportunities for extra-OMU copulations. This would allow females to enact a paternity confusion strategy, whereby mating with extra-OMU males decreases the likelihood that these males will kill any resultant offspring in the future. Indeed, the extra-OMU copulatory patterns of female OMU members in this colony were found to be consistent with a paternity confusion strategy (Chapter 3). Furthermore, should a female fail to conceive, she has an opportunity to do so in the following cycle, which comes at the temporal cost of around 30 days, whereas infanticide involves the loss of all temporal and energetic investments that females have made into their offspring up until that point. Therefore, the benefits of ovarian synchronisation are likely to far outweigh any costs under normal circumstances, and may explain why ovarian synchrony has been reported in hamadryas baboons despite the associated decrease in their conceptive probabilities. 


\section{Conclusion}

Based on the evidence from the Wellington Zoo colony, it appears that female hamadryas baboons lack the ability to coordinate their ovarian cycles with other female OMU members over periods longer than a few full cycles. This was due to the existence inter- and intra-female cycle variation, which makes phase matching impossible across multiple cycles. This result suggests that previous reports of ovarian synchrony in hamadryas baboons (Kummer, 1968; Schwibbe et al., 1992; Zinner et al., 1994) were unlikely have been synchronous in the strict mathematical sense. Rather, ovarian synchrony in this subspecies was likely to have been instigated by a combination of factors, namely initial cycle coordination, brief co-cycling periods and lengthy turgescent phases. What has been clearly demonstrated by these studies, however, is that while hamadryas females lack the ability to synchronise their cycles in the strict mathematical sense, this not mean that ovarian cycles cannot be coordinated over shorter durations. Such a trait may enable females to reduce infanticide by enacting a paternity confusion strategy. The task remains, however, to examine the extent of this phenomenon in natural populations and thereby explicate its functional significance.

\section{REFERENCES}

Arden MA, Dye L. 1998. The assessment of menstrual synchrony: comment on Weller and Weller (1997). Journal of Comparative Psychology 112:323-324.

Asanov SS. 1972. Comparative features of the reproductive biology of hamadryas baboons (Papio hamadryas), grivet monkeys (Cercopithecus aethiops) and 
rhesus monkeys (Macaca mulatta). Acta Endocrinologica Supplementum $166: 458-471$.

Caperton L, Eddy C, Leland MM, Carey KD, McCarrey JR. 2006. Alteration of the menstrual cycle in baboons placed on tethering devices and moved to individual housing-a stress model for a follicular phase defect. Journal of Medical Primatology 35:341-345.

Chalyan VG, Lapin BA, Meishvili NV, Vancatova MA. 1994. Reproductive aspects of free-ranging troups of hamadryas baboons. In: Roeder JJ, Thierry B, Anderson JR, Herrenschmidt N, editors. Current Primatology: Volume III: Behavioural Neuroscience, Physiology and Reproduction. Strasbourg: Universite Louis Pasteur Press. p 237-244.

Colinshaw G, Dunbar RIM. 1991. Dominance rank and mating success in male primates. Animal Behaviour 41:1045-1056.

Dixson AF. 1998. Primate Sexuality: Comparative Studies of the Prosimians, Monkeys, Apes, and Human Beings. Oxford University Press.

Eberhard WG. 1996. Female Control: Sexual Selection by Cryptic Female Choice. Princeton University Press.

Emlen ST, Oring LW. 1977. Ecology, sexual selection, and the evolution of mating systems. Science 197:215-223.

French JA, Stribley JA. 1987. Synchronization of ovarian cycles within and between social groups in golden lion tamarins (Leontopithecus rosalia). American Journal of Primatology 12:469-478.

Gattermann R, Ulbrich K, Weinandy R. 2002. Asynchrony in the estrous cycles of golden hamsters (Mesocricetus auratus). Hormones and Behavior 42:70-77. 
Harlow SD, Matanoski GM. 1991. The association between weight, physical activity, and stress and variation in the length of the menstrual cycle. American Journal of Epidemiology 133:38-49.

Hendrickx AG, Kraemer DC. 1969. Observations on the menstrual cycle, optimal mating time and pre-implantation embryos of the baboon, Papio anubis and Papio cynocephalus. Journal of Reproduction and Fertility (Supplement) 6:119-128.

Holm S. 1979. A simple sequentially rejective multiple test procedure. Scandinavian Journal of Statistics 6:65-70.

Hrdy SB. 2000. The optimal number of fathers: evolution, demography, and history in the shaping of female mate preferences. Annals of the New York Academy of Science 907:75-96.

Ims RA. 1990. The ecology and evolution of reproductive synchrony. Trends in Ecology and Evolution 5:135-140.

Jarett LR. 1984. Psychosocial and biological influences on menstruation: synchrony, cycle length, and regularity. Psychoneuroendocrinology 9:21-28.

Jolly CJ, Phillips-Conroy JE. 2003. Testicular size, mating system, and maturation schedules in wild anubis and hamadryas baboons. International Journal of Primatology 24:125-142.

Jolly CJ, Phillips-Conroy JE. 2006. Testicular size, developmental trajectories, and male life history strategies in four baboon taxa. In: Swedell L, Leigh SR, editors. Reproduction and Fitness in Baboons: Behavioral, Ecological, and Life History Perspectives: Springer. 
Kaumanns W, Rohrhuber B, Zinner D. 1989. Reproductive parameters in a newly established colony of hamadryas baboons (Papio hamadryas). Primate Report 24:25-33.

Knowlton N. 1979. Reproductive synchrony, parental investment, and the evolutionary dynamics of sexual selection. Animal Behavior 27:1022-1033.

Kummer H. 1968. Social Organization of Hamadryas Baboons: A Field Study. Chicago: University of Chicago Press.

Kummer H. 1995. In Quest of the Sacred Baboon: A Scientist's Journey. Princeton, NJ: Princeton University Press.

Kummer H, Banaja AA, Abo-Khatwa AN, Ghandour AM. 1981. A survey of hamadryas baboons in Saudi Arabia. In: Wittmer W, Buttiker W, editors. Fauna of Saudi Arabia. Basel: Pro Entolologica, c/o Natural History Museum. p 441-471.

Kummer H, Banaja AA, Abo-Khatwa AN, Ghandour AM. 1985. Differences in social behavior between Ethiopian and Arabian hamadryas Baboons. Folia Primatologica 45:1-8.

Kummer H, Götz W, Angst W. 1974. Triadic differentiation: an inhibitory process protecting pair bonds in baboons. Behaviour 49:62-87.

Kutsukake N, Nunn CL. 2006. Comparative tests of reproductive skew in male primates: the roles of demographic factors and incomplete control. Behavioral Ecology and Sociobiology 60:695-706.

Kvarnemo C, Ahnesjo I. 1996. The dynamics of operational sex ratios and competition for mates. Trends in Ecology and Evolution 11:404-408.

Matsumoto-Oda A, Hamai M, Hayaki H, Hosaka K, Hunt KD, Kasuya E, Kawanaka K, Mitani JC, Takasaki H, Takahata Y. 2007. Estrus cycle asynchrony in wild 
female chimpanzees, Pan troglodytes schweinfurthii. Behavioral Ecology and Sociobiology 61:661-668.

McClintock MK. 1971. Menstrual synchrony and suppression. Nature 229:244-245.

Paul A. 1997. Breeding seasonality affects the association between dominance and reproductive success in non-human male primates. Folia Primatologica 68:344-349.

Pereira ME. 1991. Asynchrony within estrous synchrony among ringtailed lemurs (primates, Lemuridae). Physiology and Behavior 49:47-52.

Plowman AB, Jordan NR, Anderson N, Condon E, Fraser O. 2005. Welfare implications of captive primate population management: behavioural and psycho-social effects of female-based contraception, oestrus and male removal in hamadryas baboons (Papio hamadryas). Applied Animal Behaviour Science 90(2):155-165.

Ridley M. 1986. The number of males in a primate troop. Animal Behaviour 34:18481858.

Rowell TE. 1970. Baboon menstrual cycles affected by social environment. Journal of Reproduction and Fertility 21:133-141.

Schank JC. 2000. Menstrual-cycle variability and measurement: further cause for doubt. Psychoneuroendocrinology 25:837-847.

Schank JC. 2001a. Do Norway rats (Rattus norvegicus) synchronize their estrous cycles? Physiology and Behavior 72:129-139.

Schank JC. 2001b. Measurement and cycle variability: Reexamining the case for ovarian-cycle synchrony in primates. Behavioural Processes 56:131-146.

Schank JC. 2001c. Oestrous and birth synchrony in Norway rats, Rattus norvegicus. Animal Behaviour 62:409-415. 
Schank JC. 2004. Avoiding synchrony as a strategy of female mate choice. Nonlinear Dynamics, Psychology, and Life Sciences 8:147-176.

Schwibbe M, Zinner D, Klensang H. Factors and effects of the synchronisation of the reproductive cycles of hamadryas baboons Papio hamadryas (Abstracts); 1992; Stausbourg. p 315.

Shaikh AA, Shaikh SA, Celaya CL, Gomez I. 1982. Temporal relationship of hormonal peaks to ovulation and sex skin deturgescence in the baboon. Primates 23:444-452.

Shuster SM, Wade MJ. 2003. Mating Systems and Strategies. Princeton University Press.

Sigg H, Stolba A, Abegglen JJ, Dasser V. 1982. Life history of hamadryas baboons: physical development, infant mortality, reproductive parameters and family relationships. Primates 23:473-487.

Smith DG, Kanthaswamy S, Disbrow M, Wagner JL. 1999. Reconstruction of parentage in a band of captive hamadryas baboons. International Journal of Primatology 20:415-429.

Soltis J, Thomsen R, Takenaka O. 2001. The interaction of male and female reproductive strategies and paternity in wild Japanese macaques, Macaca fuscata. Animal Behaviour 62:485-494.

Strassmann BI. 1997. The biology of menstruation in Homo sapiens: Total lifetime menses, fecundity, and nonsynchrony in a natural-fertility population. Current Anthropology 38:123-129.

Strassmann BI. 1999. Menstrual synchrony pheromones: Cause for doubt. Human Reproduction 14:579-580. 
Swedell L. 2000. Two takeovers in wild hamadryas baboons. Folia Primatologica 71:169-172.

Swedell L. 2006. Strategies of Sex and Survival in Hamadryas Baboons: Through a Female Lens. Sussman RW, Vasey N, editors. Upper Saddle River, NJ: Pearson Prentice Hall.

Swedell L, Tesfaye T. 2003. Infant mortality after takeovers in wild Ethiopian hamadryas baboons. American Journal of Primatology 60:113-118.

Trivers R. 1972. Parental investment and sexual selection. In: Campbell B, editor. Sexual Selection and the Descent of Man, 1871-1971. Chicago: Aldine. p 136179.

Wallis J. 1985. Synchrony of estrous swelling in captive group-living chimpanzees (Pan troglodytes). International Journal of Primatology 6:335-350.

Weller A, Weller L. 1993. Menstrual synchrony between mothers and daughters and between roommates. Physiology and Behavior 53:943-949.

Weller A, Weller L. 1997. Menstrual synchrony under optimal conditions: Bedouin families. Journal of Comparative Psychology 111:143-151.

Wildt DE, Doyle LL, Stone SC, Harrison RM. 1977. Correlation of perineal swelling with serum ovarian hormone levels, vaginal cytology, and ovarian follicular development during the baboon reproductive cycle. Primates 18:261-270.

Wilson HC. 1992. A critical review of menstrual synchrony research. Psychoneuroendocrinology 17:565-591.

Wilson HC, Kiefhaber SH, Gravel V. 1991. Two studies of menstrual synchrony: Negative results. Psychoneuroendocrinology 16:353-359.

Winfree AT. 2001. The Geometry of Biological Time. New York: Springer. 
Yang Z, Schank JC. 2006. Women do not synchronize their menstrual cycles. Human Nature 17:434-447.

Zinner D, Krebs E, Schrod A, Kaumanns W. 2006. Early sexual maturity in male Hamadryas Baboons (Papio hamadryas hamadryas) and its reproductive implications. American Journal of Physical Anthropology 129:584-590.

Zinner D, Schwibbe MH, Kaumanns W. 1994. Cycle synchrony and probability of conception in female hamadryas baboons Papio hamadryas. Behavioral Ecology and Sociobiology 35:175-183.

Ziomkiewicz A. 2006. Menstrual synchrony: Fact or artefact? Human Nature 17:419432.

Zuckerman S, Parkes AS. 1932. The menstrual cycle of the primates. V. The cycle of the baboon. Proceedings of the Zoological Society of London 1:139-191. 


\title{
Chapter 5: Manipulation of the ovarian cycle in response to
}

\section{behavioural and physiological factors in hamadryas baboons}

\begin{abstract}
Several species of old world primates exhibit exaggerated perineal swellings (EPS) during their ovarian cycles. This trait has been hypothesised to solve the 'female dilemma' by enabling females to pursue both paternity confusion and paternity concentration strategies within a single ovarian cycle and thereby reduce infanticide. However, EPS are also costly to produce and maintain. Here I evaluate the expected fitness costs and benefits associated with the turgescent phase in order to predict the optimal length of the turgescent phase for an old world primate, Papio h. hamadryas, with a one-male unit (OMU) based social system. Turgescent phase bias (TPB; the length of the turgescent phase relative to the deturgescent phase) is predicted to increase in proportion with the number of concurrently oestrus females per OMU because of its confounding effect on RM control and a subsequent increase in extra-OMU mating opportunities. These predictions were tested on one year of ovarian cycle data collected from a captive hamadryas population where females were undergoing repeated ovarian cycling due to male contraceptive treatments. The data matched the predictions; females were found to have consistently longer turgescent phases in the OMU where the average number of simultaneously turgescent females was higher. These findings suggest that female hamadryas baboons are able to manipulate the ovarian cycle in a manner which is expected to increase their reproductive success.
\end{abstract}




\section{INTRODUCTION}

Male-induced infanticide is a widespread problem amongst old world primates (Hausfater and Hrdy, 1984; van Schaik et al., 1999). Many female old world primates also exhibit conspicuous enlargement in their ano-genital and perineal regions during the follicular phase of their ovarian cycle called exaggerated perineal swellings (EPS). Recently, Nunn (1999) hypothesised that EPS may have evolved as part of a female counterstrategy to infanticide. That EPS act as a reliable, albeit imperfect, fertility signal, and that perineal turgescence and female receptivity tend to be elongated in old world primates, means that dominant males tend to concentrate their mating over the latter part of the turgescent phase, where conception is most likely, rather than copulating throughout the ovarian cycle (Nunn, 1999). This creates opportunities for subordinate males to mate during times when conception is lower, but still possible (Nunn, 1999; Zinner et al., 2004). Thus, EPS allow females to enhance the paternity probability of a single dominant male, which is likely to favour the future protection of infants by these males (i.e., a paternity concentration strategy), whilst still providing a non-zero chance of paternity to other males, which is expected to reduce the likelihood of other males committing infanticide (i.e., a paternity confusion strategy). Consequently, EPS may provide a solution to the 'female dilemma' - where the enactment of one strategy rules out the other (Nunn, 1999; van Schaik et al., 1999, 2000) - by ensuring that both strategies can be enacted within a single ovarian cycle.

The success of the paternity confusion strategy requires that the turgescent phase of the ovarian cycle be sufficiently long to ensure that females are able to mate with all the potentially infanticidal males within the group (van Schaik, 2000). However, perineal swellings are also known to be costly to females (Nunn, 1999), which is expected to favour shorter turgescent phases. Therefore, the final length of 
the turgescent phase is expected to be a trade-off between these two opposing forces, being determined when the difference between the costs and benefits of perineal turgescence is optimal.

Like all papionin baboons, female hamadryas baboons (Papio. h. hamadryas) exhibit EPS and their offspring are vulnerable to male-induced infanticide. Hamadryas baboons live in societies based around the one male unit (OMU), which comprise a single adult male (resident male, RM), and one or more females and their associated offspring (Kummer, 1968). Infanticide has been observed and inferred to occur following OMU takeovers in wild populations (Kummer et al., 1974; Swedell, 2000, 2006; Swedell and Tesfaye, 2003). Thus, extra-OMU mating may represent an important infanticide deterrent for hamadryas females. The theoretical fitness costs and benefits that are associated with the turgescent phase in hamadryas baboons, and the resultant optimal turgescent phase length in this subspecies, are outlined below.

\section{Fitness costs}

EPS are expected to impose both physiological (e.g.: maintenance of turgescence, diversion of water from other organs) and energetic (e.g.: increased body weight) costs on females during the turgescent phase of their ovarian cycle (Dixson, 1983; Nunn, 1999). Hamadryas females are also more susceptible to perineal wounding (Zinner et al., 1994) and are more likely to be involved in aggressive encounters (Plowman et al., 2005; Swedell, 2006) while in the turgescent phase. Furthermore, inter-female competition is also known to increase (Plowman et al., 2005), and conceptive probabilities decrease (Zinner 1994), as number of simultaneously oestrous females within an OMU increases, presumably due to sperm-limited RMs 
(Zinner et al., 2004; Zinner et al., 2006). Hence, RM sperm depletion and inter-female competition are expected to be exacerbated by decreases in the operational sex ratio (OSR, the number of sexually available males relative to oestrus females; Emlen and Oring, 1977) within an OMU. Because the oestrous period equates to the turgescent phase for hamadryas females (Chapter 2), the number of oestrous females is equal to the number of turgescent females. Fitness costs, therefore, are expected to increase with the length of the turgescent phase and to be positively correlated with the intraOMU OSR (Figure 18).

\section{Fitness benefits}

The fundamental fitness benefit associated with the turgescent phase of the ovarian cycle is assumed to be extra-OMU mating in order to facilitate a paternity confusion strategy (Nunn, 1999, van Schaik et al., 2000). Thus, all things being equal, females with progressively longer turgescent phases are expected to acquire an increasing number of extra-OMU copulations. Additionally, because RMs are expected to have a harder time controlling multiple simultaneously oestrous females, extra-OMU mating is expected to be negatively correlated with the intra-OMU OSR. Specifically, more simultaneously oestrous females create progressively lower intra-OMU OSRs which are expected to produce greater opportunities for extra-OMU mating over a turgescent phase of a particular length. Finally, because extra-OMU copulations are assumed to be used as part of a paternity confusion strategy, benefits are expected to plateau once all potentially infanticidal males have been mated. The net result is that the benefits are expected to increase before levelling off when all males have been mounted, with the plateau occurring earlier as the intra-OMU OSR decreases (Figure 18). 


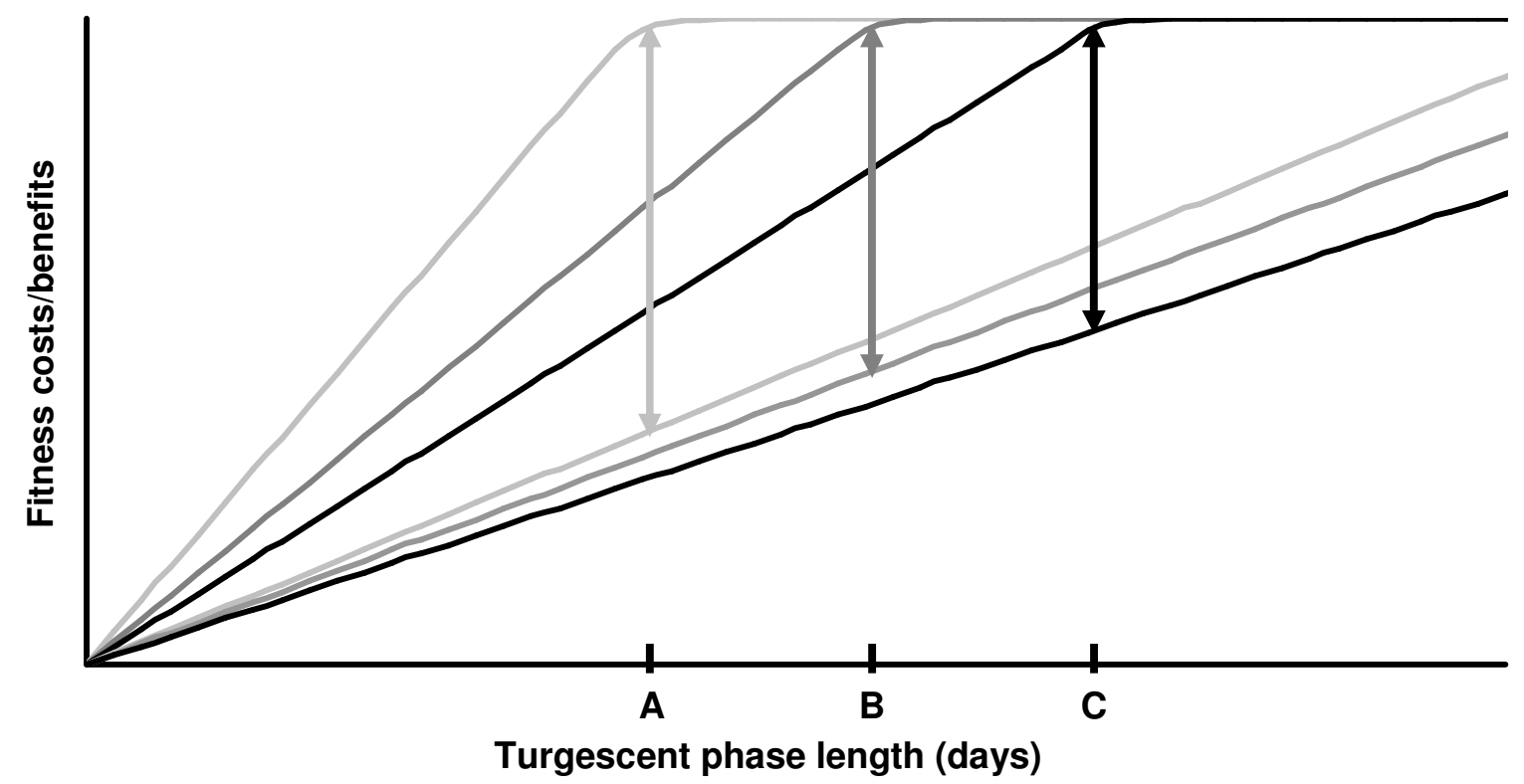

Figure 18. Theorised changes to fitness costs (aggression received, physiological costs, RM sperm-depletion, inter-female competition; straight lines) and benefits (number of extra-OMU copulations; plateauing lines) resulting from changes in turgescent phase length and the number of simultaneously turgescent females per OMU $($ one female $=$ black lines, two females $=$ dark grey lines, three females $=$ light grey lines). A, B and C indicate the optimal follicular phase length for OMUs with 1, 2 and 3 simultaneously cycling females respectively, which occur where the differences between the cost and benefit lines are maximal. Hence, increases in the number of simultaneously cycling females per OMU are predicted to result in subsequent decreases the follicular phase length of cycling females. However, because all curves are based on assumed rather than actual fitness estimates, the fitness pay-offs shown here are suggestive rather than actual. 


\section{Optimal turgescent phase length}

The length of the turgescent phase is expected to be determined by where the difference between fitness costs and benefits are maximal. Therefore, progressively shorter turgescent phases are favoured as the number of simultaneously oestrous females per OMU increases (Figure 18). Additionally, while the length of the turgescent phase is expected to change in relation with the intra-OMU OSR, the length of the non-turgescent phase (i.e., the period combining perineal deflation - i.e., deturgesence - and flatness) is not. Consequently, increases in the length of the turgescent phase are expected to result in concomitant increases in the turgescent phase bias (TPB; the length of the turgescent phase relative to the non-turgescent phase) of a given ovarian cycle. Therefore, all else being equal, the length and bias of the turgescent phase is expected to increase with decreases in the intra-OMU OSR.

Here I investigate the hypothesis that the length of the turgescent phase of female hamadryas baboons is negatively related to the OSR within their OMU. One year of ovarian cycle data is analysed, taken from a captive hamadryas baboon colony where adult female colony members were undergoing repeated ovarian cycling following RM vasectomisation. In light of the findings, the importance of a paternity confusion strategy for female hamadryas baboons is discussed.

\section{METHODS}

\section{Subjects}

At the time of the study the Wellington Zoo colony comprised 3 adult males, 10 adult females, and 7 pre-adult members (Table 16). All adult females were members of one 
Table 16. The demographic profile of the Wellington Zoo hamadryas baboon colony at the time of the study. Resident males are indicated by bold text. The list is organised by OMU affiliation, with OMU-affiliated females and individuals not affiliated to an OMU arranged from oldest to youngest in descending order. All animals were born in Wellington Zoo unless otherwise noted. See Appendix 1 for description of age and sex classes.

\begin{tabular}{lcccc}
\hline \multicolumn{1}{c}{ Name } & Sex & D.O.B. & OMU & Age Class \\
\hline Rameses & M & 11.10 .95 & Rameses & Adult \\
Tina $\dagger$ & F & 18.04 .79 & Rameses & Adult \\
Sinead & F & 29.01 .93 & Rameses & Adult \\
Beth & F & 4.06 .94 & Rameses & Adult \\
Kito & F & 21.05 .02 & Rameses & Adult \\
Albert & M & 24.06 .95 & Albert & Adult \\
Jackie $\dagger$ & F & 17.10 .86 & Albert & Adult \\
Grit* & F & 1.01 .88 & Albert & Adult \\
Helen* & F & 3.10 .92 & Albert & Adult \\
Zara & F & 21.09 .94 & Albert & Adult \\
Greet* & F & 16.09 .96 & Albert & Adult \\
Ayisha & F & 4.09 .01 & Albert & Adult \\
Carter & M & 14.05 .93 & None & Adult \\
Taila & M & 2.10 .01 & None & Subadult \\
Les & M & 19.09 .02 & None & Large juvenile \\
Rafiki & M & 24.09 .03 & None & Medium juvenile \\
Macey & F & 13.03 .04 & None & Medium-large juvenile \\
Habib & M & 7.12 .04 & None & Medium juvenile \\
Abeba & F & 24.12 .04 & None & Medium-large juvenile \\
\hline & & & &
\end{tabular}

* Introduced from Melbourne Zoo, Australia, on $12^{\text {th }}$ January 1988.

$\dagger$ Introduced from Dierenpark Emmen, the Netherlands, on $7^{\text {th }}$ June 2001. 
of the two OMUs, which comprised 6 and 4 females respectively. Membership in both OMUs remained unchanged throughout the study period. Additionally, another female, Macey, began exhibiting regular perineal swellings on the 26th of August 2007, and had undergone four complete cycles by the completion of this study. However, despite being post-menarchal, Macey had not been incorporated into either of the existing OMUs by the end of the study, nor had she formed a new OMU with an unattached male. Additionally, an adult female member of Rameses' OMU, Tina, had not exhibited any signs of perineal tumescence since initial observations began in November 2006 and was, therefore, presumed to have been post-menopausal. Consequently, both Tina and Macey are omitted from all subsequent analyses.

\section{Housing}

Since March 2000 the colony has resided in a purpose-built 0.25 ha naturalistic outdoor enclosure. This enclosure contains a number of trees, rocks, logs and open grassed areas, and is surrounded on all sides by a 3 metre tall chain-link wire fence. A $6 \times 4$ metre sleeping den adjoins the northern-western section of the enclosure. Access to the sleeping den was restricted between the daily feeding times, which occurred at approximately 10 a.m. and 3 p.m., unless it was wet or cold. The public viewing area is located on the western side of the enclosure, with a 7 metre long glass wall forming part of the perimeter fence at this point to assist in viewing. The eastern perimeter of the enclosure adjoins a public park, with the remainder being bordered by other zoo exhibits. In August 2007 an electric fence that ran parallel with the northern and eastern sections of the perimeter fence was installed inside the enclosure in order to protect several newly planted saplings. This reduced the area of the enclosure that is accessible to the baboons to approximately 0.2 hectares. 


\section{Contraceptive treatments}

In order to control population growth within the colony the two RMs (along with another RM who died in November 2006) were vasectomised in October 2004. A further adult male (Carter, Table 3) was castrated as a juvenile and had not developed the characteristic mantle of adult hamadryas males, nor acquired an OMU of his own. Additionally, a subadult male (Taila) received a hormonal castration treatment (Suprelorin ${ }^{\circledR}$, a gonadotrophin-releasing hormone agonist produced by the Peptech corporation) in October 2006, after he was observed mating with females. No pregnancies or births had been observed in the colony from March 2005 until the completion of the study in February 2008. Hence, 3 out of the 4 females in Rameses OMU (excluding Tina), and all 6 females in Albert's OMU, had been undergoing repeated ovarian cycling from at least March 2005 until the end of the present study.

\section{Ovarian cycles}

Observations on the state of perineal turgescence (inflating, deflating or flat) and visible signs of menses were recorded daily for all mature, fertile females in the Wellington Zoo colony over a 366 day period between the $2^{\text {nd }}$ of February 2007 and the $2^{\text {nd }}$ of February 2008. All observations were made from the public viewing area located at the eastern side of the enclosure. Ovarian cycle parameters were categorised as follows:

- The turgescent phase of the ovarian cycle coincided with the period beginning on the first day perineal turgescence and ending the day prior to the subsequent first day of perineal deturgescence (DoD). 
- The non-turgescent phase of the ovarian cycle coincided with the period beginning on the DoD and ending the day prior to first day of the subsequent perineal turgescence.

- One complete ovarian cycle was defined as the period of time occurring between two consecutive DoD events, an interval which begins on the day of DoD and ending on the day prior to the DoD for the subsequent cycle. This interval was used because deturgescence was a clearly demarcated event amongst the Wellington Zoo females, whereas external signs of menses were not always observed and the early stages of turgescence were difficult to distinguish. Previous studies on savannah baboons have demonstrated that the time between consecutive DoDs closely matches that for the inter-menses period (Hausfater, 1975; Wildt et al., 1977). Thus, this interval provides an accurate measure of ovarian cycle length for baboons.

\section{Statistical analysis}

The relationship between the length of turgescent phase and intra-OMU OSR is investigated using a mixed effects ANCOVA model. Because of the expected positive association between follicular phase length and TPB, the TPB is used as the dependent variable in the model. The magnitude of the TPB is calculated by dividing the length of the turgescent phase by the length of the non-turgescent phase and taking the natural logarithm of the result. Because ovarian cycles with a non-turgescent phase bias are bounded by 1 and 0 , whereas cycles with a turgescent phase bias are bounded by $+\infty$ and 1, taking the natural logarithm makes reciprocal TPB values symmetrical around 0 (e.g.; the natural logarithm of $2 / 3$ and $3 / 2$ have the same 
magnitude but different signs). Hence, cycles where the turgescent phase is longer than the non-turgescent phase have a positive TPB $(>0)$, cycles with where the nonturgescent phase is longer than the turgescent phase have a negative TPB $(<0)$, and equal phase lengths have an TPB of 0 . The test includes OMUs as opposed to individual females as the independent variable, as the intra-OMU OSR remained constant throughout the study period. Hence, a significant difference between the average TPB of females grouped by OMU should be expected if the hypothesis is correct. Specifically the OMU with the lowest OSR is expected to have the largest TPB. Furthermore, the model includes cycle length as a covariate to control for the potential correlation between cycle length and the TPB, and females were included as a random factor to control for repeated measurements amongst females.

In order to explore whether the TPB was more consistent amongst females from the same OMUs than it was between females from different OMUs, a nested mixed effects ANOVA is used to assess how the magnitude of variation in the TPB is partitioned according to inter-OMU (between females in different OMUs), interfemale (between females in the same OMU) and intra-female (between cycles in the same female) groupings. Standardised TPB values were utilised in the place of observed TPB values in order to control for the possible influence of cycle length and OMU membership on the TPB. Standardised TPB values for each female were derived by adding the residual TPB values (i.e.: the differences between observed and expected TPB values) from the mixed effects ANCOVA to the mean TPB value for the OMU that the female belonged to. As with the previous model, cycle length was included as a covariate to control for the potential correlation between cycle length and the TPB, and females were included as a random factor to control for repeated cycle measurements amongst females. 
All tests were conducted on $\mathbf{R}$ 2.6.2 mathematical software. The mixed effects ANCOVA was one-sided, with females in the OMU with the lower OSR expected to have the larger FPB. Significance was set at $\alpha<0.05$.

\section{RESULTS}

\section{Mixed effects ANCOVA}

96 complete ovarian cycles were recorded for the 9 cycling female OMU members over the study period (Rameses OMU $=30$, Albert's OMU =66), with a minimum of 9 and maximum of 12 cycles recorded for each female (Table 17). Females in Rameses' OMU had a significantly larger TPB than females in Albert's OMU $\left(F_{1,7}=\right.$ 28.07, $p$-value $<0.001 ;$ Figure 19). These differences remained even after allowing for the significant positive correlation between the TPB and cycle length $\left(F_{1,85}=\right.$ 53.65, $p$-value < 0.001). Females in Rameses' OMU had longer average cycle lengths than females in Albert's OMU (Table 17), indicating that the inter-OMU differences in TPB were not due to the cycle length differences between the two OMUs. Additionally, no interaction between cycle length and OMU was found $\left(F_{1,85}=1.39\right.$, $p$-value $=0.241)$. This indicates that the rate at which the TPB increases with cycle length was similar for both OMUs. Given equal cycle lengths, therefore, females in Rameses' OMU tended to spend a greater proportion of their cycle in the turgescent phase, and a smaller proportion in the non-turgescent phase, than did females in Albert's OMU (Figure 20). 


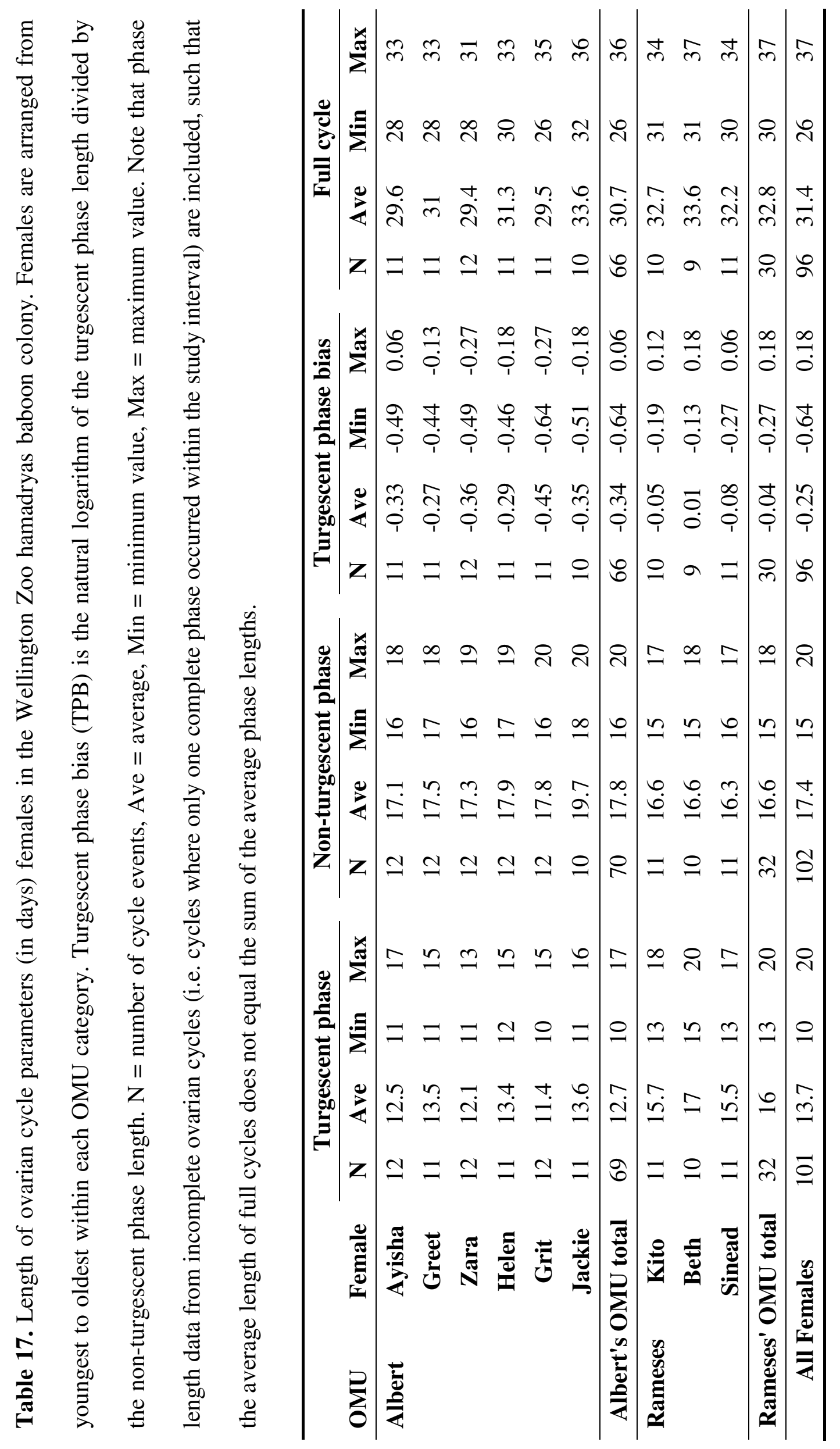




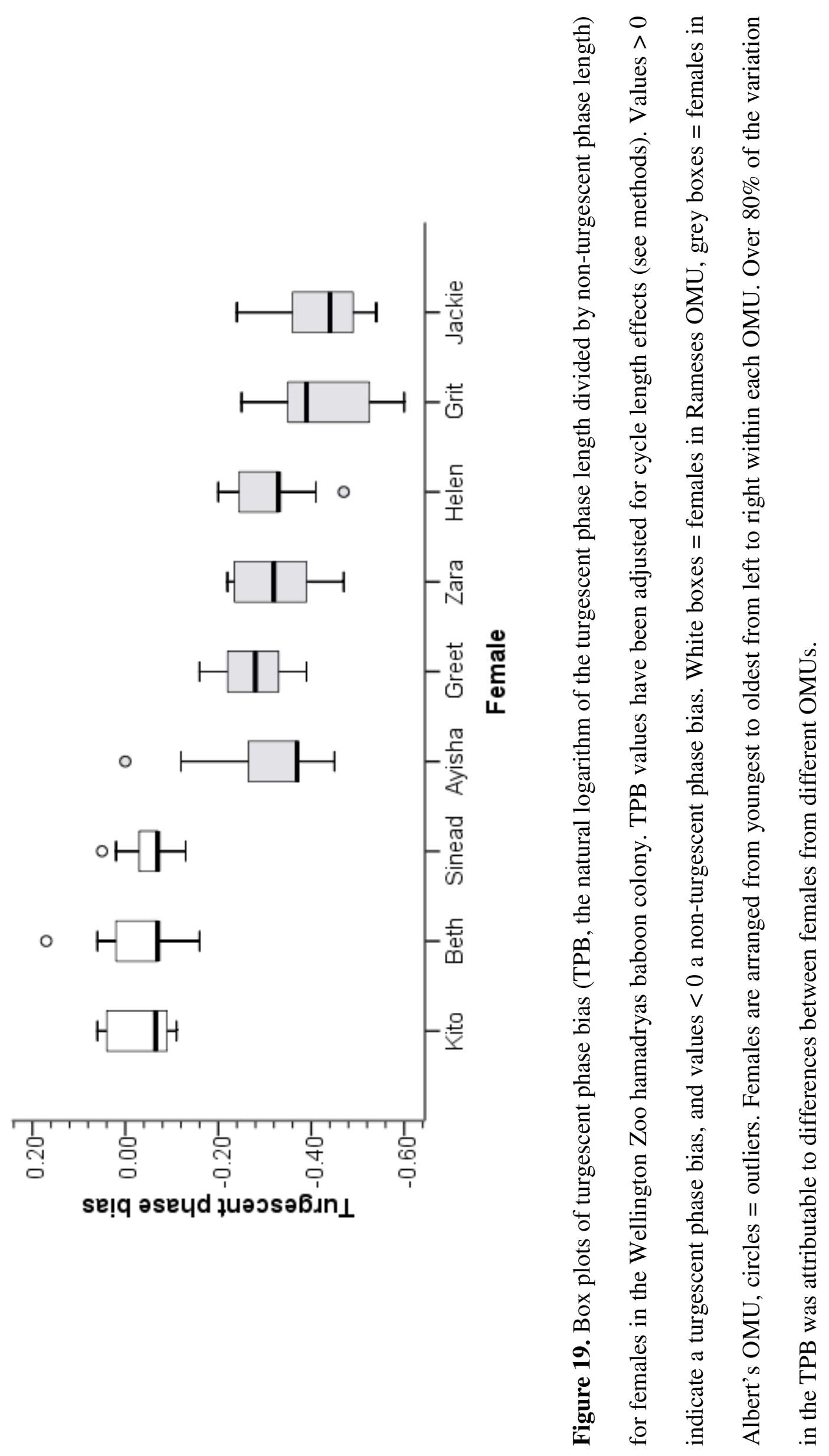




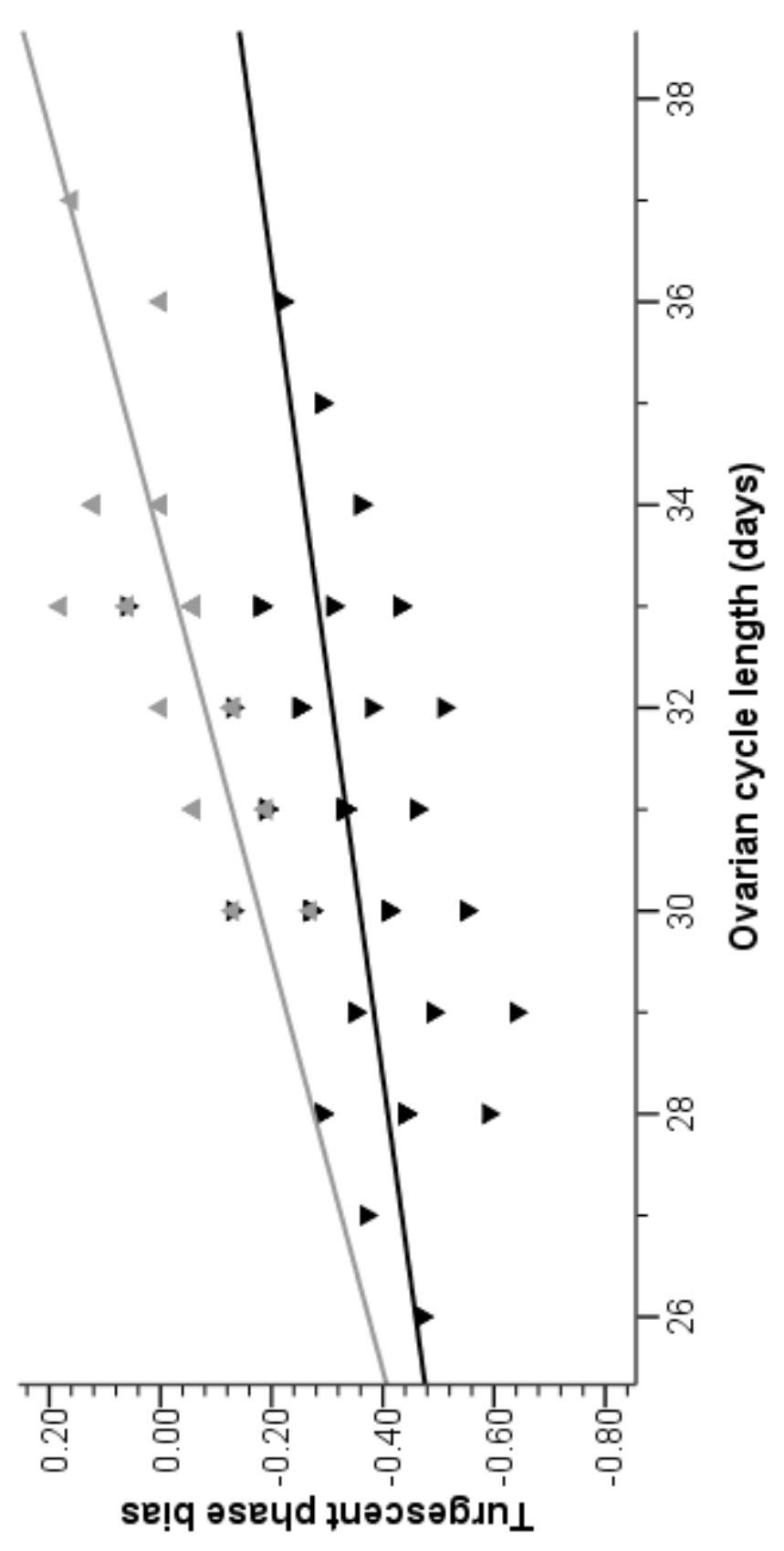

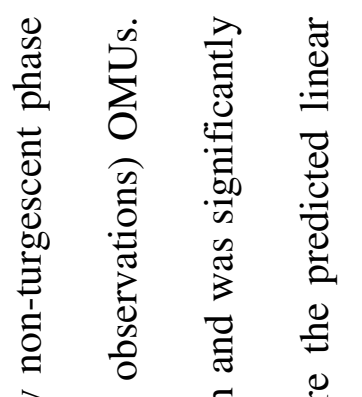

हो

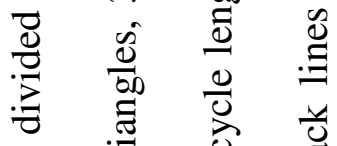

苛 芯

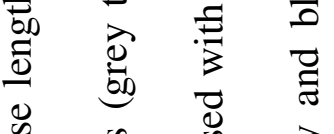

总

氙

然

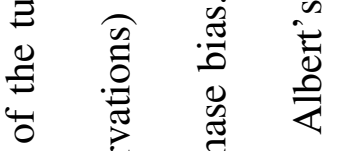

E

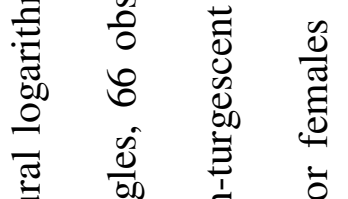

胥 $\frac{0}{60}$ 焉

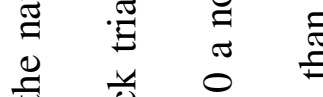

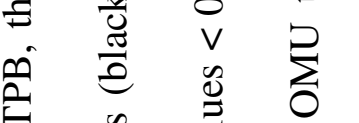

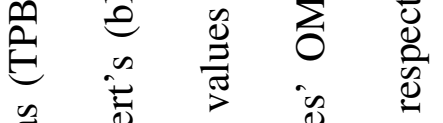

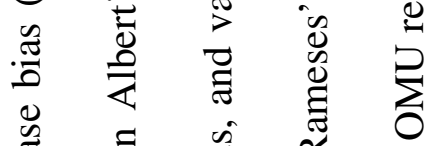

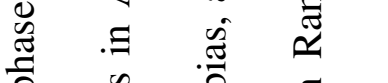

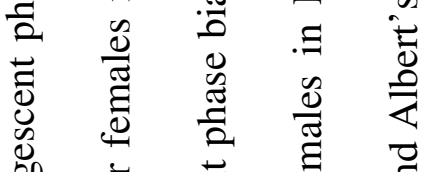

龸节焉

पे $\begin{aligned} & 5 \\ & 0\end{aligned}$

苛

矛

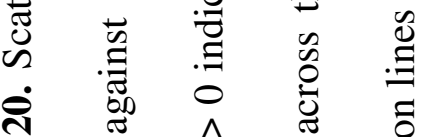

จ

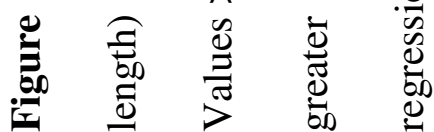


Additionally, it was observed that females in Rameses' OMU tended to begin their perineal turgescence sooner after the first visible indication of menses than females in Albert's OMU. This pattern was consistent across females within each OMU, with all 6 females in Albert's OMU having a longer average gap between first visible menses and turgescence than females in Rameses' OMU (Table 18). In order to test whether this interval was significantly shorter for females in Rameses' OMU, the mixedeffects ANCOVA was rerun using the time between the onset of menses and the onset of perineal turgescence as the dependent variable. Indeed, this period was significantly longer for females in Rameses' OMU than for females in Albert's OMU $\left(F_{1,7}=4.43, p\right.$-value $=0.064 ;$ however, because the hypothesis was one-sided, the equivalent $t$-test value is 0.032 ). Thus, in addition to having significantly lower TPB, this result suggests that females in Rameses' OMU also tend to initiate the onset of turgescence earlier in their follicular phase than females in Albert's OMU.

\section{Nested mixed effects ANOVA}

Amongst the OMU affiliated females in the Wellington Zoo colony, $80.5 \%$ of all TPB variation was accounted for by differences between the two OMUs (Figure 19). In contrast, only $3.7 \%$ was due to differences amongst females within the same OMU, with the remainder $(15.8 \%)$ being due to within-female differences. In other words, there is strong evidence that the degree of TPB experienced by females in the Wellington Zoo colony was primarily determined by which OMU a female was a member of. 


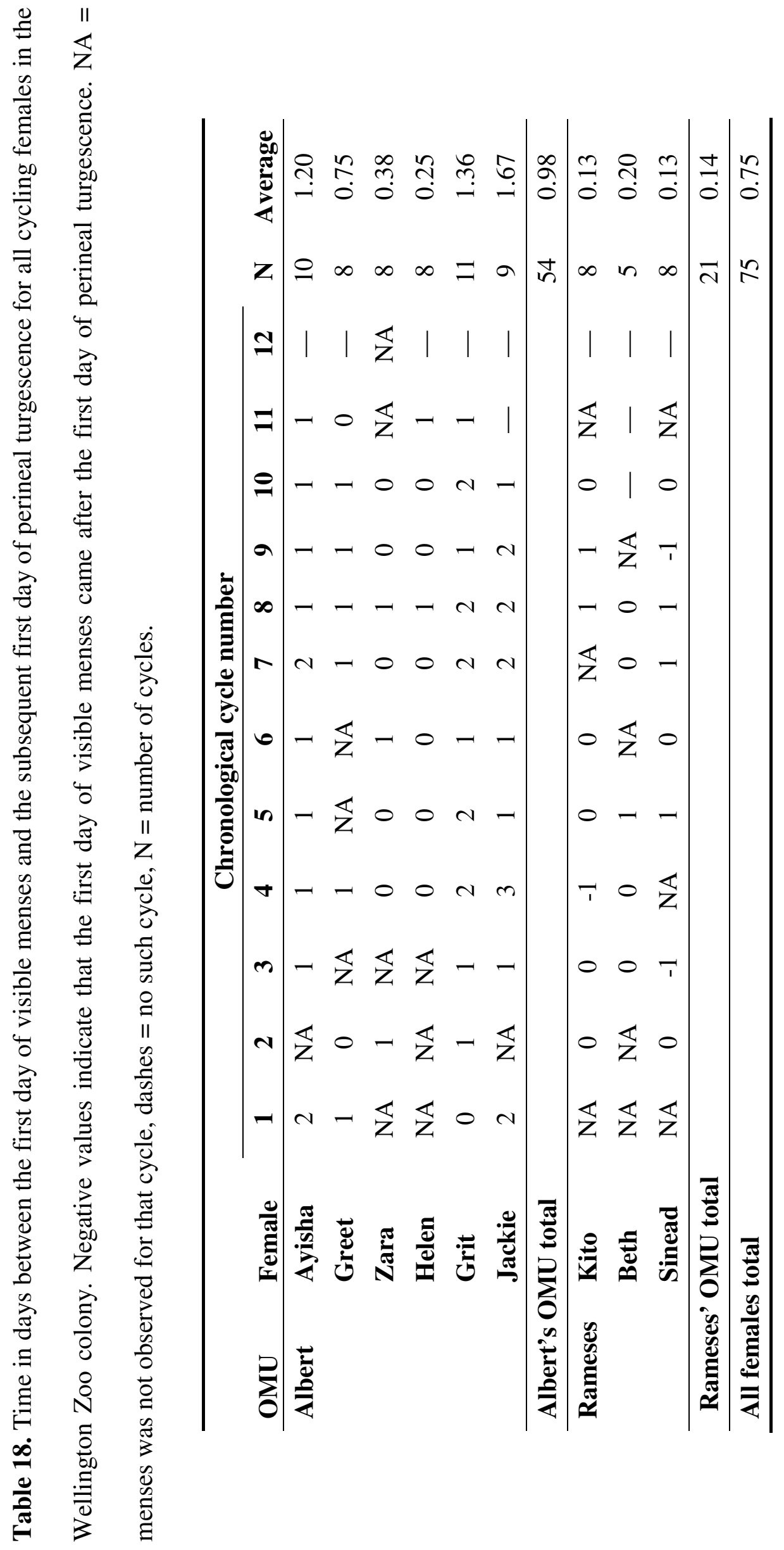




\section{DISCUSSION}

The findings from the Wellington Zoo hamadryas baboon colony matched the predictions of the fitness cost-benefit model. Females in Rameses' OMU, which had half the intra-OMU OSR of Albert's OMU on average during the study, had a significantly larger TPB, whereas the TPB of females that were members of the same OMU were largely consistent. The differences in TPB resulted primarily from the tendency for follicular phases to be longer amongst females in Rameses OMU, with the luteal phase length tending to be similar amongst females in both OMUs. Furthermore, the finding that females in Rameses' OMU also displayed a shorter period between the first day of menses and the first day of tumescence suggests that females may manipulate both the onset and end point of perineal tumescence in order to control the length of the follicular phase of a given ovarian cycle. Consequently, it appears that hamadryas females alter the length of the turgescent phase of their ovarian cycle in a manner that is expected to improve their reproductive success.

Pathological factors are also known to affect the length of perineal turgescence in old world primates, whereby the patterns in the Wellington Zoo colony may have a pathological explanation. For instance, high intensity agonistic incidents and movement into social isolation shortly prior to or during the early part of the turgescent phase have also been shown to produce abnormally long turgescent phases in baboons (Caperton et al., 2006; Rowell, 1970). However, no individual was removed from the enclosure during the study, nor were high intensity agonistic events of the type described Rowell's study (i.e. sustained attacks and threats as opposed to spontaneous, brief attacks) observed during the study period. Furthermore, the rates of agonism were actually lower in the OMU where turgescent phases were longer (Chapter 2), which suggests that chronic stress in the form of long term agonism can 
also be ruled out as an explanatory variable. Alternatively, nutrition has been implicated in altering the length of the perineal turgescence in some primate species (Mori et al., 1997; Setchell and Wickings, 2004; Zinner et al., 2004). However, during the daily provisioning regime at the Wellington Zoo hamadryas colony, food was dispersed widely around the enclosure so to ensure that no individual or OMU could monopolise access to food resources. Hence, it was highly unlikely that females from the two different OMUs had food intakes that were sufficiently different to produce the observed effects. Hence, the inter-OMU differences in the Wellington Zoo hamadryas colony do not appear to have a pathological explanation.

\section{Importance of a paternity confusion strategy to female hamadryas baboons}

Recently, Swedell (2006) and Swedell and Saunders (2006) have argued that the combination of agonistic RM herding and harsh environmental conditions have made paternity confusion a relatively costly strategy, such that hamadryas females have adopted paternity concentration as their primary anti-infanticide strategy. In doing so, RMs are expected to provide increased protection to the offspring of female OMU members to the extent that it 'obviates the need for a paternity confusion strategy' (Swedell, 2006, p.196). Indeed, RMs were observed to retrieve infants that had been forcibly taken from their mothers by non-RM males (Swedell, 2006), but this did not occur on two occasions when the kidnapping occurred shortly after a takeover, which resulted in the death of the juvenile on one occasion. While this suggests that RMs do play an important role in offspring protection, there is still the problem that females may actually increase the likelihood of infanticide occurring following a takeover by having previously concentrated paternity in a single male. This is because such an exaggerated form of paternity concentration acts to decrease the paternity probability 
of non-RM males to practically zero, meaning that the likelihood of their committing infanticide is expected to become correspondingly high (van Schaik et al., 2004). Hence, while favouring a paternity concentration strategy is likely to be suitable during the period when RMs are in their physical peak, sole focus on this strategy is expected to be counterproductive when RMs are in a state of physical decline or injured, and subsequently prone to usurpation. A paternity confusion strategy, therefore, may actually become more important than a paternity concentration strategy in situations where an RM is no longer physically capable of maintaining the integrity of his OMU, providing of course that there are prime aged males around who are willing and able to usurp him.

Notably, female hamadryas baboons, like other animals, are thought to use a range of strategies to counteract infanticide. Specifically, female hamadryas baboons have been observed to develop perineal swellings during periods of infertility (i.e.: pseudo-oestrus) and to terminate pregnancy via abortion or premature birth, following takeover events (Colmenares and Gomendio, 1988; Swedell, 2006; Zinner and Deschner, 2000). Pseudo-oestrus may serve to reduce the likelihood of infanticide by allowing females to initiate copulations with new RMs and thereby confer them with some paternity probability (Hausfater and Hrdy, 1984; Hrdy, 1977, 1979). Likewise, pregnancy termination may act as an effective cost-reduction measure, whereby females cease investment in offspring that represent a high infanticide risk, thereby curtailing the potential for further lost investments.

The effectiveness of both of these strategies as infanticide deterrents, however, is dependent on the reproductive status of the female at the time of the takeover. For instance, males are less likely to be deceived by faux perineal swellings in the latter stages of pregnancy or shortly after parturition, such that pseudo-oestrus is likely to 
become increasingly ineffective in deterring infanticide beyond the early stages of pregnancy. Similarly, pre-emptive pregnancy termination is expected to become increasingly costly at later stages of gestation, in accordance to the extent of maternal investment that is subsequently lost by this action. Hence, both strategies are expected to be most useful to females in the early stages of pregnancy, and relatively ineffective to females beyond this stage. This reinforces the importance of using a proactive strategy like paternity confusion, which can potentially be utilised by all hamadryas females prior to a takeover event, rather than relying solely on reactive strategies which, in the cases examined above, are useful only to subset of females following a takeover event.

There remains a potential weakness in this argument, however. Because extraOMU copulations appear to be rare in wild hamadryas populations, it seems highly unlikely that females would be able to mate with all the males in their wider social group under the conditions that are typical in the wild. Notably, males with previously established OMUs, or initial OMUs (where the females members are prepubescent), have been involved in OMU takeovers that have resulted in the death of offspring (Abegglen, 1984; Kummer, 1995; Swedell, 2006). Since extra-OMU copulations involving RMs have yet to be reported, it seems possible, therefore, that a paternity confusion strategy may be relatively ineffective in deterring such males.

That extra-OMU copulations involving females and RMs from other OMUs have not been reported in academic literature, however, does not mean that they do not occur whatsoever. It is possible that the discretion required for successful extraOMU copulations means that of the majority of them take place out of the line of sight of observers. Indeed, they may occur predominantly during the night, an interval which has not yet been the focus of behavioural research in this species, particularly 
as this is the time when large numbers of OMUs typically congregate on sleeping cliffs in wild populations. Furthermore, there may still be some benefits to females in enacting a correspondingly restricted version of the paternity confusion strategy even if mating between females and RMs from other OMUs is entirely absent. By mating with bachelor males, females may ensure that these males are the most likely to initiate any future takeovers. Two lines of evidence support this idea. Firstly, females vary in the extent of their resistance to the herding efforts of new RMs following takeovers, and a female was observed to return to her defeated RM several days after being usurped from her previous OMU (Swedell, 2006). Secondly, experimental evidence indicates that males are aware of female mate preferences, and use these to assess whether or not to attempt to usurp females from their current RMs (Bachmann and Kummer, 1980). Taken together, this suggests that the probability of female compliance following a takeover may be an important factor determining whether a male attempts a takeover or not, and that females may utilise extra-OMU copulations as a signal of their future compliance and thereby favour the takeover bids of some males over others. By doing so, females are expected to increase the likelihood of takeovers involving males with whom they have previously copulated and, therefore, reduce the chances of post-takeover infanticide. Alternatively, even in the event that the males with whom females have maintained extra-OMU sexual relationships do not become their RM following a takeover, they may still be able to provide some protection for that female's offspring, and may be better placed to do so than a potentially aging or injured RM. Therefore, paternity confusion may still represent an important infanticide avoidance strategy to hamadryas females, even though it may operate within a restricted context. 


\section{Conclusion}

In summary, a positive relationship between the length of the turgescent phase and the intra-OMU OSR was found in the Wellington Zoo hamadryas colony. This agrees with the hypothesis that females in OMUs with more simultaneously turgescent females would be able to acquire intra-OMU mounts more quickly than would females where this number was larger, resulting in a subsequent decrease in the length of the turgescent phase. Furthermore, other anti-infanticide strategies known to be utilised by hamadryas females appear to provide insufficient protection from infanticide by new RMs following a takeover event, such that paternity confusion is expected to become an important component of the general hamadryas female reproductive strategy in situations where takeovers are likely. Such a strategy may still be useful even if females are unable to mate with all potentially infanticidal males, by manipulating the probability of a takeover by previously mated males. That the empirical basis of this study rests on nine captive females from only two OMUs, however, means that these findings must be regarded as preliminary and that testing on larger, preferably wild, populations is necessary. Nonetheless, the hypothesis makes testable predictions and, moreover, may be generalised to other species with EPS or similar costly and conspicuous traits.

\section{REFERENCES}

Abegglen JJ. 1984. On Socialization in Hamadryas Baboons. London: Associated University Presses.

Bachmann C, Kummer H. 1980. Male assessment of female choice in hamadryas baboons. Behavioral Ecology and Sociobiology 6:315-321. 
Bielert C, Busse C. 1983. Influences of ovarian hormones on the food intake and feeding of captive and wild female chacma baboons (Papio ursinus). Physiology and Behavior 30:103-111.

Caperton L, Eddy C, Leland MM, Carey KD, McCarrey JR. 2006. Alteration of the menstrual cycle in baboons placed on tethering devices and moved to individual housing-a stress model for a follicular phase defect. Journal of Medical Primatology 35:341-345.

Colmenares F, Gomendio M. 1988. Changes in female reproductive condition following male take-overs in a colony of hamadryas and hybrid baboons. Folia Primatologica 50:157-174.

Dixson AF. 1983. Observations on the evolution and behavioral significance of “sexual skin” in female primates. In: Rosenblatt JS, Hinde RA, Beer C, Busnel M-C, editors. Advances in the Study of Behaviour. New York: Academic Press. p 63-106.

Hausfater G, Hrdy SB. 1984. Infanticide: Comparative and Evolutionary Perspectives. New York: Aldine.

Hrdy SB. 1977. The Langurs of Abu: Female and Male Strategies of Reproduction. Cambridge, MA: Harvard University Press.

Hrdy SB. 1979. Infanticide among animals: A review, classification, and examination of the implications for the reproductive strategies of females. Ethology and Sociobiology 1:13-40.

Kummer H. 1968. Social Organization of Hamadryas Baboons: A Field Study. Chicago: University of Chicago Press.

Kummer H. 1995. In Quest of the Sacred Baboon: A Scientist's Journey. Princeton, NJ: Princeton University Press. 
Kummer H, Götz W, Angst W. 1974. Triadic differentiation: an inhibitory process protecting pair bonds in baboons. Behaviour 49:62-87.

Mori A, Yamaguchi N, Watanabe K, Shimizu K. 1997. Sexual maturation of female Japanese macaques under poor nutritional conditions and food-enhanced perineal swelling in the Koshima troop. International Journal of Primatology 18:553-579.

Nunn CL. 1999. The evolution of exaggerated sexual swellings in primates and the graded-signal hypothesis. Animal Behaviour 58:229-246.

Plowman AB, Jordan NR, Anderson N, Condon E, Fraser O. 2005. Welfare implications of captive primate population management: behavioural and psycho-social effects of female-based contraception, oestrus and male removal in hamadryas baboons (Papio hamadryas). Applied Animal Behaviour Science 90:155-165.

Rowell TE. 1970. Baboon menstrual cycles affected by social environment. Journal of Reproduction and Fertility 21:133-141.

Setchell JM, Wickings EJ. 2004. Social and seasonal influences on the reproductive cycle in female mandrills (Mandrillus sphinx). American Journal of Physical Anthropology 125:73-84.

Sigg H, Stolba A, Abegglen JJ, Dasser V. 1982. Life history of hamadryas baboons: Physical development, infant mortality, reproductive parameters and family relationships. Primates 23:473-487.

Swedell L. 2000. Two takeovers in wild hamadryas baboons. Folia Primatologica 71:169-172. 
Swedell L. 2006. Strategies of Sex and Survival in Hamadryas Baboons: Through a Female Lens. Sussman RW, Vasey N, editors. Upper Saddle River, NJ: Pearson Prentice Hall.

Swedell L, Tesfaye T. 2003. Infant mortality after takeovers in wild Ethiopian hamadryas baboons. American Journal of Primatology 60:113-118.

van Schaik CP, Hodges JK, Nunn CL. 2000. Paternity confusion and the ovarian cycles of female primates. In: Janson $\mathrm{CH}$, Van Schaik CP, editors. Infanticide by Males and its Implications. Cambridge: Cambridge University Press. p $361-387$.

van Schaik CP, Pradhan GR, van Noordwijk MA. 2004. Mating conflict in primates: Infanticide, sexual harassment and female sexuality. In: Kappeler P, van Schaik CP, editors. Sexual Selection in Primates: New and Comparative Perspectives: Cambridge University Press. p 131-150.

van Schaik CP, van Noordwijk MA, Nunn CL. 1999. Sex and social evolution in primates. In: Lee PC, editor. Comparative Primate Socioecology: Cambridge University Press. p 204-231.

Zinner D, Deschner T. 2000. Sexual swellings in female hamadryas baboons after male take-overs: "Deceptive" swellings as a possible female counter-strategy against infanticide. American Journal of Primatology 52:157-168.

Zinner D, Krebs E, Schrod A, Kaumanns W. 2006. Early sexual maturity in male Hamadryas Baboons (Papio hamadryas hamadryas) and its reproductive implications. American Journal of Physical Anthropology 129:584-590.

Zinner D, Nunn CL, van Schaik CP, Kappeler PM. 2004. Sexual selection and exaggerated sexual swellings of female primates. In: Kappeler PM, van Schaik 
CP, editors. Sexual Selection in Primates: New and Comparative Perspectives: Cambridge University Press. p 71-89.

Zinner D, Schwibbe MH, Kaumanns W. 1994. Cycle synchrony and probability of conception in female hamadryas baboons Papio hamadryas. Behavioral Ecology and Sociobiology 35:175-183. 


\section{Chapter 6: Summary}

The Wellington Zoo hamadryas baboon colony provided the opportunity to perform a fine scale analysis on the relationship between ovarian cycle parameters and sexual behaviour in a group-living old world primate. This was made possible by all mature females having undergone repeated ovarian cycling during the study as a result of RM vasectomisation. Furthermore, because the colony exhibited the archetypal OMU structure of wild hamadryas populations, the fundamental sociospatial parameters of hamadryas life were preserved within the colony despite of RM vasectomisation. This allowed findings to be interpreted in a broader context, albeit with the caveat that the colony contained only a small number of individuals and OMUs. In this section I reiterate the key findings from the study, in particular those concerning female sexual behaviour and the ovarian cycle, and touch upon the wider implications of these results where possible.

Female promiscuity was found to be much greater amongst OMU members in the Wellington Zoo colony than has been reported for wild hamadryas populations. One young female in particular, Ayisha, was found to be particularly promiscuous and exhibited only a weak socio-spatial attachment to her OMU. However, while Ayisha was exceptional, two thirds of females OMU members had at least $20 \%$ of their sexual encounters with males other than their RM. This appeared to have been the result of the problems RMs had in controlling females during the turgescent phase of their cycle, presumably because of the relatively large OMU sizes and the artificially inflated numbers of simultaneously cycling females in an OMU.

Closer examination of the patterning of female sexual behaviour in relation to the ovarian cycle revealed that females may have been utilising extra-OMU mating to 
facilitate a dual paternity concentration/paternity confusion strategy. RMs dominated the number of mounts and ejaculations performed over the latter part of the turgescent period, the interval in which a conceptive mating is most likely to occur. With the exception of Ayisha, females were generally unlikely to actively solicit extra-OMU copulations. This occurred even though several females from the same OMU were often in the peri-ovulatory phase of their cycle at the same time, which is expected to increase the likelihood of RM sperm depletion and subsequently increase the chances of females having a non-conceptive cycle, while also making it easier for females to pursue extra-OMU copulations. Indeed, the females that received the fewest ejaculatory mounts from their RM were no more likely to seek out extra OMU mating than those that received the most. Moreover, all females were most likely to reject copulations from non-OMU males around the time when they were most likely to conceive. Taken together, these results do not support the notion that extra-OMU mating served female mate choice or fertility insurance strategies, but are consistent with a dual paternity concentration/paternity confusion strategy as outlined by van Shaik and colleagues (2000) and Nunn (1999).

The latter half of the study examined whether females were actively modifying their cycle in a manner expected to increase their reproductive success. Female OMU members were not found to synchronise nor asynchronise their ovarian cycles over the one year study interval. Examination of the ovarian cycles in the colony revealed that the degree of intra- and inter-female variation in ovarian cycle length was sufficient to make coordination impossible over multiple ovarian cycles. A similar result was reported recently for women that shared dormitory rooms over a one year period (Yang and Schank, 2006). These findings suggest that ovarian cycle variation may generally act as a barrier to long term cycle entrainment amongst 
primates and other mammals. However, this does not prevent females from being able to synchronise their cycles in the short term. Hamadryas females appear to be able to coordinate the onset of ovarian cycling, either post-amenorrhea or following menarche, with other females in their OMU. Furthermore, that female hamadryas baboons generally conceive within their first few cycles and have a turgescent phase that occupies half the length of the average ovarian cycle, indicates that maintaining overlap in the turgescent phase over a few cycles would be expected were they to start cycling around the same time. Therefore, when put into the context of natural populations, the finding that female hamadryas baboons do not exhibit the ability to entrain their ovarian cycles over the long term is not surprising, as doing so over the short term would probably suffice. While the benefits of ovarian synchrony for hamadryas females remain to be verified, the findings here suggest that such a trait may have been used to confound RM control and to improve extra-OMU copulatory opportunities for the purposes of paternity confusion strategy.

The importance of the paternity confusion strategy to hamadryas females was further strengthened by the finding that females in the Wellington Zoo colony altered the length of the turgescent phase of their cycle in a manner which optimises the theoretical fitness pay-off associated with perineal turgescence. It was assumed that extra-OMU mating was the primary benefit of perineal turgescence, following the arguments of van Shaik and colleagues (2000) and Nunn (1999), and that both physiological and behavioural costs would also accrue as the turgescent phase lengthened. The length of the turgescent phase was found to be shorter in the OMU where the average number of females that were simultaneously in the turgescent phase of their ovarian cycle was higher, which concurs with the theory that obtaining extra-OMU mating should also be faster in these OMUs leading to shorter turgescent 
phases. Although only a few cases of male induced infanticide in wild hamadryas baboons populations has been observed, there is growing empirical evidence to suggest that it may be a reasonably common event following takeovers. A proactive strategy that can lead to the minimisation of infanticide following a take-over, therefore, is likely to be highly beneficial for female hamadryas baboons.

In summary, this study provides further evidence for the existence of socially mediated ovarian plasticity in mammals. The findings support the idea that some of the variation in ovarian cycle length within a group-living primate can have an adaptive explanation. In this case the variation in the length of the turgescent phase was found to be OMU dependent, an indicator of social mediation. Furthermore, although there was no evidence for ovarian synchrony or asynchrony, there is sufficient evidence from other populations to suggest that female hamadryas baboons may be able to achieve short term ovarian synchrony in natural fertility populations. I have argued that social control of the ovarian cycle facilitates extra-OMU mating opportunities by confounding the coercive abilities of dominant males. I suggest that this may ultimately benefit hamadryas females by facilitating a paternity confusion strategy, which is expected to reduce the chances of male-induced infanticide and increase female reproductive success.

\section{FUTURE WORK}

There remains a need for the questions in this study to be examined in wild hamadryas populations that live in the conditions under which these behaviours are expected to have evolved. In particular, inter- and intra-population comparisons are vital to elucidate the role of demographic and environmental factors in determining 
these patterns. Additionally, in answering these questions, new lines of enquiry have been generated, such as how changes in OMU size and the intra-OMU OSR effects RM herding abilities and the mating tactics of both sexes, and whether hamadryas females exhibit context dependent anti-infanticide strategies. These questions also require further testing in wild populations.

There is also scope to extend some of these hypotheses to other species. Specifically, I predict that long-term ovarian cycle coordination is unlikely to have arisen in any animal species, but that initial coordination of cycles may be commonplace in species where male control reduces female fitness (Chapter 4). Notably, should selection favour females with shorter ovarian cycling periods (the causal factor underlying the first part of this hypothesis), then testing long-term cycle coordination is likely to suffer from a lack of suitable natural populations (whilst indirectly supporting the hypothesis). Additionally, amongst species with EPS, I predict that the length of the turgescent phase of the ovarian cycle will be shorter in groups where more females are concurrently undergoing ovarian cycling (Chapter 5). Because the length of the turgescent phase is predicted to be under the control of local demographic variables, which are amenable to manipulation, experimental procedures should be useful in investigating this hypothesis.

\section{REFERENCES}

Colmenares F. 2004. Kinship structure and its impact on behavior in multilevel societies. In: Chapais B, Berman C, editors. Kinship and Behavior in Primates: Oxford University Press, USA. p 242-270. 
Nunn CL. 1999. The evolution of exaggerated sexual swellings in primates and the graded-signal hypothesis. Animal Behaviour 58:229-246.

Swedell L. 2002. Affiliation among females in wild Hamadryas baboons (Papio hamadryas hamadryas). International Journal of Primatology 23:1205-1226.

Swedell L. 2006. Strategies of Sex and Survival in Hamadryas Baboons: Through a Female Lens. Sussman RW, Vasey N, editors. Upper Saddle River, NJ: Pearson Prentice Hall.

van Schaik CP, Hodges JK, Nunn CL. 2000. Paternity confusion and the ovarian cycles of female primates. In: Janson $\mathrm{CH}$, Van Schaik CP, editors. Infanticide by Males and its Implications. Cambridge: Cambridge University Press. p $361-387$.

Yang Z, Schank JC. 2006. Women do not synchronize Their menstrual cycles. Human Nature 17:434-447. 
Appendix 1: Age classes for hamadryas baboons used in this study. Taken from

Swedell, 2006, adapted from the descriptions in Sigg et al. 1982.

\begin{tabular}{|c|c|c|}
\hline Age class & $\begin{array}{l}\text { Estimated age } \\
\text { range (years) }\end{array}$ & Description \\
\hline Black infant & $0-1$ & $\begin{array}{l}\text { Hair completely of partially black; } \\
\text { face and perineal region pink. }\end{array}$ \\
\hline Small juvenile & $1-2$ & $\begin{array}{l}\text { Hair brown; longer snout; sitting } \\
\text { height } 25-30 \mathrm{~cm} \text {; no differences } \\
\text { between sexes. }\end{array}$ \\
\hline Medium juvenile male & $2-5$ & $\begin{array}{l}\text { Sitting height } 30-45 \mathrm{~cm} \text {; smaller than } \\
\text { an adult female; no testicular bulges. }\end{array}$ \\
\hline $\begin{array}{l}\text { Medium-large juvenile } \\
\text { female }\end{array}$ & $2-4$ & $\begin{array}{c}\text { Sitting height } 30-45 \mathrm{~cm} \text {; very first } \\
\text { sexual swellings. }\end{array}$ \\
\hline Large juvenile male & $5-6$ & $\begin{array}{l}\text { Sitting height } 45-55 \mathrm{cms} \text {; around same } \\
\text { size as an adult female; canine fossae } \\
\text { evident; testes descending. }\end{array}$ \\
\hline Subadult female & $4-5.5$ & $\begin{array}{l}\text { Sitting height } 45-50 \mathrm{cms} \\
\text { reproductively cycling. }\end{array}$ \\
\hline Subadult male & $6-10$ & $\begin{array}{l}\text { Sitting height } 55-60 \mathrm{cms} \text {; partial } \\
\text { growth of mantle; pendulant scrotum } \\
\text { but no clear separation of testes. }\end{array}$ \\
\hline Young adult female & $5.5-7$ & $\begin{array}{l}\text { Sitting height } 50-55 \mathrm{cms} \text {; cycling } \\
\text { regularly; muzzle shorter than adult } \\
\text { females. }\end{array}$ \\
\hline Adult male & $10+$ & $\begin{array}{l}\text { Sitting height } 65 \mathrm{cms} \text {; mantle fully } \\
\text { developed; testes clearly separated. }\end{array}$ \\
\hline Adult female & $7+$ & $\begin{array}{c}\text { Sitting height } 50-55 \mathrm{cms} \text {; cycling } \\
\text { regularly. }\end{array}$ \\
\hline
\end{tabular}




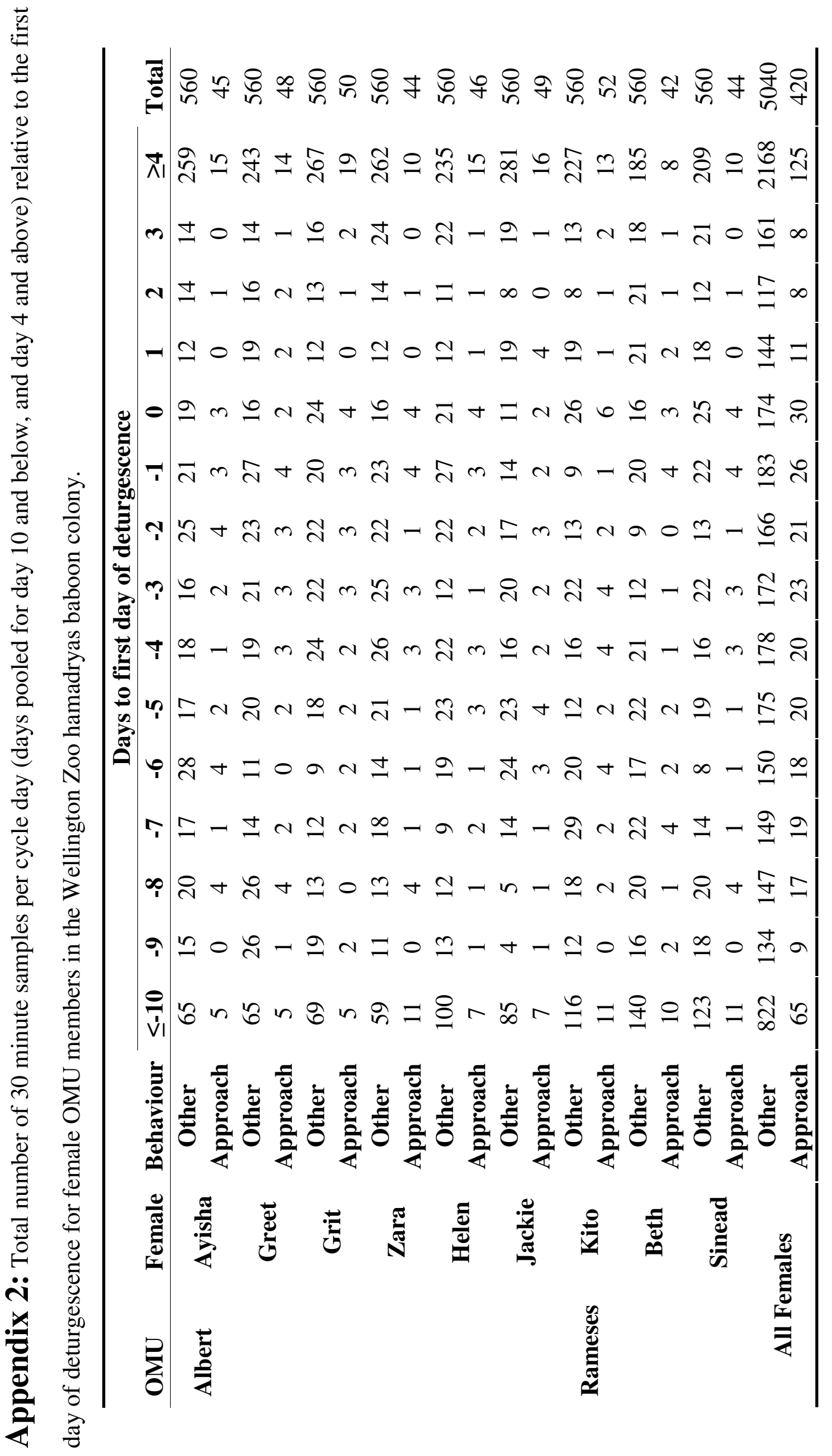




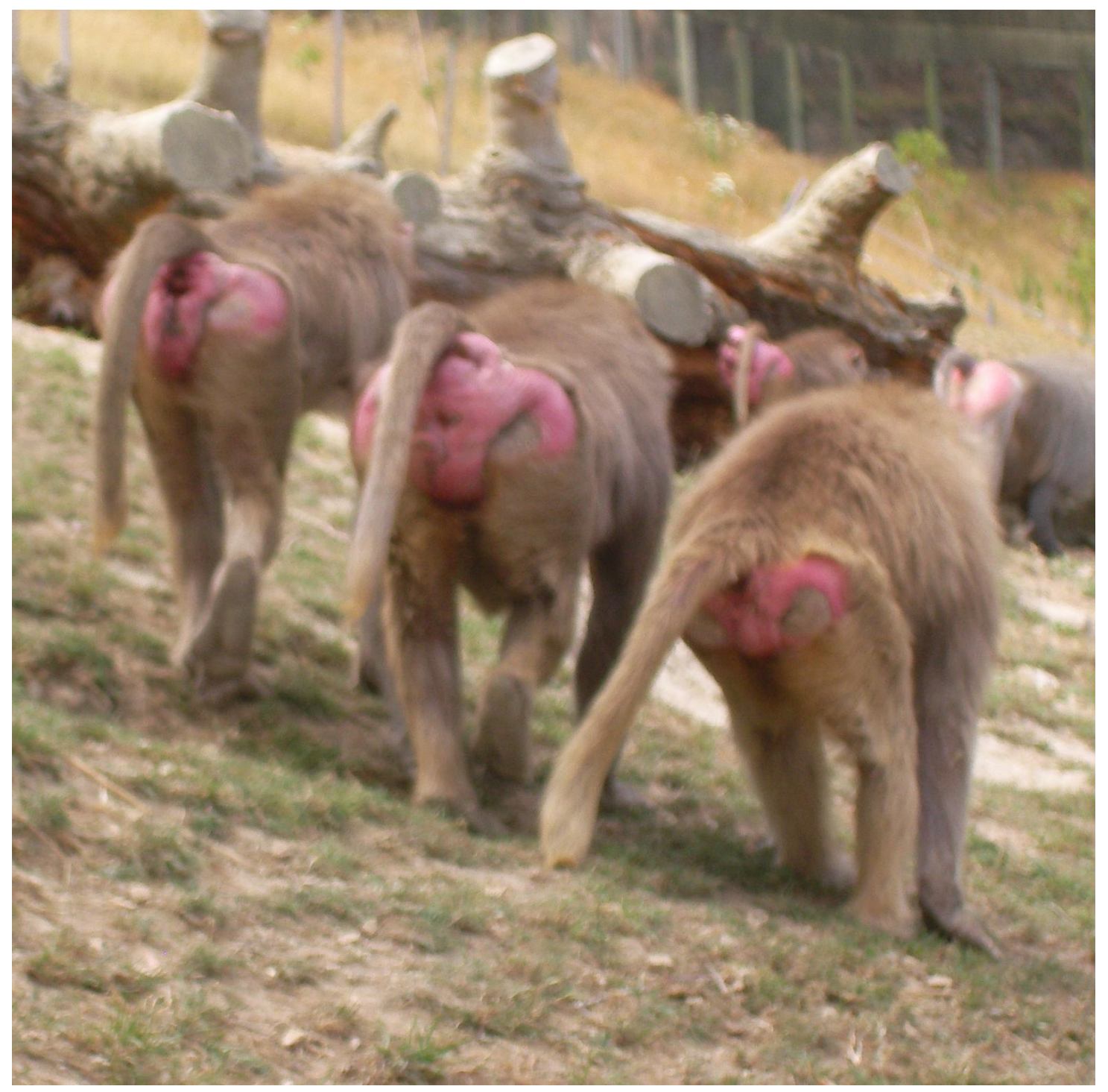

The End 